\title{
Estudos estruturais de xerogéis de óxido de níquel
}

Dissertação apresentada

$$
\text { por }
$$

\section{Hannes Fischer}

\author{
para 0 \\ Instituto de Física da Universidade de São Paulo \\ para obtenção do título de \\ Mestre em Física \\ na área de \\ Cristalografia
}

Universidade de São Paulo

São Paulo, SP, Brasil

[fevereiro] [2000] 
Aos meus pais, irmãos, orientador e amigos.

As duas coisas mais importantes que descobri em minha vida foram que eu sou um grande pecador e que Jesus é um salvador ainda maior. (Isaak Newton)

Porque Deus amou o mundo de tal maneira, que deu o seu Filho unigênito, para que todo aquele que nEle crê, não pereça, mas tenha a vida eterna. (extraído do livro de João 3:36 da Bíblia) 
(c) 2000 por Hannes Fischer

Todos direitos reservados.

[IFUSP - São Paulo - SP - Brasil]

Este trabalho recebeu apoio financeiro do

Conselho Nacional de PESQUiSA E DESENVOlVIMENTO (CNPq). 


\section{Resumo}

Foram estudadas as características estruturais de xerogéis obtidos pelo método sol - gel a partir de soluções líquidas precursoras compostas de cloreto de níquel, butanol, água e ácido acético, secos em estufa e tratados a diferentes temperaturas entre 150 e $900^{\circ} \mathrm{C}$. Nos tratamentos isotérmicos a essas temperaturas os elementos voláteis se desprendem do material inicial e transformações estruturais acontecem.

Analisaram-se os materiais porosos resultantes (xerogéis) mediante técnicas estruturais: espalhamento de raios $X$ a baixo ângulo ( $S A X S$ ), espectroscopia de absorção de raios $X$ (XANES e EXAFS), difração de raios $X(X R D)$ e microscopia eletrônica de varredura. Complementaramse estes estudos mediante análise química (espectroscopia de infravermelho), térmica (análise térmica diferencial), gravimétrica (perda de massa) e de densidade.

Os resultados experimentais demonstraram que a estrutura porosa do material inicial à base de $\mathrm{NiCl}_{2}$ se transforma numa estrutura bifásica, também porosa, composta por uma fase rica em $\mathrm{NiCl}_{2}$ e outra em $\mathrm{NiO}$, sendo que a fração de volume ocupada pela fase de $\mathrm{NiO}$ no material final aumenta com a temperatura de tratamento térmico. No caso de temperaturas acima de $500^{\circ} \mathrm{C}$, praticamente todo o volume da amostra se transforma e é ocupado pela fase $\mathrm{NiO}$.

Mostrou-se que a estrutura porosa presente em todos os materiais, estudada por $S A X S$, é composta por nanoporos $(10-150 \AA)$ e mesoporos (maiores que $150 \AA$ ), sendo que a fração de volume ocupada pelos mesmos depende da temperatura do tratamento térmico. Em particular os nanoporos somente estão presentes nas amostras tratadas abaixo de $500^{\circ} \mathrm{C}$.

A ordem local média ao redor dos átomos de $N i$, determinada por EXAFS, corresponde ao esperado de sistemas bifásicos cujas frações de volume dependem da temperatura de tratamento, em concordância com os resultados de $X R D$.

Investigaram-se as características dos materiais obtidos após os diferentes tratamentos térmicos em função de diferentes condições de preparação das soluções precursoras. Numa primeira série de experiências, variouse o conteúdo de ácido acético na solução. Demonstrou-se que maiores concentrações de ácido acético promovem a formação de um material com 
estrutura mais compacta. Numa segunda série de experiências variou-se o conteúdo de água. Determinou-se que a quantidade de água afeta somente a estrutura dos materiais tratados a temperaturas inferiores à $500^{\circ} \mathrm{C}$. 


\section{Abstract}

Structural properties of several xerogels obtained by the sol - gel procedure and heat treated at different temperatures between 150 and $900^{\circ} \mathrm{C}$ were studied. The initial systems were dry gels prepared from liquid solutions composed of nickel chloride, buthanol, water and acetic acid. During the different isothermal treatments, volatile species leave the inicial material and structural transformations occur.

The resulting porous materials (xerogels) were studied by means of several structural techniques: small angle $X$ ray scattering $(S A X S), X$ ray absorption spectroscopy ( $X A N E S$ and $E X A F S$ ), $X$ ray diffraction $(X R D)$ and scanning electron microscopy. These studies were complemented with chemical analysis (infrared spectroscopy), differential thermal analisis, mass loss and density measurements.

The experimental results demonstrated that the porous structure of the starting material, based on nickel chloride, transforms in a also porous biphasic structure composed of nickel chloride and nickel oxide, respectively, rich fase. The volume fraction occupied by the nickel oxide rich fase of the final material increases with temperature of heat treatment. For temperatures above $500^{\circ} \mathrm{C}$, practically all the sample volume transforms and is occupied by the $\mathrm{NiO}$ phase.

It was demonstrated that the porous structure of all materials, studied by $S A X S$, is composed of nanopores (sizes ranging from 10 to $150 \AA$ ) and mesopores (larger than $150 \AA$ ), their fraction depending on the heat treatment temperature. Particularly, nanopores are only present in samples treated below $500^{\circ} \mathrm{C}$.

The average local order close to nickel atoms, determined by $E X A F S$, corresponds to the expected one for biphasic systems whose volume fractions depend on treatment temperature, in agreement with $X R D$ results.

The structural properties of the several materials obtained after different heat treatments were studied as functions of preparation conditions of precursor solutions. In a first series of experiments, acetic acid content in the solution was varied. It was demonstrated that higher acetic acid content promotes the 
formation of more compact structures. In a second series of experiments, water content was varied. It was concluded that water content only affects the structure of the materials heat treated at temperatures below $500^{\circ} \mathrm{C}$. 


\section{Sumário}

I. Introdução e objetivos

II. Princípios das principais técnicas experimentais 3

II.1. - Espalhamento de $\operatorname{raios} X$ á baixos ângulos $(S A X S) \ldots \ldots \ldots 4$

2.1 Origem e características do espalhamento de raios $X$ a baixo ângulo ...... 4

2.1.1 Espalhamento produzido por um elétron $\ldots \ldots \ldots \ldots \ldots \ldots \ldots \ldots 6$

2.1.2 Espalhamento produzido por objetos isotrópicos, sem ordenamento a longa distância e com heterogeneidades na densidade eletrônica de dimensões coloidais ...............................6

2.2 Obtenção de parâmetros estruturais de uma curva de $S A X S \ldots \ldots \ldots \ldots 11$

2.2.1 Raio de giro médio de um conjunto diluído e isotrópico de partículas coloidais $\left(\left\langle R_{g}\right\rangle\right)$ - Lei de Guinier $\ldots \ldots \ldots \ldots \ldots \ldots \ldots \ldots \ldots \ldots \ldots \ldots \ldots \ldots \ldots \ldots$

2.2.2 Superfície total de interfaces - Lei de Porod $\ldots \ldots \ldots \ldots \ldots \ldots \ldots$

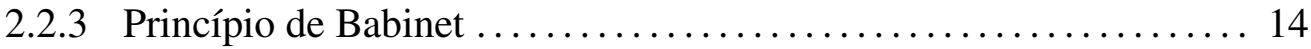

2.3 Modelos estruturais utilizados para tratamento de dados ............ 15

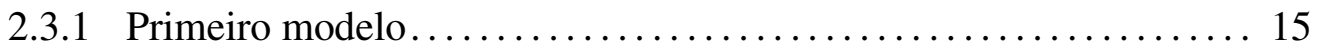

2.3.2 Segundo modelo................................ 16

2.4 Descrição da linha de $S A X S$ do $L N L S \ldots \ldots \ldots \ldots \ldots \ldots \ldots \ldots \ldots \ldots$

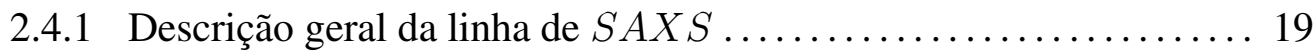

2.4.2 Sistema de detecção e configuração experimental $\ldots \ldots \ldots \ldots \ldots 23$

II.2. Espectroscopia de absorção de raios $X$ de estrutura fina

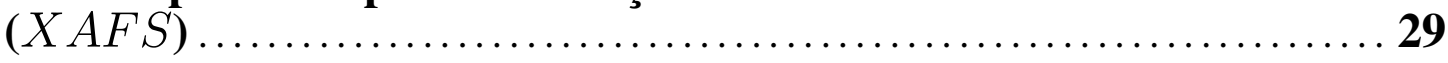




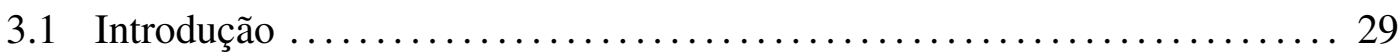

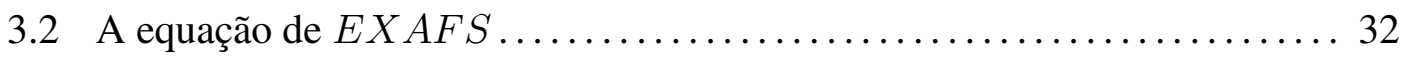

3.3 Análise de dados: Introdução e programas .................. 37

3.3.1 Isolamento e interpretação do sinal de $E X A F S \ldots \ldots \ldots \ldots . \ldots 38$

3.3.2 Medida de $\mu(E) \ldots \ldots \ldots \ldots \ldots \ldots \ldots \ldots \ldots \ldots \ldots \ldots \ldots$

3.4 Descrição da linha de $X A F S$ do $L N L S \ldots \ldots \ldots \ldots \ldots \ldots \ldots \ldots \ldots \ldots \ldots \ldots \ldots \ldots$

3.4.1 Monocromador e fendas horizontais $\ldots \ldots \ldots \ldots \ldots \ldots \ldots \ldots .41$

3.4.2 Câmaras de ionização............................ 46

III. Resultados experimentais ........................... 48

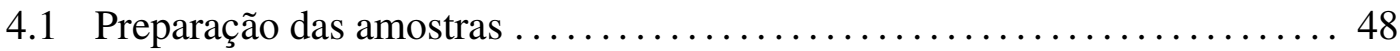

4.2 Primeira série de experiências ............................ 49

4.2.1 Resultados experimentais de espalhamento de $\operatorname{raios} X$ a baixos

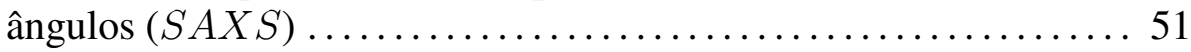

4.2.2 Resultados de difração de $\operatorname{raios} X(X R D) \ldots \ldots \ldots \ldots \ldots \ldots$

4.2.3 Resultados de espectroscopia de infravermelho por transformada de

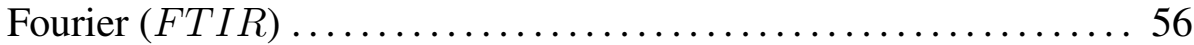

4.2.4 Resultados de calorimetria diferencial de varredura $(D S C) \ldots \ldots 59$

4.3 Segunda série de experiências (precursor $100 \% \mathrm{NiCl}_{2} \cdot 6 \mathrm{H}_{2} \mathrm{O}$ ) $\ldots \ldots \ldots 60$

4.3.1 Resultados de espalhamento de raios $X$ a baixos ângulos $(S A X S) 61$

4.3.2 Resultados de análise termogravimétrica $(T G A)$ e análise térmica

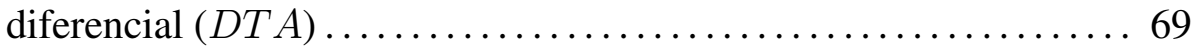

4.3.3 Resultados de microscopia eletrônica de varredura $(S E M) \ldots \ldots 70$

4.3.4 Resultados de difração de $\operatorname{raios} X(X R D) \ldots \ldots \ldots \ldots \ldots \ldots \ldots$

4.3.5 Resultados de espectroscopia de absorção de raios $X$ perto da borda

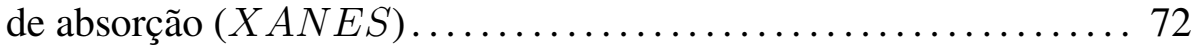

4.3.6 Resultados de espectroscopia de raios $X$ longe da borda de absorção

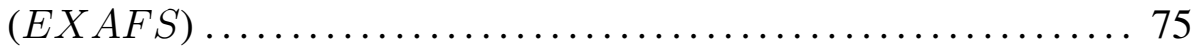


4.4 Terceira série de experiências (precursor $80 \% \mathrm{NiCl}_{2} \cdot 6 \mathrm{H}_{2} \mathrm{O}+20 \%$ $\left.\mathrm{Ti}\left[\mathrm{O}\left(\mathrm{CH}_{2}\right) \mathrm{CH}_{3}\right]_{4}\right)$

IV. Discussão final e conclusão 87

Referências. 91

Teses 91

Internet 91

Livros 91

Artigos 92

A Apêndice A: Resultados dos ajuste dos dados de $E X A F S$ por $F E F F$ utilizando o programa WinXAS

B Apêndice B: Resultados das experiências de $S A X S$ em amostras com substituição parcial do $N i$ por $T i$. . 103

C Apêndice C: Observações 109 


\section{Introdução e objetivos}

Este trabalho visa o estudo das transformações estruturais produzidas durante a parte final do processo sol - gel para obter materiais cerâmicos baseados em óxidos de metais de transição. Este tipo de estudo atrai o interesse de um grande número de pesquisadores (Brinker and Scherrer, 1990; Schmidt, 1990). A escolha do sistema analisado (xerogéis a base de hidróxido de níquel) se justifica tanto pela sua importância como pesquisa básica quanto pelas suas aplicações em dispositivos para reações eletroquímicas e eletrocrômicas (Fantini et al., 1996; Sharma et al., 1998).

No processo sol - gel, parte-se de um sol precursor composto por moléculas ou partículas coloidais (monômeros) inicialmente estáveis. Mediante o uso de um catalisador apropriado, os monômeros iniciam a agregação que conduz a um gel "úmido". Com a secagem deste gel, obtem-se um material seco e poroso chamado xerogel. Este por sua vez, é aquecido a diversas temperaturas. O produto final, dependendo da composição e da história térmica, poderá ser um material cerâmico ou vítreo com diversos graus de porosidade. Nos casos do material final ser um vidro, pode-se conseguir em condições controladas corpos monolíticos e homogêneos (sem porosidade).

Sintetizou-se muitos sistemas de óxidos metálicos, como $\mathrm{TiO}_{2}, \mathrm{SiO}_{2}, \mathrm{ZrO}_{2}, \mathrm{Al}_{2} \mathrm{O}_{3}$ etc. pelo método sol - gel, conduzindo a materiais cerâmicos ou vidros com uma porosidade muito fina (Sharma and Ramanan, 1996; Orignac et al., 1997; Ramamurthi et al., 1990; Kumagai and Messing, 1984). Apesar da importância dos materiais de óxido/hidróxido níquel, publicou-se poucas pesquisas sobre seu procedimento de preparação (Fantini et al., 1996; Sharma et al., 1998).

O objetivo específico desta dissertação é estudar as características estruturais de diferentes xerogéis a base de óxido de níquel em função da temperatura de tratamento isotérmico de duração fixa e em função das condições de preparação, variando os seus conteúdos de ácido acético e de água no sol precursor.

Para a caracterização experimental dos diversos tipos da estrutura porosa dos materiais estudados em nível desde $1 \mathrm{~nm}$ até o $0,1 \mu \mathrm{m}$ que se formam durante as transformações que conduzem ao óxido de níquel, utilizou-se a técnica de espalhamento de raios $X$ a baixo ângulo ( $S A X S$ ) (Guinier and Fournet, 1955; Glatter and Kratky, 1982).

Para estudar a estrutura local ao redor do átomo de níquel utilizou-se a técnica de espectroscopia de absorção de raios $X(X A F S)$ em regiões de energia abaixo e acima das bordas de absorção do níquel e, em alguns casos, também do titânio. 
Os resultados das experiências de $S A X S$ e $X A F S$ foram complementados com os obtidos utilizando outras técnicas que focalizam outros aspectos estruturais e químicos: difração de raios $X(X D R)$; espectroscopia de infravermelho por transformada de Fourier (FTIR); microscopia eletrônica de varredura $(S E M)$; calorimetria diferencial de varredura $(D S C)$; e densidade.

Publicou-se os resultados parciais obtidos nesta dissertação em diversos artigos (Sharma, Fischer and Craievich, 1999; Sharma et al., 1999; Fischer, Sharma and Craievich, 1999). 


\section{Princípios das principais técnicas experimentais}




\section{II.1. - Espalhamento de raios $X$ á baixos ângulos $(S A X S)$}

Neste capítulo, apresenta-se a teoria básica do espalhamento de raios $X$ a baixo ângulo, uma descrição da linha de $S A X S$ do Laboratório Nacional de Luz Síncrotron $(L N L S)^{1}$ (componentes e sistemas de detecção), sua caracterização óptica e diversos métodos numéricos de análise de dados.

\subsection{Origem e características do espalhamento de raios $X$ a baixo ângulo}

A técnica de $S A X S$ analisa o espalhamento a ângulos baixos com um valor mínimo do mesmo (este valor mínimo é em geral limitado pelas condições experimentais). Por isso somente heterogeneidades da densidade eletrônica de dimensões coloidais (dezenas a milhares de Å) podem ser observadas. Já as flutuações da densidade eletrônica em nível das distâncias interatômicas não se observam na região angular de interesse.

Se designamos por $\rho(\vec{r})$ a densidade eletrônica de um corpo a um ponto definido pelo vetor $\vec{r}$, então $A(\vec{q})$ é a transformada de Fourier de $\rho(\vec{r})$ no ponto definido pelo vetor $\vec{q}$ no espaço recíproco, é dada por:

$$
A(\vec{q})=\int \rho(\vec{r}) e^{-i \vec{q} \vec{r}} d \vec{r} .
$$

A teoria de espalhamento de raios $X$ demonstra que $A(\vec{q})$ representa também a amplitude da radiação espalhada em condições experimentais tais que:

$$
\vec{q}=\frac{2 \pi}{\lambda}\left(\vec{s}-\overrightarrow{s_{0}}\right),
$$

onde $\lambda$ é o comprimento de onda da radiação e $\overrightarrow{s_{0}}$ e $\vec{s}$ são os vetores unitários na direção dos raios incidentes e espalhados, respectivamente, como mostrado na figura 1. O módulo de $\vec{q}$ é $(4 \pi / \lambda) \sin \theta$, onde $2 \theta$ é o ângulo de espalhamento (Guinier, 1955).

Lembrando que $S A X S$ se limita ao estudo de pequenos ângulos (corresponde a estruturas da ordem de $10-1000 \AA ̊$ no espaço direto), e que em difração de raios $X$ a altos ângulos se lida com estruturas com resolução atômica, o que se observa em $S A X S$ é somente uma média da densidade eletrônica num volume de dimensão da ordem de $10 \AA$. A intensidade espalhada $I(\vec{q})$ a um certo valor do vetor posição no espaço recíproco $\vec{q}$ é o quadrado de $|A(\vec{q})|$, onde $A(\vec{q})$ é o componente para $\vec{q}$ da

1 Mais informações sobre o LNLS podem ser encontradas no endereço de internet: $w w w . l n l s . b r$ 


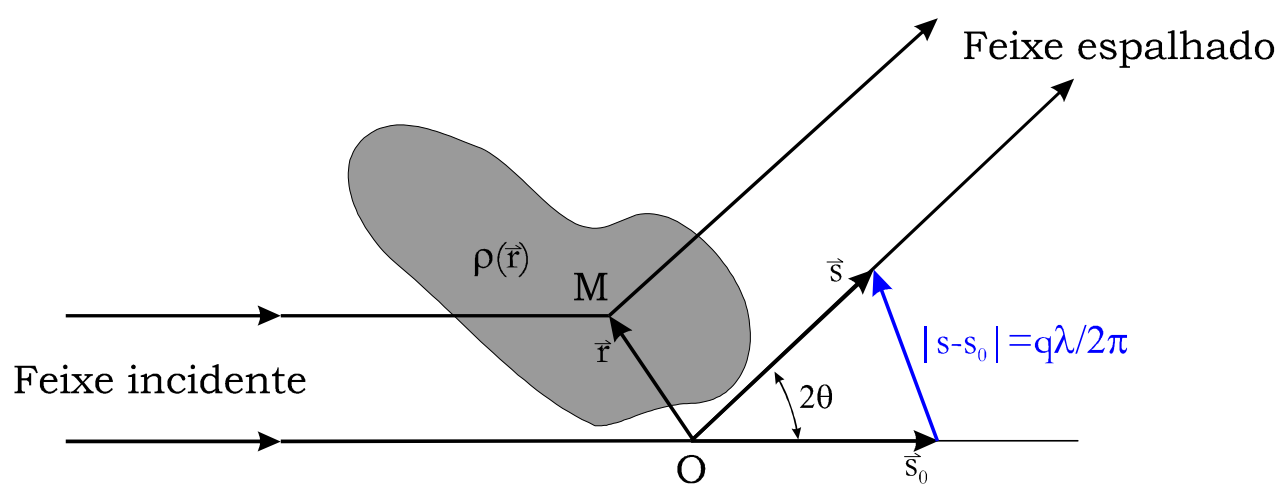

Figura 1.Esquema ilustrando a difração por uma partícula.

transformada integral de Fourier de $\rho(\vec{r})$. Para pequenos $\vec{q}$ 's, isto é, para ângulos muito pequenos, já que neste caso $\overrightarrow{s_{0}}$ e $\vec{s}$ são quase paralelos (ver equação 2.2), os termos em $\rho(\vec{r})$ que contribuem primariamente para a amplitude de $A(\vec{q})$ são aqueles que mostram uma peridiocidade de $r=2 \pi / q$, que é larga em comparação com o comprimento de onda utilizado (p.ex.: para $\vec{q}$ 's da ordem típica variando de 0,005 a $0,5 \AA^{-1}$ temos $r$ da ordem de $12-1200 \AA$ ). Estas informações mostram que $S A X S$ fornece informações da estrutura numa escala que é grande comparada com o comprimento de onda dos raios $X$. Experimentalmente, visualiza-se este tipo de espalhamento, quando feixes de raios $X$ atravessam amostras constituídas por partículas coloidais de tamanho submicroscópico porém maior que o de átomos isolados. Este espalhamento foi primeiramente observado por Krishnamurti e Warren (Guinier, 1955).

Agora, no caso de raios $X$, quem espalha, não são as partículas ou poros, mas os elétrons que compõem a matéria e da mesma forma que as ondas visíveis, os raios $X$ são espalhados em fase (na verdade há uma mudança de fase em $\pi$ radianos) na direção paralela ao feixe incidente (espalhamento frontal) com a defasagem aumentando à medida que o ângulo cresce. A técnica de $S A X S$ pode dar informação estrutural somente para partículas que se encontram dentro de certos limites. Se a dimensão máxima da partícula $(D)$ é grande demais, o espalhamento fica limitado a ângulos muito pequenos muitas vezes inacessíveis experimentalmente e se $D$ for pequeno demais, da ordem do comprimento de onda o espalhamento se produz a altos ângulos. Nos casos de se querer estudar heterogeneidades em $\rho(\vec{r})$ muito pequenas (por exemplo redondezas de átomos individuais), o uso das técnicas de $W A X S$ (Wide Angle $X$-ray scattering ${ }^{2}$ ) ou EXAFS (Extended $X$ - ray Absorption Fine Structure) é necessário.

$2 W A X S$ nada mais é que difração de raios $X(X R D)$ a altos ângulos. 


\subsubsection{Espalhamento produzido por um elétron}

O processo de espalhamento dos fótons por um elétron no qual não há mudança de comprimento de onda é chamado espalhamento Thomson. Neste processo a interação fóton-elétron é elástica e a intensidade emitida $I(\vec{q})$ é dada por:

$$
I(\vec{q})=A_{e}^{2}(\vec{q})=\frac{I_{0}}{r_{0}^{2}}\left(\frac{e^{2}}{m c^{2}}\right)^{2} \frac{\left(1+\cos ^{2} 2 \theta\right)}{2}
$$

onde $1+\cos ^{2} 2 \theta$ é o fator de polarização que depende do ângulo de espalhamento $2 \theta, m$ e $e$ são a massa e carga do elétron, respectivamente, $c$ é a velocidade da luz no vácuo, $I_{0}$ é a intensidade do feixe de fótons incidente, $A_{e}$ é a intensidade espalhada por um elétron e $r_{0}$ é o raio do átomo de Bohr. A propriedade importante do espalhamento Thomson é que a onda de radiação emitida pelo elétron é coerente com a onda correspondente ao feixe incidente.

Compton demonstrou que o espalhamento dos fótons por elétrons tem uma componente inelástica. Esta contribuição ao espalhamento é incoerente e de intensidade desprezível a baixo ângulo. Por isso ela não é considerada.

\subsubsection{Espalhamento produzido por objetos isotrópicos, sem ordenamento a longa distância e com heterogeneidades na densidade eletrônica de dimensões coloidais}

Nesses sistemas, não existe organização a longo alcance e a intensidade espalhada se concentra a ângulos baixos. São estudados pela técnica de $S A X S$. Focalizou-se o caso de um sistema formado por partículas coloidais isoladas em que $(i)$ as partículas formam um sistema diluído, isto é, a distância entre uma partícula e outra é muito maior que o tamanho da partícula, (ii) o sistema é isotrópico, (iii) as partículas têm todas a mesma forma podendo ter diferentes tamanhos e $(i v)$ o sistema poder ser descrito por somente duas densidades eletrônicas (a das partículas e da matriz).

O processo de espalhamento pode ser visualizado da seguinte maneira: elétrons ressoam com a frequiência dos raios $X$ incidentes, emitindo ondas secundárias que interferem umas com as outras. Ilustra-se este fenômeno por um simples exemplo.

A Figura $2 a$ mostra uma partícula esférica. Assume-se que as ondas espalhadas por dois pontos num ângulo $2 \theta$ tenham uma diferença de caminho de $1 \lambda$. É fácil ver que, se se inclui o espalhamento de todos os elétrons, a superposição de ondas na direção $2 \theta$ resultará numa interferência destrutiva. Mas se se considerar ângulos de espalhamento menores, a diferença de fase ficará cada vez menor e as ondas começam a se somar umas 


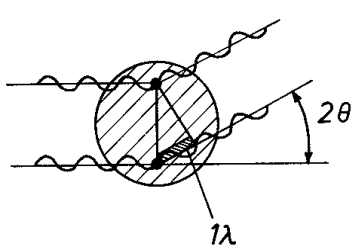

(a)

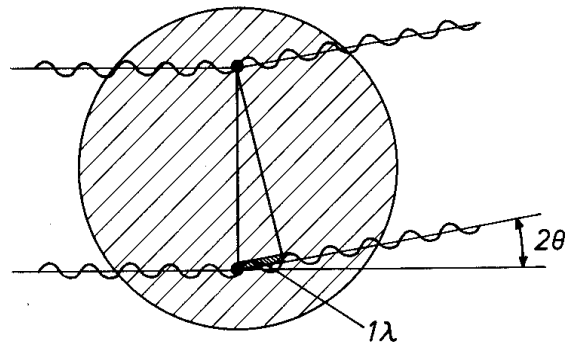

(b)

Figura 2.Esferas com diferentes diâmetros mostrando como se comporta o espalhamento

com as outras. O espalhamento máximo é observado para o ângulo de espalhamento nulo onde todas as ondas estão exatamente em fase.

Qualitativamente, as curvas de espalhamento observada tem, por exemplo, a forma da curva 1 da Figura 3. Imagina-se agora uma esfera muito mais larga (para o mesmo comprimento de onda - Figura $2 b$ ). Tem-se que a diferença de caminho $1 \lambda$ resulta em ângulos de espalhamento bem menores (curva 3, figura 3). Assim para partículas grandes (largas), o espalhamento de raios $X$ se concentra em ângulos menores (Glatter and Kratky, 1982).

No caso do espalhamento a baixo ângulo, o efeito devido as flutuações de densidade eletrônica em nível das distâncias interatômicas é desprezível, já que o fóton só vê uma distribuição média num volume maior que o atômico. Portanto podemos escrever a intensidade espalhada em função de $\rho(\vec{r})$ que representa a distribuição de densidade eletrônica da amostra.

Se se designar por $d A$ a amplitude espalhada por cada um dos elementos $\rho(\vec{r}) d V$ da amostra por:

$$
d A(\vec{q})=A_{e}(\vec{q}) \rho(\vec{r}) e^{-i \vec{q} \vec{r}} d V
$$

a amplitude total será

$$
A(\vec{q})=A_{e}(\vec{q}) \int_{V} \rho(\vec{r}) e^{-i \vec{q} \vec{r}} d V
$$

onde $\vec{q}=\frac{2 \pi}{\lambda}\left(\vec{s}-\overrightarrow{s_{0}}\right)$ é o vetor de espalhamento e $\vec{r}$ é o vetor que vai da origem até ao elemento de volume $d V$.

Experimentalmente, só se pode medir o fluxo de energia do feixe espalhado $I(\vec{q})$ que é igual ao quadrado do módulo da amplitude por:

$$
I(\vec{q})=A(\vec{q}) \cdot A^{*}(\vec{q})=|A(\vec{q})|^{2}
$$




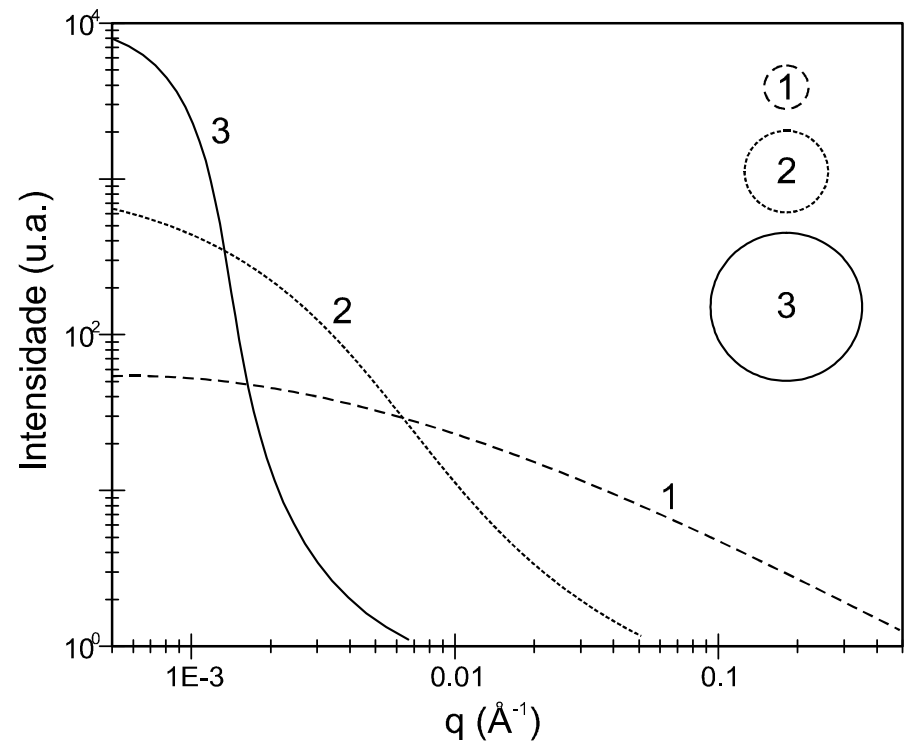

Figura 3.Gráfico da intensidade versus o ângulo de espalhamento para diversos objetos de tamanhos crescentes $(1<2<3)$ 
Isso implica que ao medir a intensidade perde-se informação da fase da onda espalhada.

\section{Intensidade de espalhamento no caso geral}

Substituindo a equação 2.5 na 2.6 vem que:

$$
I(\vec{q})=\iint_{V} \rho\left(\overrightarrow{r_{1}}\right) \rho\left(\overrightarrow{r_{2}}\right) e^{-i \vec{q}\left(\overrightarrow{r_{1}}-\overrightarrow{r_{2}}\right)} d V_{1} d V_{2}
$$

que é a transformada de Fourier envolvendo somente a distância relativa $\vec{r}=\left(\overrightarrow{r_{1}}-\overrightarrow{r_{2}}\right)$ para cada par de pontos $\overrightarrow{r_{1}}$ e $\overrightarrow{r_{2}}$. Reescrevendo a equação 2.7 temos:

$$
I(\vec{q})=\int_{V} \int_{V} \rho\left(\vec{r}+\overrightarrow{r_{2}}\right) \rho\left(\overrightarrow{r_{2}}\right) e^{-i \vec{q} \vec{r}} d V_{2} d V=\int_{V} P(\vec{r}) e^{-i \vec{q} \vec{r}} d V
$$

onde $P(\vec{r})=\int_{V} \rho\left(\vec{r}+\overrightarrow{r_{2}}\right) \rho\left(\overrightarrow{r_{2}}\right) d V_{2}$ é a chamada função de auto-correlação eletrônica. Em Cristalografia, essa função é conhecida como função de Patterson.

Considerando o caso particular de partículas (mesmo anisotrópicas), porém aleatóriamente orientadas, isto é, não há direção previlegiada (desprezando qualquer efeito externo como campo elétrico ou magnético, bem como gravidade aplicada para determinados sistemas de partículas), deve-se fazer uma média das intensidades espalhadas por cada partícula para todas as direções possíveis que o sistema pode assumir (chamada promediação orientacional). Tem-se então que

$$
I(q)=\langle I(\vec{q})\rangle_{\Omega}=\frac{1}{4 \pi} \int_{0}^{4 \pi} I(\vec{q}) d \Omega=4 \pi \int_{0}^{D} \gamma(r) \frac{\sin (q r)}{q r} r^{2} d r
$$

onde $q$ é o módulo do vetor $\vec{q}$ no espaço recíproco, $r$ o módulo do vetor $\vec{r}$ no espaço real, $D$ é o diâmetro máximo das partículas e $\gamma(r)=\frac{1}{4 \pi} \int_{0}^{4 \pi} P(\vec{r}) d \omega$ é a função de correlação definida como a promediação orientacional da função de Patterson, descrevendo a correlação entre as flutuações de densidade eletrônica.

Nos casos de sistemas isotrópicos, pode-se obter a função de correlação $\gamma(r)$, aplicando a transformada inversa de Fourier na equação 2.9, resultando em:

$$
\gamma(r)=\frac{1}{2 \pi^{2}} \int_{0}^{\infty} I(q) \frac{\sin (q r)}{q r} q^{2} d q
$$

A função de correlação $\gamma(r)$ pode ser calculada diretamente das intensidades medidas, permitindo desta forma obter uma informação direta da estrutura das partículas. 


\section{Espalhamento por um sistema diluído de partículas iguais com densidade eletrônica uniforme no vácuo}

Supondo que a densidade eletrônica é constante através da partícula, a função de correlação no ponto zero fica

$$
\gamma(0)=\eta^{2} V
$$

onde $\eta$ é o contraste eletrônico e definido por $\eta=\rho-\rho_{0}=\rho$ onde $\rho$ é a densidade da partícula e $\rho_{0}$ a densidade eletrônica do vácuo ( $\rho_{0}=0$ neste caso). Comparando a equação acima com a equação 2.10 tem-se que:

$$
2 \pi^{2} \gamma(0)=\int_{0}^{\infty} I(q) q^{2} d q=2 \pi^{2} \eta^{2} V=Q
$$

onde o valor $Q$ é conhecido como "invariante" que é proporcional à integral da intensidade de espalhamento em todo volume do espaço recíproco.

A função $\gamma(r)$ bem como a função distribuição de distâncias $p(r)$ para sistemas isotrópicos é dada por:

$$
p(r)=r^{2} \cdot \gamma(r) \text {. }
$$

A função $p(r)$ é muito usada em aplicações de $S A X S$ já que depende da geometria da partícula e do contraste de densidade eletrônica entre as duas fases (partícula e matriz).

\section{Função característica $\gamma_{0}(\vec{r})$ de uma partícula}

Pode-se expressar a função $\gamma(\vec{r})$ (Porod, 1951) como:

$$
\gamma(\vec{r})=\eta^{2} \cdot \gamma_{0}(\vec{r}), \text { onde } \gamma_{0}(0)=1, \gamma_{0}(r \geq D)=0
$$

A função $\gamma_{0}(\vec{r})$ está somente relacionada com a geometria da partícula. Como a partícula é finita, com diâmetro máximo $D, \gamma_{0}(\vec{r})$ se anula para $r \geq D$.

Para entender melhor a função $\gamma_{0}(\vec{r})$, analisa-se a figura 4 . Imagina-se uma partícula deslocada por um vetor $\vec{r}$. É fácil visualizar que o volume $V(\vec{r})$ em comum com a partícula e sua imagem contem todos os pontos que contribuem para $\gamma_{0}(\vec{r})$. Logo, só se precisa fazer a média orientacional sobre todas as direções de $\vec{r}$, com $|\vec{r}|=r$ permanecendo constante (Glatter and Kratky, 1982), logo:

$$
\gamma_{0}(r)=\frac{\langle V(\vec{r})\rangle}{V(0)}=\frac{\langle V(\vec{r})\rangle}{V} .
$$

Substituindo a equação 2.13 na 2.9 tem-se a intensidade espalhada para uma partícula de densidade uniforme, considerando todas suas orientações possíveis: 


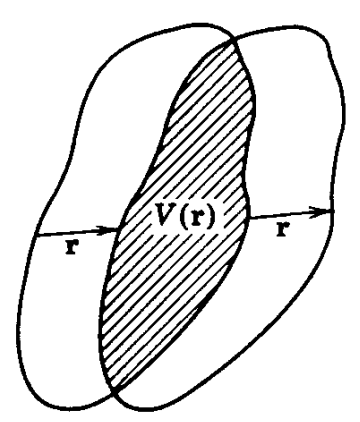

Figura 4.A figura mostra a partícula e sua imagem. Onde $V(\vec{r})$ é o volume comum e $\vec{r}$ o vetor de deslocamento. 


$$
I(q)=4 \pi \eta^{2} V \int_{0}^{D} \gamma_{0}(r) \frac{\sin (q r)}{q r} r^{2} d r .
$$

Conseqüentemente

$$
\gamma_{0}(r)=\frac{1}{2 \pi^{2} \eta^{2}} \int_{0}^{\infty} I(q) \frac{\sin (q r)}{q r} q^{2} d q
$$

No caso de um sistema diluido composto por partículas iguais com todas orientações possíveis, a intensidade de espalhamento é simplesmente igual a $N$ vezes a intensidade de espalhamento produzida por uma partícula individual (com todas orientações possíveis delas). No caso do sistema ser concentrado, as amplitudes do espalhamento produzido pelas partículas produzem efeitos de interferência que devem ser considerados de maneira apropriada.

\subsection{Obtenção de parâmetros estruturais de uma curva de $S A X S$}

\subsubsection{Raio de giro médio de um conjunto diluído e isotrópico de partículas coloidais $\left(\left\langle R_{g}\right\rangle\right)$ - Lei de Guinier}

Analisa-se o comportamento de $I(q)$ para valores baixos de $q$. Expandindo $\frac{\sin (q r)}{q r}$ (equação 2.14) em torno de $q=0$ obtem-se:

$$
I(q)=I(0)\left(1-\frac{q^{2} R_{g}^{2}}{3}+\ldots\right), \text { para } q \longrightarrow 0,
$$

que pode ser considerada como uma expansão dos primeiros termos de:

$$
I(q)=I(0) e^{-\frac{q^{2} R_{g}^{2}}{3}}, \text { para } q \longrightarrow 0,
$$

onde $R_{g}$ é o raio de giro da partícula coloidal. A equação 2.15 é chamada de lei de Guinier. O raio de giro é definido como a raiz quadrada das distâncias quadráticas médias entre os elétrons da partícula e o centro de massa eletrônico $\overrightarrow{r_{e}}$ :

$$
R_{g}=\sqrt{\frac{\sum_{i=1}^{N}\left|\overrightarrow{r_{i}}-\overrightarrow{r_{e}}\right|^{2}}{N}}
$$


ou na forma integral

$$
R_{g}=\sqrt{\frac{1}{N_{e}} \int \rho(\vec{r})\left|\vec{r}-\overrightarrow{r_{e}}\right|^{2} d V}=\sqrt{\frac{1}{V} \int_{V}\left|\vec{r}-\overrightarrow{r_{e}}\right|^{2} d V}
$$

onde $N_{e}$ é o número total de elétrons na amostra.

Fazendo o gráfico de $\ln I(q) \times q^{2}$, podem-se determinar dois parâmetros, que são $I(0)$ (valor da função da reta no ponto em que corta o eixo das ordenadas) e $R_{g}$ (inclinação da reta).

A lei de Guinier é também válida para um sistema diluído de partículas de forma igual e com uma certa distribuição de tamanhos. Neste caso, o valor do módulo da inclinação da reta no gráfico de $\ln I(q) \times q^{2}\left(=\frac{1}{3} R_{g}^{2}\right)$, no limite de baixo $q^{2}$ fornece um valor médio do raio de giro definido por:

$$
\left\langle R_{g}\right\rangle=\left[\frac{\left\langle R_{g}^{8}\right\rangle}{\left\langle R_{g}^{6}\right\rangle}\right]^{1 / 2}
$$

ou seja, que se trata de um valor médio que privilegia as partículas maiores.

Glatter mostra em seu livro uma tabela que relaciona o raio de giro de partículas de diversas formas com o raio no caso de esferas, eixos principais no caso de elipsóides, arestas no caso de paralelepípedos, etc. (Glatter, 1977 - ver p. 156).

\subsubsection{Superfície total de interfaces - Lei de Porod}

Considera-se o fim da curva de espalhamento, isto é, para $q$ grandes. Espera-se que o comportamento assintótico da curva de espalhamento para altos $q^{\prime} s$ dependa principalmente da estrutura fina da partícula. Isto corresponde no espaço real à dependência $\gamma_{0}(r)$ para pequenos valores de $r$. Para pequenos valores de $r$, a função característica $\gamma_{0}(r)$ pode ser aproximada por (Glatter and Kratky, 1982):

$$
\gamma_{0}(r)=\frac{\langle V(\vec{r})\rangle}{V} \approx 1-\frac{S}{4 V} r+\ldots
$$

onde $S$ é a superfície da interface entre as partículas e a matriz+. Substituindo a função $\gamma_{0}(r)$ (equação 2.16) na 2.9 tem-se:

$$
I(q)=4 \pi \eta^{2} V \int_{0}^{D}\left(1-\frac{S}{4 V} r+\ldots\right) \frac{\sin (q r)}{q r} r^{2} d r .
$$

Esta equação pode ser resolvida por partes levando a:

$$
I(q)=\frac{2 \pi \eta^{2} S}{q^{4}}, \text { para } q \longrightarrow \infty .
$$


Esta equação é chamada lei de Porod e apesar de ter sido desenvolvida para um sistema monodisperso ${ }^{3}$, ela também é válida para sistemas polidispersos mesmo sendo densamente empacotados. A lei de Porod é válida, enquanto a interface entre as partículas e a matriz é bem definida (ou seja, temos somente duas densidades eletrônicas) e as partículas estão aleatoriamente orientadas.

Multiplicando a equação 2.18 por $q^{4}$, obtem-se a constante de Porod $K$ :

$$
K=q^{4} I(q) \approx 2 \pi \eta^{2} S, \text { para } q \longrightarrow \infty,
$$

$K$ é obtida experimentalmente através de um gráfico $I(q) q^{4} \times q$, sendo o valor da função na região de $q$ na qual ela permanece constante.

$\mathrm{Na}$ prática sempre existe um espalhamento de fundo presente no sinal medido. Esse espalhamento de fundo ${ }^{4} I_{b}$, é devido a pequenas flutuações de curto alcance na densidade eletrônica das partículas e/ou da matriz e é em geral independente de $q$. A equação 2.19 fica então:

$$
q^{4} I(q) \approx 2 \pi \eta^{2} S+I_{b} q^{4}, \text { para } q \longrightarrow \infty .
$$

Nestas condições $K$ é o valor de $I(q) q^{4}$ extrapolado para $q^{4}=0$ e $I_{b}$ é a inclinação (positiva) da parte linear da função. Quando em gráficos de $I(q) q^{4} \times q^{4}$ se encontra um comportamento assintótico linear com inclinação negativa, isto se deve à presença de interfaces difusas (não bem definidas).

\subsubsection{Princípio de Babinet}

O princípio de Babinet em óptica afirma que objetos complementares produzem os mesmos efeitos de difração.

Para aplicar este princípio ao fenômeno de espalhamento de raios $X$ por partículas voltaremos à equação 2.1. A amplitude espalhada pela matéria num volume $V$ é:

$$
A_{1}(\vec{q})=\int_{V} \rho_{1}(\vec{r}) e^{-i \vec{q} \vec{r}} d \vec{r},
$$

onde $\rho_{1}(r)$ é a densidade eletrônica no elemento de volume $d \vec{r}$ cuja posição é fixa pelo vetor $\vec{r}$. Vamos considerar agora um espaço complementar, onde a densidade eletrônica $\rho_{2}(\vec{r})$ é definida como: $\rho_{2}(\vec{r})=\rho_{0}-\rho_{1}(\vec{r})$ onde $\rho_{0}$ é uma constante. A

3 Um sistema monodisperso é constituído por partículas que apresentam a mesma forma de tamanhos iguais. Por exemplo: esferas de $5 \AA$ de raio todas iguais ou cilindros idênticos formariam um sistema monodisperso. Já sistemas polidispersos apresentam uma dispersão em tamanho e/ou forma.

$4 I_{b}$ vem do termo inglês "background intensity". 
amplitude de espalhamento deste espaço complementar é

$$
A_{2}(\vec{q})=\int\left[\rho_{0}-\rho_{1}(\vec{r})\right] e^{-i \vec{q} \vec{r}} d \vec{r}
$$

Temos que a intensidade de espalhamento é dada pelo quadrado do módulo da amplitude, logo

$$
I_{1}(\vec{q})=A_{1}(\vec{q}) A_{1}(\vec{q})^{*} \text { e } I_{2}(\vec{q})=A_{2}(\vec{q}) A_{2}(\vec{q})^{*}
$$

Escrevendo $A_{0}(\vec{q})=A_{1}(\vec{q})+A_{2}(\vec{q})=\int \rho_{0} e^{-i \vec{q} \vec{r}} d \vec{r}$, então a função $I_{0}(\vec{q})=$ $A_{0}(\vec{q}) A_{0}(\vec{q})^{*}$ é um máximo para $q=0$, isto é, $I_{0}(0)=V^{2} \rho_{0}^{2}$ e decresce rapidamente a medida que $q$ cresce e se anula após um ângulo definido por $q_{0}=2 \pi / D_{0}$, onde $D_{0}$ é a dimensão média de $V$. Assim pode-se calcular o seguinte:

$$
\begin{aligned}
I_{2}(\vec{q})= & {\left[A_{0}(\vec{q})-A_{1}(\vec{q})\right]\left[A_{0}(\vec{q})^{*}-A_{1}(\vec{q})^{*}\right]=} \\
& I_{1}(\vec{q})+I_{0}(\vec{q})-A_{1}(\vec{q}) A_{0}(\vec{q})^{*}-A_{0}(\vec{q}) A_{1}(\vec{q})^{*}
\end{aligned}
$$

Para $q>q_{0}, I_{0}(\vec{q})$ é efetivamente zero, e conseqüentemente $A_{0}(\vec{q})$ e $A_{0}(\vec{q})^{*}$ também. Então $I_{1}(\vec{q})=I_{2}(\vec{q})$, confirmando o princípio da reciprocidade. Porém, se $q<q_{0}$ então a equação 2.22 demonstra que o princípio da complementaridade não será mais válido.

Portanto, o princípio da reciprocidade por ser aplicado somente para calcular a intensidade espalhada a ângulos tais que o valor correspondente de $q$ seja maior que o limite $2 \pi / D_{0}$, onde a dimensão $D_{0}$ se refere a dimensão média do volume no qual a densidade eletrônica complementária foi definida.

Na prática, o princípio da reciprocidade se aplica numa experiência de $S A X S$, quando o espalhamento é produzido por um conjunto de poros numa matriz de densidade eletrônica constante. Neste caso, a intensidade de espalhamento é equivalente à produzida por um conjunto de partículas de geometria igual à dos poros com densidade igual a da matriz distribuída no vácuo.

Outra aplicação dessa idéia é calcular o espalhamento de partículas que ao invés de estarem no vácuo, estão imersas num meio homogêneo de densidade eletrônica $\rho_{0}$ (por exemplo, o solvente de uma suspensão coloidal). Os espalhadores podem ser considerados como sendo a superposição de um meio contínuo de densidade $\rho_{0}$ e partículas de densidade $\rho-\rho_{0}$. A amplitude de espalhamento é a soma da amplitude espalhada pelo meio contínuo e pelas partículas fictícias. A primeira delas é zero, pois o espalhamento se dará numa região inacessível ao experimento. $\mathrm{O}$ espalhamento observado é simplesmente devido ao de partículas com densidade $\rho-\rho_{0}$. Todas as equações que se estabelecem são válidas pela condição que se considera $\rho$ como sendo a diferença entre a densidade eletrônica das partículas e do meio que as envolve. $\mathrm{O}$ 
espalhamento a baixos ângulos se anula, se as partículas têm uma densidade equivalente ao do meio que as envolve mesmo que tenham uma estrutura atômica bem diferente. (Guinier \& Fournet, 1955)

\subsection{Modelos estruturais utilizados para tratamento de dados}

Para realizar a análise dos dados, utiliza-se dois modelos diferentes, onde se aplica um à primeira série e outro à segunda e terceira séries de experiências realizadas nesta dissertação.

\subsubsection{Primeiro modelo}

Considera-se que a intensidade de espalhamento de $S A X S$ é produzida por poros existentes dentro dos agregados de partículas (cristalitos) constituintes do xerogel bem como por poros existentes entre os agregados.

Pelo fato da densidade dos xerogéis ser 20-30\% menor que o $\mathrm{NiO}$ puro considerase que a fase minoritária é constituída por poros, sendo eles os espalhadores. Como se mostrou, aplica-se ao caso o princípio de Babinet.

Como não foi observado um comportamento linear na região de Guinier (gráfico de $\log I$ por $q^{2}$ ) (Guinier e Fournet, 1955), concluí-se que o sistema é formado por poros com uma larga distribuição de tamanhos.

Por outro lado, para todas as amostras, observou-se um comportamento linear nos gráficos $\log$ - $\log$ (figura 5), indicando que a dependência da intensidade de $S A X S$ em $q$ é dada por

$$
I(q) \propto q^{-\alpha}
$$

onde $\alpha$ é a inclinação da reta em escala $\log -\log$. Este comportamento é esperado para sistemas poros esféricos com uma larga distribuição de raios obedecendo a uma lei potencial $\left(g(R) \propto R^{-\gamma}\right)$, e $R$ é o raio do poro. Demonstrou-se que $\gamma=7-\alpha$ para sistemas tridimensionais (Schmidt, 1982). Em materiais porosos, $g(R)$ é geralmente definido num intervalo $R_{\text {min }}<R<\infty$, onde $R_{\text {min }}$ é o limite inferior do tamanho de poros (supõe-se que não existam poros com tamanho menor que $R_{\min }$ ). Com estas suposições para a função de distribuição $g(R)$, pode-se calcular o tamanho médio do 

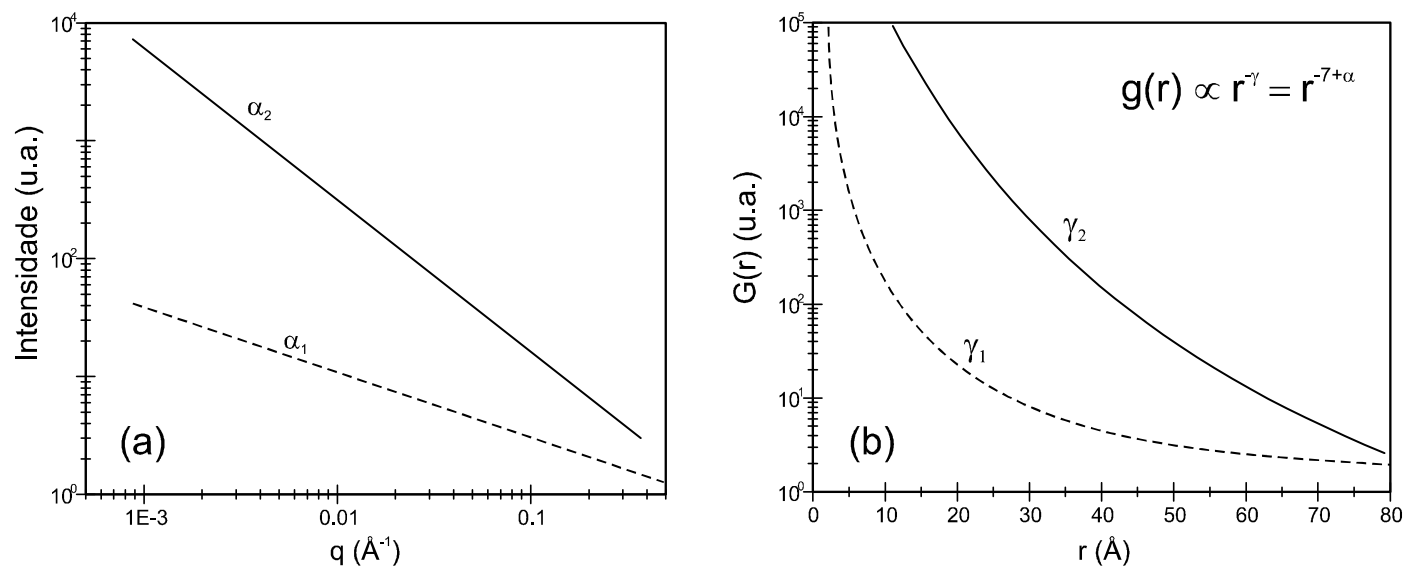

Figura 5.(a) curvas de espalhamento de partículas em escala $\log -\log$, indicando a inclinação das curvas, onde $\left|\alpha_{1}\right|<\left|\alpha_{2}\right|$ e (b) gráfico semilog da função $g(R)$, onde $\left|\gamma_{1}\right|>\left|\gamma_{2}\right|$.

raio dos poros $<R>$ que é dado por:

$$
\langle R\rangle=\frac{\int_{R_{\min }}^{\infty} g(R) R d R}{\int_{R_{\min }}^{\infty} g(R) d R}=\frac{\int_{R_{\min }}^{\infty} R^{-\gamma+1} d R}{\int_{R_{\min }}^{\infty} R^{-\gamma} d R} .
$$

Conseqüentemente, o quociente $\langle R\rangle / R_{\min }$ é:

$$
\frac{\langle R\rangle}{R_{\min }}=\frac{1-\gamma}{2-\gamma}=\frac{6-\alpha}{5-\alpha}
$$

A equação 2.26 mostra que o tamanho médio do raio dos poros cresce para valores crescentes de $\alpha$, que é o módulo do valor da inclinação nos gráficos $\log -\log$ assim, quanto maior for $\alpha$, tanto maior será o tamanho médio dos poros (figura 5).

Supõe-se no modelo que a intensidade espalhada é produzida por um sistema com duas densidades eletrônicas, consistindo de uma matriz na qual estão inseridos os poros. Utiliza-se como aproximação o modelo de partículas esféricas. Este modelo simplificado pode também ser de fato aplicado com boa aproximação a sistemas compostos por poros aproximadamente isodiamétricos.

\subsubsection{Segundo modelo}

Desta vez, o modelo aplicado para estudar a porosidade dos xerogéis é um pouco diferente do anterior. Na primeira série, observou-se um comportamento linear em toda região de espalhamento. Na segunda série de experiências, analisou-se uma faixa de 
$q$ bem maior e, nessas condições, afastamentos do comportamento linear nos gráficos $\log -\log$ foram observados.

Nos casos em que $g(R)$ não é proporcional a $R^{-\gamma}$, o primeiro modelo não pode ser aplicado. No caso de um conjunto de poros (partículas) com uma distribuição de tamanho arbitrária sem correlação espacial entre eles, a intensidade de espalhamento é dada por (Glatter and Kratky, 1982):

$$
I(q)=\int g(R) I_{1}(q, R) d R
$$

onde $I_{1}(q)$ é a intensidade espalhada por uma partícula isolada de densidade eletrônica constante numa matriz de densidade também constante, com forma qualquer. $I_{1}(q)$ é dada pela equação 2.14 e é denominada em casos gerais (sistemas de partículas com ou sem correlação espacial) fator de forma da partícula. Resolvendo a equação 2.14 para o caso particular de uma partícula ou poro de forma esférica, obtém-se

$$
I_{1}(q, R)=|\phi(q, R)|^{2},
$$

onde $\phi(q, R)$ é dado por

$$
\phi(q, R)=\Delta \rho \frac{4}{3} \pi R^{3}\left[\frac{3 \sin (q R)-q R \cos (q R)}{(q R)^{3}}\right],
$$

sendo $\Delta \rho$ em nosso caso (poros) a diferença da densidade eletrônica $\rho_{1}$ da fase sólida e da dos poros $\rho_{2}$ ( $\rho_{2}=0$ no caso de poros vazios).

Obtem-se a resolução numérica da integral especificada na equação 2.28, usando o programa de transformada indireta GNOM (Semenyuk and Svergun, 1991). Este programa calcula a função de distribuição de volume $V(R)=\frac{4}{3} \pi R^{3} g(R)$, bem como a função de espalhamento da intensidade produzida por um conjunto de esferas com distribuição de raio $g(R)$. Comparações entre as funções de intensidades calculadas e as experimentais permitem ter uma idéia da qualidade do ajuste.

Para análise de dados de $S A X S$ se utilizou o programa GNOM 4.2. Lê as curvas de espalhamento unidimensionais (possivelmente "smeared" por distorções instrumentais) e estima a função de correlação de distâncias $p(r)$ para sistemas monodispersos ou a função de distribuição de tamanhos $D(R)$ para sistemas polidispersos. A idéia do método da transformada indireta foi primeiramente proposto por Glatter (Glatter, 1977). Os algoritmos usados no GNOM estão descritos em vários artigos (Svergun et al., 1988; Semenyuk and Svergun, 1991; Svergun, 1992).

Algumas das principais características do programa são as seguintes:

1. GNOM pode ser utilizado para investigar dados relacionados aos seguintes sistemas:

- sistema monodisperso de partículas globulares; 
- sistema monodisperso de partículas alongadas;

- sistema monodisperso de partículas achatadas;

- sistema polidisperso de partículas esféricas (utilizado nesta dissertação) e

- sistema polidisperso de partículas com um fator de forma arbitrário.

2. Como os outros pacotes de transformação indireta, o GNOM produz uma resolução suave e estável, utilizando a técnica de regularização. Nos outros programas utilizados, o usuário tem que ajustar os parâmetros de regularização. Já para o GNOM isso é feito automaticamente. Além de encontrar a solução, GNOM também estima a qualidade do ajuste, permitindo verificar a validade das suposições feitas sobre o sistema em consideração.

3. GNOM é muito simples de ser utilizado. O usuário precisa definir somente o intervalo, onde pretende encontrar a solução, isto é, os tamanhos máximo e mínimo estimados das partículas. Qualquer pesquisador, mesmo com pouca experiência em computação facilmente usaria o programa.

4. Diferentes tipos de configurações experimentais são suportadas (colimação pontual, geometria de feixe linha, detetores $1 D$ e $2 D$ ). É possível combinar automaticamente duas medidas duma mesma amostra realizadas em regiões angulares diferentes com diferentes condições de "smearing".

5. O conhecimento dos erros nos dados de entrada é importante, mas não necessário. Uma rotina do GNOM estima os erros estatísticos, se estes não forem conhecidos. Computa-se a propagação de erros, usando a técnida de Monte-Carlo (Svergun and Pedersen, 1994).

\subsection{Descrição da linha de $S A X S$ do $L N L S$}

\subsubsection{Descrição geral da linha de $S A X S$}

A linha de $S A X S$ é constituída por vários componentes, entre eles por um espelho para focalização vertical do feixe (figura 6 - 1). O espelho é uma placa de vidro (float glass) revestida por um filme fino de ouro. A focalização é obtida, ajustando-se o raio de curvatura pelo peso do próprio vidro, apoiado nas suas extremidades. Determinouse o ângulo crítico para reflexão total desse espelho experimentalmente como sendo de 7,0 mrad para uma energia de $8 \mathrm{keV}$. O espelho opera sob vácuo (Vicentin, 1993) e suas dimensões são $800 x 100 x 19 \mathrm{~mm}$. 

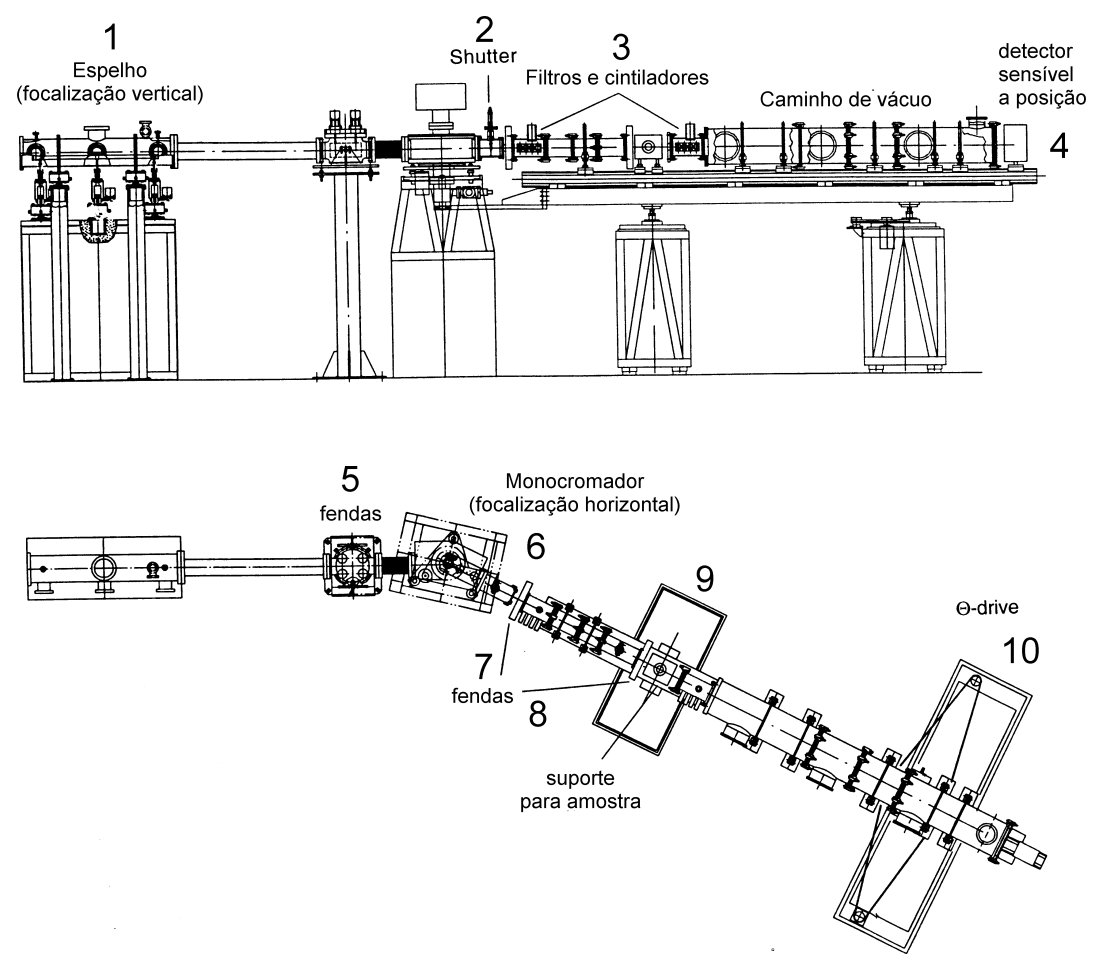

Figura 6.Estação experimental de $S A X S$ do $L N L S$. Os números indicam o (1) espelho para focalização vertical, (2) shutter após monocromador, (3) filtros e cintiladores, (4) detector (sensível a posição ou imaging plate), (5) fendas, (6) monocromador (que também focaliza o feixe horizontalmente), (7 e 8) fendas, (9) suporte para amostra e (10) mesa de apoio para deslocamento em $\theta$ caso necessário (mudança de comprimento de onda por exemplo). 


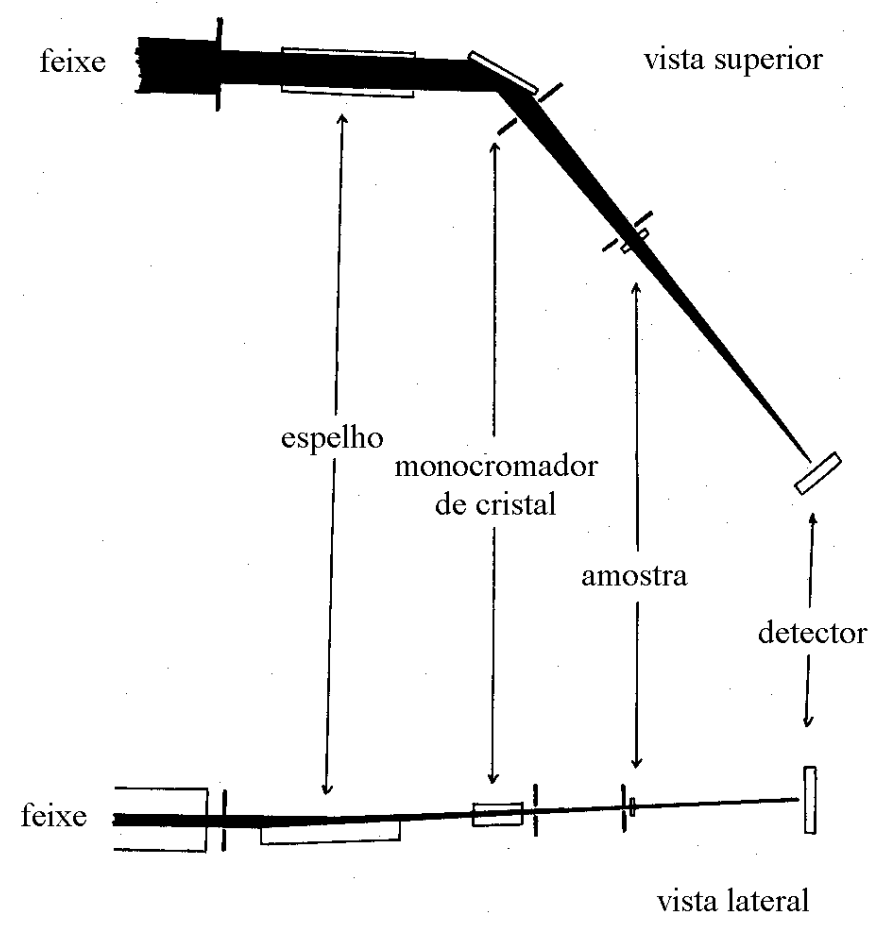

Figura 7.Outra vista destacando o feixe e sua focalização. 
O módulo de fendas de entrada (figura 6 - 5) possui quatro lâminas de tântalo controladas por motores de passo com movimentos independentes para limitar o tamanho do feixe que chega ao monocromador. Esse módulo se encontra entre o espelho e o monocromador. Todos os motores de passo que controlam as fendas estão ligados a um potenciômetro (encoder) que serve para registrar a posição das fendas. Este conjundo de fendas bem como outros é controlado por um sistema remoto (computador), facilitando a operação. As placas de interface foram todas projetadas pelo grupo de eletrônica do $L N L S$.

As fendas pré-monocromador (6 - 5) podem limitar o feixe incidente quando as amostras são muito espalhadoras. Assim o fluxo de fótons espalhado é maior do que o detector pode registrar. Também pode limitar o feixe quando a secção transversal das amostras assim o requeira.

O monocromador de cristal de silicio curvo (2) monocromatiza e focaliza o feixe no plano horizontal (figura 7) para comprimentos de onda entre 1, 0 a 2, $0 \AA$ A. O cristal permite que se ajuste os ângulos de Bragg, quando se muda o ângulo de incidência da radiação sobre o cristal, para selecionar um comprimento de onda desejado. Também possui um sistema para a variação do raio de curvatura do cristal e um outro ajuste que serve para controlar a posição vertical do cristal (tilt). O cristal de forma triangular tem $250 \mathrm{~mm}$ de comprimento dos quais $240 \mathrm{~mm}$ são aproveitáveis e sua espessura é de 1,5mm. A família de planos (111) do cristal de silício forma um ângulo $\alpha$ (ângulo de assimetria) de 11 graus em modo condensador (Fischer, 1997).

O conjunto de fendas pós-monocromador (6) serve para colimação adicional do feixe monocromático caso necessário. Nesse conjunto de fendas as bordas encostam no feixe produzindo espalhamento parasita. Para reduzir ao máximo esse espalhamento, há um conjunto de fendas adicional que estão próximas, mas não tocam o feixe (7).

Dependendo da energia do feixe que incide no monocromador ele pode estar sujeito a uma carga térmica alta o que pode modificar suas características de trabalho (distorções induzidas no cristal pela variação térmica por exemplo). Então é preciso um certo tempo (que pode ser longo) para estabelecer novamente um regime estável de operação. Para evitar este problema foi colocado após o monocromador um bloqueador do feixe (obturador secundário, figura 6 - 2) que serve para interromper o feixe monocromático, permitindo fazer mudanças nas condições experimentais sem interromper a iluminação do monocromador pelo feixe branco.

Até o monocromador, a pressão é mantida bem baixa $\left(<10^{-8}\right.$ torr $)$, visto que o espelho e monocromador são bem sensíveis à contaminação das superfícies. O restante da linha de $S A X S$ se encontra num vácuo na ordem de $10^{-2}-10^{-3}$ torr suficiente 
para eliminar os efeitos de absorção e espalhamento do ar. A proteção de alto vácuo é feita por uma janela de berílio que isola o vácuo mas permite que os raios $X$ passem. $\mathrm{Na}$ região de vácuo primário, temos janelas de Kapton, que são também bastante transparentes ao raios $X$.

Como para cada comprimento de onda do feixe incidente desejado, deve-se utilizar diversos ângulos de Bragg, os raios difratados saem com um ângulos $2 \theta^{\prime} s$ diferentes, sendo necessário mudar a posição de todos os componentes localizados após o monocromador (fendas anti-parasíticas, porta-amostras, beam stopper e detector de raios $X$ ). Estes componentes estão montados sobre uma mesa de granito sustentada por um colchão de ar que permite deslocar facilmente todo o conjunto.

Os equipamentos após o monocromador estão montados sobre um trilho óptico que permite variar as distâncias do monocromador-amostra e amostra-detector conforme necessidade da experiência. O porta-amostras também pode ser colocado em várias posições após a última fenda. O porta-amostra bem como o detector estão montados num dispositivo, controlado por motor de passo, que permite a variação em todas as direções no plano perpendicular à direção do feixe de raios $X$.

Antes e depois da amostra, existem monitores de intensidade que permitem determinar a absortância (inverso da transmitância) da mesma e monitorar a intensidade do feixe incidente.

Filtros atenuadores servem para diminuir o fluxo de fótons que chega ao detector de maneira controlada. A sua disponibilidade é muito útil durante procedimentos de alinhamento e na caracterização de amostras de grande poder espalhador (figura 6 - 7).

A estação de $S A X S$ permite o uso dos mais variados tipos de detectores (a gás uni e bidimensional, placa de imagem e $C C D$ ). Na primeira série de experiências, foi utilizou-se um detector do tipo sensível a posição unidimensional. Na segunda série, utilizou-se uma placa de imagem. O fato de não se ter utilizado a placa de imagem nas primeiras medidas fez com que tivesse de realizar duas medidas de cada amostra para corrigir a saturação causada pelo espalhamento intenso a baixos ângulos. Como a placa de imagem tem uma faixa dinâmica muito maior que o detector a gás (na ordem de 100 vezes maior) não foi preciso fazer várias medidas para cada amostra estudada.

\subsubsection{Sistema de detecção e configuração experimental}

Realizou-se as experiências na linha de $S A X S$ do $L N L S$ (Kellermann et al., 1997). Utilizou-se um feixe de raios $X$ monocromático de comprimento de onda $\lambda=1,608 \AA$. 
Na primeira série de experiências, a distância da amostra ao detector foi de $1115 \mathrm{~mm}$. Um detector sensível a posicão unidimensional foi utilizado para fazer a aquisição dos fótons espalhados. Como o sistema de colimação produzia um feixe de raios $X$ de secção quase pontual, o efeito de sua geometria na curva de $S A X S$ ("smearing") foi quase desprezível. Por isso não foi necessário uma deconvolução matemática das curvas de espalhamento experimental para corrigir as aberrações decorrentes. O espalhamento produzido pelas amostras era muito alto a baixos ângulos, sendo assim, foram realizadas duas medidas da mesma amostra com fendas diferentes. Uma medida foi feita com uma fenda de $1 \mathrm{~mm}$ frente ao detetor para não saturar o mesmo e evitar efeitos de "smearing" nas curvas de $S A X S$. Outra medida, com uma fenda de $8 \mathrm{~mm}$, para ter uma melhor estatística de contagem de fótons a altos ângulos. $\mathrm{O}$ "smearing" acontece quando o perfil do feixe utilizado não é pontual (perfil de linha por exemplo ou denominado feixe linha) ou quando o detector integra fótos espalhados fora do plano horizontal do feixe espalhado, sendo necessárias assim operações matemáticas para deconvoluir a intensidade espalhada ou mudar as condições experimentais a ponto de se ter uma medida sem borramento esta geralmente conseguida com um feixe ponto e um detector bidimensional (sensível a posição ou imaging plate) ou unidimensional com uma abertura muito pequena a partir da qual o efeito de "smearing" é quase nulo. A figura 8 ilustra, porque foram necessárias duas medidas.

Realizou-se este procedimento em todas as medidas, garantindo assim uma boa estatística mesmo em altos ângulos. Porém, na análise de dados, utilizou-se somente os dados referentes a ângulos baixos (início da curva de espalhamento), isto é, $q$ menores que $0,03 \AA^{-1}$ ( $q$ entre $0,01-0,03 \AA^{-1}$ ) devido a problemas com a remoção do espalhamento parasita causado pelo Mylar ${ }^{5}$.

O detector sensível a posição usado na linha de $S A X S$ do $L N L S$ está acoplado a uma eletrônica de processamento e esta ligada a um analisador multicanal. Quando um fóton incide numa certa posição do detector, o multicanal recebe uma contagem em um de seus canais. A relação entre o número do canal do analisador e a coordenada de entrada do fóton é linear, como mostrado na figura $9 a$.

O módulo do vetor de espalhamento é dado por:

$$
q=\frac{4 \pi}{\lambda} \sin \theta
$$

Para ângulos baixos, $\operatorname{sen} 2 \theta \approx 2 \theta(\mathrm{rad})$, e $2 \theta \approx \frac{\Delta x}{L}$, onde $\Delta x$ é a distância entre o feixe incidente e a posição de espalhamento, dada em milímetros por canal e $L$ é a distância entre a amostra e o detector ( $1115 \mathrm{~mm}$ e $\lambda$ foi $1,608 \AA$ ).

5 Polímero usado como vedante da cela contendo a amostra. 


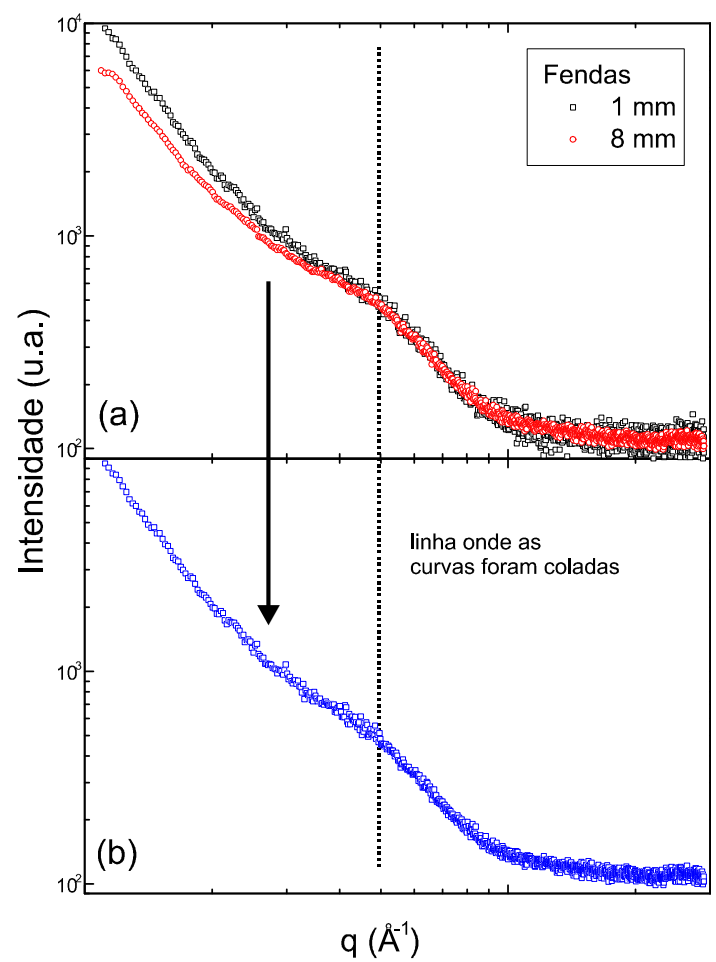

Figura 8.(a) Figura ilustrando o "smearing " causado pelo alargamento da fenda para valores pequenos de $q$. (b) Curvas corrigidas para comparação. 

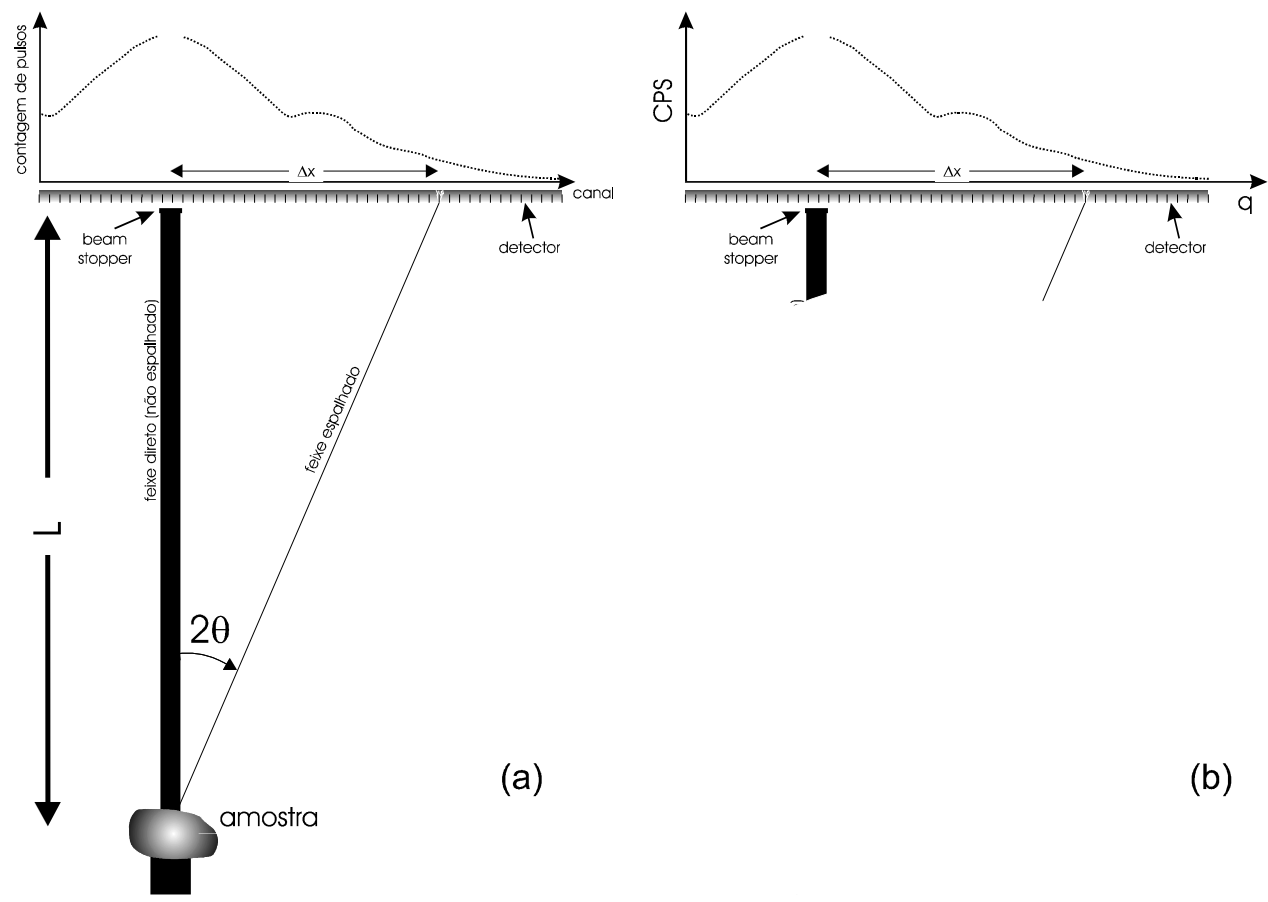

Figura 9.Esquema do espalhamento produzido por uma amostra, ilustrando o esquema de detecção (a) do detector (b) número de contagens por segundo e na abcissa o módulo do vetor de espalhamento. 
Logo,

$$
q=\frac{2 \pi}{\lambda} \frac{\Delta x}{L} \quad \therefore \quad q=k \Delta x
$$

Conhecida a constante $k$, obtem-se os gráficos de intensidade de espalhamento (em número de contagens por segundo) em função do módulo do vetor de espalhamento, como mostra a figura $9 b$.

O espalhamento parasita foi substraído do espalhamento total obtido experimentalmente.

$\mathrm{Na}$ segunda série de experiências, utilizou-se uma placa de imagem. O procedimento de obtenção do vetor de espalhamento foi o mesmo, entretanto, foram obtidos 2000 pontos ao invés de 1024 (resolução dos “canais" da placa de imagem era cerca de 2 vezes maior - cada ponto tinha $50 x 50 \mu \mathrm{m}$ ). Utilizou-se um sistema de placa de imagem da Kodak e um sistema de leitura STORM 820 para fazer a aquisição e leitura da intensidade de espalhamento como função do módulo do vetor de espalhamento $q$. A distância amostra-detector foi ajustada de tal forma a registrar valores de $q$ entre $0,005-0,14 \AA^{-1}(1852 \mathrm{~mm})$. A intensidade parasita produzida pelo ar e fendas foi subtraído da intensidade total espalhada. Da mesma forma como na primeira série de medidas, o feixe de raios $X$ era quase pontual, sendo assim se considerou o efeito de "smearing" da curva de $S A X S$ desprezível, não sendo necessária uma deconvolução matemática por este motivo para fazer a restauração da curva. Como o detector que se utilizou nesta experiência foi bidimensional (e não unidimensional como na primeira série de medidas) e supondo um feixe de secção pontual, uma integração radial resolveria o problema do "smearing" causado pelo fator da integração dos fótons que chegam num determinado ponto do detector. Isso foi observado na primeira série de experiências e corrigido, fazendo-se duas aquisições com fendas diferentes. Porém, na época em que se fez as medidas, não se dispunha dos programas para fazer a integração radial. Foi feita manualmente.

A figura 10 mostra como foi feita a integração para obtenção das curvas de $S A X S$. Não se fez a integração radial por não se dispor de programas na época. Hoje porém, há excelentes programas para realizar a integração radial, setorial e linear de arquivos de $S A X S$. Estes programas se encontram livremente na Internet ( $X-$ Ray e $F I T 2 D$ ) e podem ser encontrados na homepage (www.pagina.de/hannes) do autor. 

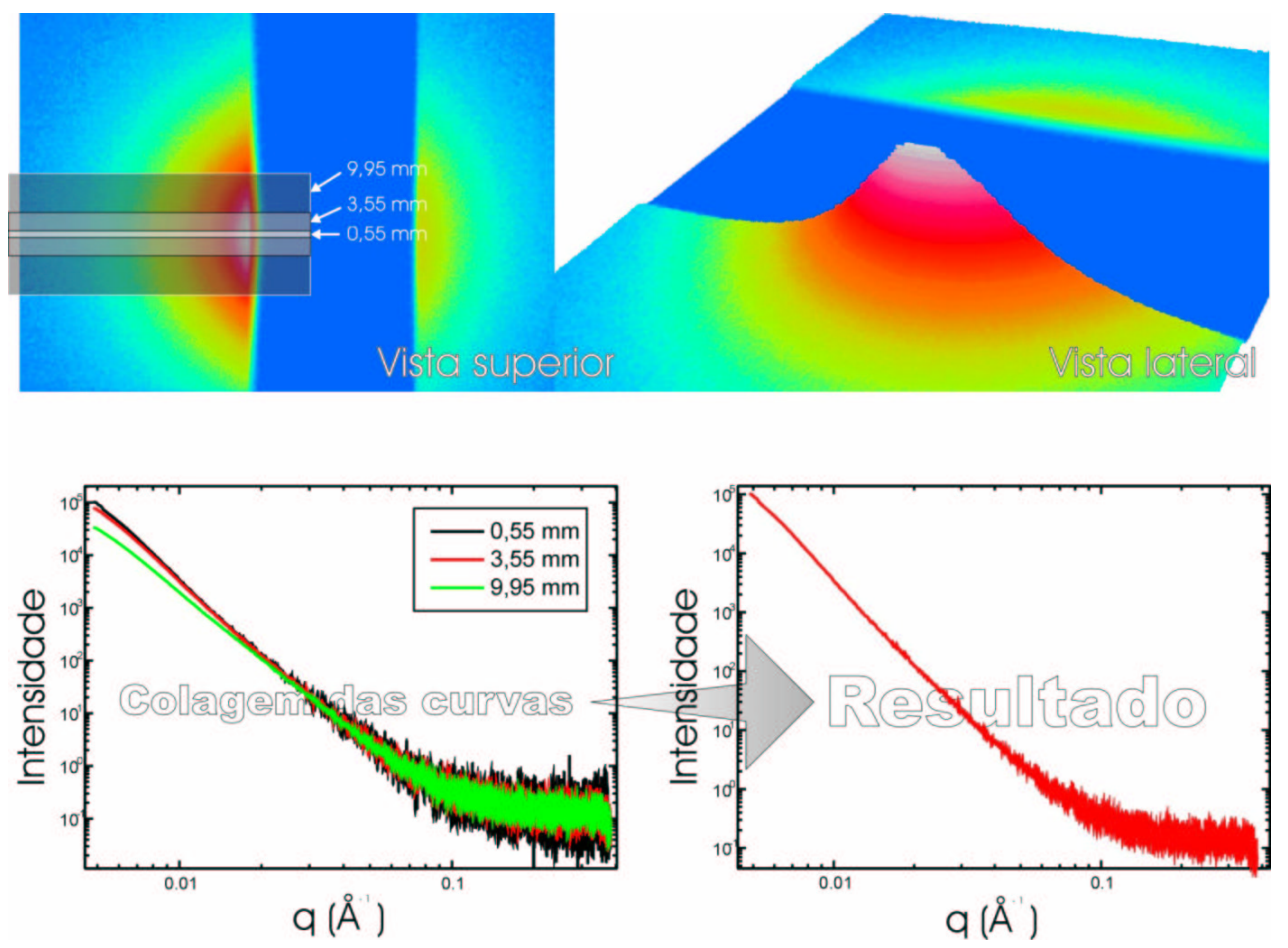

Figura 10.Figura ilustrando o espalhamento produzido pelas amostras e as faixas de integração utilizadas para compor a curva de espalhamento. 


\section{II.2. Espectroscopia de absorção de raios $X$ de estrutura fina $(X A F S)$}

\subsection{Introdução}

A técnica de $X A F S$ está baseada no efeito de interferência entre a onda do fotoelétron que sai do átomo absorvedor, quando um fóton de raio $X$ é absorvido por este, e a fração da onda retroespalhada pelos átomos vizinhos. Ela fornece informações sobre o estado químico e sobre as distâncias e números de vizinhos do átomo absorvedor ${ }^{6}$.

Desta maneira, pode-se determinar a estrutura média local de diferentes elementos de forma independente. A combinação da informação correspondente aos diversos tipos de átomos absorvedores pode fornecer dados detalhados da estrutura local do material. Como a função de $X A F S$ independe das correlações a longo alcance, ela é particularmente sensível a estrutura local ao redor do átomo absorvedor. Consequentemente, a técnica de $X A F S$ tem sido útil nos estudos da estrutura local ao redor de cada átomo em particular, especialmente em sistemas que não tem organização a longo alcance. Nos casos de materiais com ordem somente de curto alcance os estudos por difração tradicional $(X D R)$ informam apenas sobre a estrutura local média considerados todos os tipos de átomos.

O estado inicial de um elétron ligado num nível interno de um átomo pode ser representado por, $|i\rangle$. A secção de choque para uma promoção fotoelétrica do elétron ligado, para um estado final $|f\rangle$ num contínuo de energia é dado pela regra de ouro de Fermi (Fermi's golden rule) por

$$
\sigma(\omega)=4 \pi^{2} \alpha_{e f} \hbar \omega|\langle f|\widehat{r} \cdot \widehat{\varepsilon}| i\rangle|^{2} \delta\left(E_{f}-E_{i}-\hbar \omega\right) \rho\left(E_{f}\right),
$$

onde $\alpha_{e f}=e^{2} /$ hc é a constante de estrutura fina, $\rho\left(E_{f}\right)$ é a densidade de estados eletrônicos não ocupados na energia final $E_{f}$; $\widehat{\varepsilon}$ é o vetor unitário ao longo da direção da polarização linear do fóton e $E_{\gamma}=\hbar \omega$ é a energia do fóton.

A figura 11 mostra esquematicamente os níveis de energia relevantes onde a energia de ligação do elétron profundo é representado por $E_{B}$ : justamente a energia necessária para excitar um elétron a um estado final de elétron ligado e com energia cinética nula (fóto elétron - f.e.). Num metal, isto seria a diferença de energia entre o estado fundamental e o início da banda de condução. Uma transição desse tipo

6 Onde o átomo absorvedor é escolhido sintonizando a borda de absorção dele. 


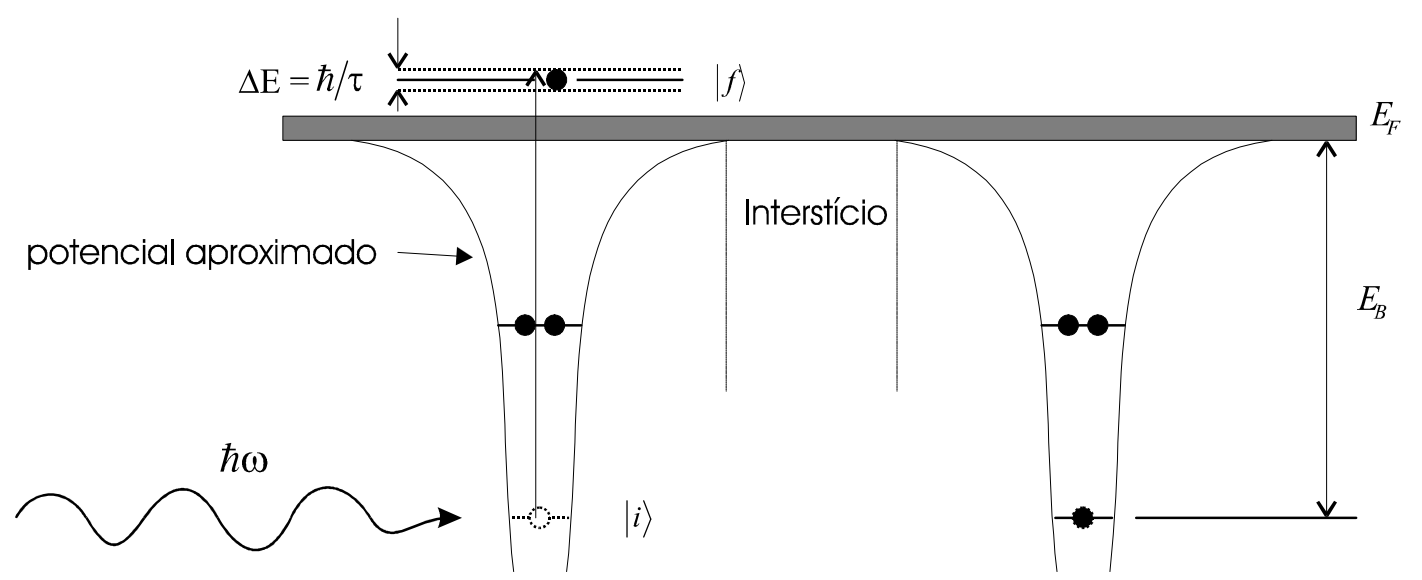

Figura 11.Diagrama de energia esquemático indicando a transição fóto-induzida. $E_{B}$ é a energia de ligação do elétron mais interno medido em relação ao fundo do potencial do interstício. A energia limiar de ligação é $E_{\gamma}=E_{B}+E_{F}$ desde que todos os estados abaixo de $E_{F}$ estejam ocupados. O estado final tem um tempo de vida finito $\tau$ e portanto é alargado por $\hbar / \tau$.

$\left(E_{\gamma}=E_{B}\right)$ seria impossível neste caso devido ao princípio de exclusão de Pauli: todos os estados abaixo do nível de Fermi $E_{F}$ estão preenchidos, assim o mínimo de energia cinética para um f.e. no estado final é $\hbar^{2} k_{F}^{2} / 2 m$.

A energia de ligação para que excitações f.e.'s ocorram é quando $E_{\gamma}-E_{B}=$ $E_{f . e .} \geq E_{F}$. O número de onda $k$ do f.e. é definido relativamente ao nível de Fermi, isto é:

$$
k=\frac{\sqrt{2 m\left(E_{f . e .}-E_{F}\right)}}{\hbar} .
$$

Variando a energia do fóton na vizinhança da energia de ligação dos elétrons, observa-se um salto na secção de choque de absorção. Para um átomo isolado, a secção de choque varia quase monotonicamente com a energia do fóton acima da borda de absorção. Isto é simulado e mostrado na figura 12 pela curva tracejada .

O estado final consiste de um f.e. mais um buraco num orbital profundo do átomo (vacância no estado $1 s$ por exemplo). Uma configuração destas é instável com tempo de vida típico da ordem de $\tau \approx 10^{-15}-10^{-17} \mathrm{~s}$, dependendo do tipo de átomo absorvedor e estado do núcleo. Este tempo de vida finito do estado excitado corresponde a um alargamento final de energia em torno de $\Delta E \approx \hbar / \tau$. Para a borda $K$ do $N i$ (estado inicial $1 s) \Delta E \approx 1,5 \mathrm{eV}$ contribui para o alargamento ("broadening") no espectro mostrado na figura 12. Outros fatores que contribuem para o alargamento do espectro são o espalhamento inelástico dos f.e.'s e principalmente a resolução experimental em energia do feixe de raios $X$ incidente, como se verá mais adiante. 

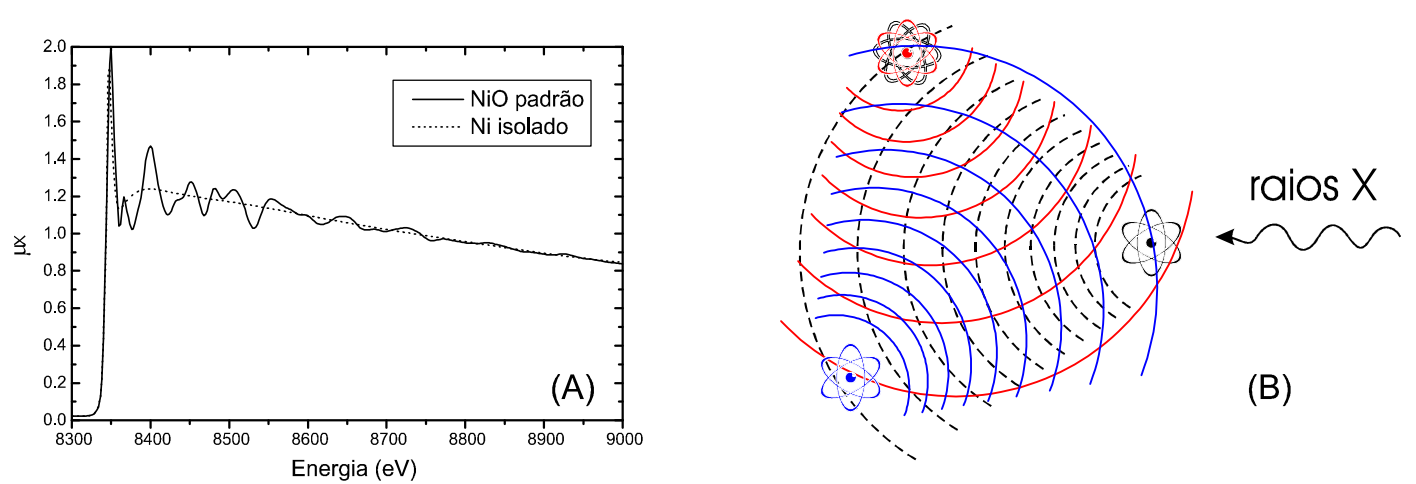

Figura 12.(A) A figura mostra o coeficiente de absorção de raios $-X$ vezes a espessura da amostra contra a energia dos fótons perto da borda $K$ do $N i O$. A linha tracejada simula a seção de choque na ausência de átomos nas vizinhanças. $(B)$ Esquema de interferência dos f.e.'s emitidos e espalhados e da distância entre átomos resultando em modulações da secção de choque de absorção. 
Quando o átomo absorvedor está rodeado de vizinhos, como num sólido, os f.e.'s que saem deste átomo são espalhados pelo potencial dos átomos vizinhos (veja figura $12 B$ ), interferindo com a onda inicial na posição do átomo absorvedor (definido como origem), modificando os elementos da matriz da equação $3.29^{7}$.

A interferência na origem entre as ondas que saem e retornam dos f.e.'s muda conforme a energia do fóton incidente aumenta (já que a energia cinética dos f.e.'s aumenta), enquanto que a distância entre os átomos permanece aproximadamente constante. A modulação dependente da energia do estado final introduz as oscilações na secção de choque de absorção mostrado na figura 12 pela linha sólida. Essas oscilações $(X A F S)$ contêm informação estrutural como distâncias dos átomos retroespalhadores ao átomos absorvedores, os tipos de átomos e seu número.

\subsection{A equação de $E X A F S$}

O coeficiente de absorção de raios $X$ acima da borda de absorção pode ser escrito como

$$
\mu(k)=\mu_{0}(k)[1+\chi(k)]
$$

onde a dependência da energia está relacionada ao número de onda pela equação 3.30, sendo $k=0$ para o limiar de absorção. Tratando-se de elétrons situados na camada mais interna $K$ e, considerando somente eventos de espalhamento simples $(E S)$ no qual a onda dos f.e.'s é espalhada somente por um átomo vizinho antes de interferir com a onda de saída, e dentro da aproximação harmônica para as vibrações atômicas, a modulação de $X A F S$ é dada por (Stern, 1974; Rehr et al., 1986; Rehr et al., 1990; DeLeon et al., 1991)

$$
\chi(k)=\sum_{j} 3\left(\widehat{\varepsilon} \cdot \widehat{r}_{j}\right)^{2} \frac{N_{j} S_{0}^{2} F_{j}\left(\pi, k, r_{j}\right)}{k r_{j}^{2}} e^{-2 k^{2} \sigma_{j}^{2}} e^{-2 r_{j} / \lambda(k)} \sin \left(2 k r_{j}+\delta_{j}\left(k, r_{j}\right)\right),
$$

onde

$k=$ é o módulo do vetor de onda do fóto-elétron;

$\chi(k)=$ é o coeficiente de absorção normalizado. (Parte do espectro de absorção ligada somente às oscilações de $E X A F S$ );

$j$ = índice referente a cada esfera de coordenação do átomo estudado;

$\widehat{\varepsilon}=$ vetor unitário ao londo da direção da polarização linear do fóton;

$r_{j}=$ distância entre o átomo $j$ e o átomo absorvedor;

$N_{j}=$ número de átomos do tipo $j$;

7 O estado inicial é altamente localizado na origem, assim o elemento de matriz é determinado pelo valor de $|f\rangle$ perto do núcleo. 
$S_{0}=$ fator de redução da amplitude devido a efeitos de correlação eletrônica;

$F_{j}\left(\pi, k, r_{j}\right)=$ amplitude de retro-espalhamento do foto-elétron pelos átomos vizinhos;

$\sigma_{j}=$ fator de Debye Waller;

$\lambda(k)=$ livre caminho médio dos foto-elétrons;

$\delta_{j}\left(k, r_{j}\right)=$ defasagem dos foto-elétrons devido aos potenciais do átomo absorvedor e de seus vizinhos.

Na equação 3.32, onde $N_{j}, r_{j}$ e $\sigma_{j}$ são parâmetros estruturais e $\lambda(k), F_{j}\left(\pi, k, r_{j}\right)$ e $\delta_{j}\left(k, r_{j}\right)$ parâmetros eletrônicos.

A maior parte dos componentes da equação 3.32 podem ser explicados de um um ponto de vista qualitativo. Pela discussão aqui é conveniente separar os termos que determinam a amplitude de $X A F S$ dos termos que determinam sua fase, isto é:

$$
\chi(k)=\sum_{j} \chi_{j}(k)=\operatorname{Re}\left[\sum_{j} A_{j}\left(k, r_{j}\right) e^{i \varphi_{j}\left(k, r_{j}\right)}\right],
$$

onde a soma é realizada sobre todos os centros de $E S j$. Ressalta-se primeiramente $\chi_{j}(k)$ a contribuição parcial do total de $X A F S$ do espalhador localizado no sítio $j$. Como o sinal de $X A F S$ está relacionado com a interferência na origem da onda que sai do absorvedor e é retroespalhada (i.é, no próprio absorvedor, $r=0$ ), a fase $\varphi_{j}$ é dada pela diferença de fase dessas duas ondas (chamada de fase do caminho óptico). A fase do caminho óptico, $2 k r_{j}$ no termo senoidal da equação 3.32 é a fase adquirida pelo f.e. após percorrer a distância até o outro espalhador $r_{j}$ e voltar ao átomo central (totalizando $2 r_{j}$ ). Acréscimos de fase adicionais $\delta_{j}(k)$ são devidos ao espalhamento dos f.e.'s, pelos potenciais atômicos do átomo absorvedor (duas vezes) e retroespalhador em $r_{j}$, i.é, $\delta_{j}\left(k, r_{j}\right)=2 \delta_{a}(k)+\delta_{r, j}\left(k, r_{j}\right)$, onde $a$ e $r$ correspondem ao átomo absorvedor e retroespalhador respectivamente.

A fase de espalhamento em $r_{j}$ depende não somente de $k$ mas também da distância, devido à natureza de onda esférica dos f.e.'s (Rehr et al., 1986). Tudo isto explica os termos da fase na equação 3.32, exceto o termo $\sin \varphi(k)$ no lugar da dependência em $\cos \varphi(k)$ que é obtida da parte real de $e^{i \varphi_{j}(k)}$. Isto não pode ser explicado qualitativamente, mas é devido a uma diferença de fase de $\pi / 2$ na forma assintótica $\left(k r_{j}>>1\right)$ da função esférica de Hankel que sai da posição do espalhador, $h_{l}^{+}\left(k r_{j}\right)$, com $l=1$ (Stern, 1974).

Um fator relevante, talvez o principal que contribui à amplitude do sinal de $X A F S$ é a amplitude de retroespalhamento da onda esférica, $F_{j}\left(\pi, k, r_{j}\right)$ (Rehr et al., 1986). Esta é a amplitude espalhada devido ao potencial do átomo a uma distância $r_{j}$ num ângulo $\theta=\pi$; i.é, de volta ao átomo central. Depende da distância, devido à 
natureza de onda esférica dos f.e.'s (Rehr et al., 1986). A dependência em $k$ de $F_{j}$ é um pouco complicada (Teo and Lee, 1979), mas sua variação com o número atômico $Z$ pode ser usada para distinguir entre diferentes tipos de retroespalhadores numa estrutura desconhecida.

Até agora considerou-se que a coerência no estado final é preservada; i.é, a diferença de fase entre as partes que saem e são retroespalhadas das ondas associadas aos f.e.'s, na presença da vacância eletrônica, são independentes do tempo. Efeitos que destroem o estado de coerência final, destroem o processo de interferência e resultam numa redução da amplitude de $X A F S$. Esses efeitos advêm de tempos de vida finitos do buraco eletrônico e dos f.e.'s, do termo $e^{-2 r_{j} / \lambda(k)}$ da eq. 3.32 e de desvios da distância interatômica de $r_{j}$ devido a vibrações na rede (termo $e^{-2 k^{2} \sigma_{j}^{2}}$ da eq. 3.32).

Tempos de vida finitos dos f.e.'s são descritos fenomenologicamente em termos do livre caminho médio $\lambda(k)$. Valores típicos de $\lambda$ a energias intermediárias do f.e. são da ordem de $10 \AA$, assim $\chi_{j}(k)$ a uma distância de $10 \AA$ é reduzido da ordem de 90\%. E este fato determina a escala de comprimento espacial da técnica de XAFS e sua limitação em investigar somente uma ordem de curto alcance no arranjo atômico ${ }^{8}$.

O termo de Debye-Waller $e^{-2 k^{2} \sigma_{j}^{2}}$ é um efeito produzido pelas vibrações da rede (e também desordens estáticas se presentes) na aproximação harmônica causando desvios médios da distância interatômica e assim, alterando a fase do caminho óptico. Como o tempo de vida dos estados excitados é muito pequeno $\left(\sim 10^{-15} s\right)$ comparado a tempos de vida característicos das vibrações da rede $\left(\sim 10^{-13} s\right), X A F S$ vê os átomos vizinhos como se estivessem congelados em suas posições instantâneas.

Porém a medida de $X A F S$, consiste no registro de cerca de $10^{8}$ eventos de absorção para cada energia do fóton incidente ${ }^{9}$ e, por esta razão, a distância instantânea $\left[r_{i}(t)\right]$ vai diferir de um átomo absorvedor do outro (ou do mesmo átomo absorvedor em tempos distintos), levando a uma perda de coerência. Considerando o termo da fase óptica ponderada por uma distribuição Gaussiana de distâncias em torno de $r_{j}$ (raiz da média quadrática (r.m.q.) $\left.\sigma_{j}=\sqrt{\left\langle\left(r_{i}-r_{j}\right)^{2}\right\rangle_{i}}\right)$, tem-se:

$$
\int_{-\infty}^{+\infty} \frac{1}{\sqrt{2 \pi \sigma_{j}^{2}}} e^{-\left(r_{i}-r_{j}\right)^{2} / 2 \sigma_{j}^{2}} e^{i 2 k r_{i}} d r_{i},
$$

\footnotetext{
8 Mas nem sempre era assim, nos primórdios do desenvolvimento teórico para explicar as oscilações $X A F S$ utilizou-se do conceito de estrutura de faixas de energia, cujo enfoque foi chamado de teoria do longo alcance (Kronig, 1931). Levou 40 anos para ser provado que essa teoria não era correta para explicar as oscilações $X A F S$.

9 Isto depende é claro do tipo de amostra e fonte de síncrotron que se está utilizando. Para amostras com pouco átomos que se está estudando nunca tantos eventos podem ser medidos. $10^{8}$ eventos de absorção seria o caso de uma amostra bem absorvedora.
} 
e definindo $r_{i}=r_{j}+\Delta r$, resulta:

$$
\begin{aligned}
\frac{1}{\sqrt{2 \pi \sigma_{j}^{2}}} \int_{-\infty}^{+\infty} e^{-(\Delta r)^{2} / 2 \sigma_{j}^{2}} e^{i 2 k\left(r_{j}+\Delta r\right)} d \Delta r & = \\
e^{i 2 k r_{j}} \frac{2}{\sqrt{2 \pi \sigma_{j}^{2}}} \int_{0}^{+\infty} e^{-(\Delta r)^{2} / 2 \sigma_{j}^{2}} \cos (2 k \Delta r) d(\Delta r) & =e^{i 2 k r_{j}} e^{-2 k^{2} \sigma_{j}^{2}},
\end{aligned}
$$

onde somente a parte real de $e^{i 2 k \Delta r}$ contribui à integral da eq. 3.35. A correção da fase óptica devido à desordem é dada pela correção da amplitude por $e^{-2 k^{2} \sigma_{j}^{2}}$. Se existir mais de 1 átomo do mesmo tipo à mesma distância média $r_{j}$ do átomo absorvedor, introduzse conceito de esfera de coordenação (e.c.) e $\chi_{j}(k)$ se torna a contribuição da j-ésima e.c. para $X A F S$, sendo $N_{j}$ (eq. 3.32) o número de átomos idênticos à mesma distância (número de coordenação ou degenerescência). Nesta notação, $\sigma_{j}^{2}$ representa o desvio quadrático médio na distribuição das distâncias em torno da média das distâncias da e.c. $r_{j}$.

A princípio, uma expressão ponderada da distribuição de distâncias deveria ser obtida para todos os termos que dependem de $r_{j}$ na eq. 3.32. Porém os outros termos, fora o termo da fase óptica, variam lentamente com $r_{j}$ (do tipo ou $1 / r_{j}$ ou $1 / r_{j}^{2}$ ) e assim, o valor médio de $r_{j}$ é usado para estes termos. O fator de Debye-Waller (eq. 3.32) contribue para o desaparecimento das oscilações de $X A F S$ para altos $k^{\prime} s$. A medida que $k$ aumenta, o comprimento de onda dos f.e.'s diminui e o efeito de incoerência provocado pela desordem aumenta. Porém o principal fator responsável pela atenuação do sinal a altos $k^{\prime} s$ é a amplitude de retroespalhamento dos átomos retroespalhadores.

O termo $S_{0}^{2}$ na eq. 3.32 é o fator de redução de amplitude ${ }^{10}$ é uma correção de muitos corpos que leva em conta os efeitos nas funções de onda dos elétrons passivos (diferente dos elétrons ativos, fotoexcitados) devido à presença da vacância eletrônica. A sobreposição dos $(N-1)$ elétrons passivos no estado inicial e final, $|\langle f \mid i\rangle|$, com $|i\rangle \mathrm{e}$ $|f\rangle$ sendo as funções de onda de muitos corpos, é reduzida levando a uma diminuição na transição associada a simples excitação dos f.e.'s sendo dado pelo elemento de matriz da eq. 3.29. Por definição, $S_{0}^{2}=|\langle f \mid i\rangle|^{2}$. (Rehr et al., 1978).

Outros dois termos que aparecem na eq. 3.32 são os termos $1 / r_{j}^{2}$ e o fator de polarização $3\left(\widehat{\varepsilon} \cdot \widehat{r}_{j}\right)$. A amplitude da onda retroespalhada é proporcional não somente a $F_{j}$ mas também à amplitude da onda que sai da posição do espalhador; i.é,

10 O fator de redução de amplitude leva em conta os efeitos multieletrônicos na transição. Varia tipicamente entre 0,7 e 0,9 e, no caso de amplitudes teóricas, deve ser ajustado com um padrão. Neste ajuste, é conveniente mantê-lo para reduzir o erro na determinação dos valores de $N_{j}$. 
$\sim F_{j} \frac{e^{i k r_{j}}}{r_{j}} \frac{e^{i k\left|r-r_{j}\right|}}{\left|r-r_{j}\right|}$, com a onda saindo originalmente a $r=0$ e a onda retroespalhada originando a $r=r_{j}$. A quantidade relevante para $X A F S$ é o valor da amplitude da onda retroespalhada na origem, que em sua forma complexa é $\sim F_{j} \frac{e^{i 2 k r_{j}}}{r_{j}^{2}}$, explicando a origem do fator $r^{-2}$.

O termo de polarização vem da dependência angular do operador de dipolo $\widehat{r} \cdot \widehat{\varepsilon}$ na eq. 3.29 junto com a dependência angular do estado inicial. Para oscilações $X A F S$ provenientes da camada $K$, o estado inicial é isotrópico $(l=0)$, e como o operador de dipolo tem dependência de $\cos \theta$ (escolhendo o vetor do campo de polarização elétrica $\widehat{\varepsilon}$ ao longo de $\widehat{z})$, o estado final deve ter uma dependência angular em $\cos \theta(l=1$, $m=0$ ) para dar um elemento de matriz não nulo na eq. 3.29 (regra de seleção de dipolo). A contribuição de espalhamento devido ao estado final é portanto proporcional à amplitude da onda emitida pelo retroespalhador, $\sim \cos \theta_{j}, \operatorname{com} \theta_{j}=\cos ^{-1}\left(\widehat{r_{j}} \cdot \widehat{\varepsilon}\right)$, resultando numa dependência angular da eq. 3.32 (o quadrado vem do quadrado do elemento de matriz na eq. 3.29) (Stern, 1974). Para uma amostra policristalina ou numa solução com partículas aleatóriamente orientadas, uma média angular precisa ser realizada sobre todas as orientações relativas possíveis do vetor de polarização e a direção de espalhamento, resultando em

$$
\frac{1}{4 \pi} \int_{0}^{\pi} \int_{0}^{\pi} 3 \cos ^{2} \theta_{j} \sin \theta_{j} d \theta_{j} d \varphi_{j}=1
$$

Negligencia-se os efeitos de espalhamento múltiplo, implicando ser a $\chi(k)$ uma soma linear das contribuições de $\chi_{j}(k)$ (dos átomos retroespalhadores). Esta aproximação é muito útil, facilitando muito as contas, mas é conhecido que o espalhamento múltiplo pode se tornar importante, quando o átomo absorvedor e os retroespalhadores são colineares. A estrutura geral da equação de $X A F S$ é uma soma de funções seno amortecidas: uma amplitude dependente em $k$ multiplicada pelo seno de uma fase aproximadamente linear em $k$. Em outras palavras, num gráfico da contribuição do sinal sinoidal de cada átomo versus $k$, oscila tanto mais quanto maior a distância (oscilações rápidas em $X A F S$ significam distâncias longas e vice-versa). Quanto maior a amplitude de espalhamento dos f.e.'s maior será o sinal ${ }^{11}$.

11 Numa amostra orientada, num monocristal por exemplo, a contribuição de um dado átomo é maior, quando seu raio vetor está orientado ao longo do eixo de polarização dos raios $-X$. 


\subsection{Análise de dados: Introdução e programas}

$\mathrm{Na}$ análise dos dados de $X A F S$ geralmente se faz um ajuste dos dados por mínimos quadrados pela soma do par de átomos (absorvedor e retroespalhador) de um material padrão. Cada padrão tem associados três parâmetros principais: a amplitude (proporcional ao número de primeiros vizinhos), a distância entre os átomos de um par, os ângulos formados entre os átomos ${ }^{12}$ e o parâmetro de Debye-Waller. O número de vizinhos e as distâncias dos átomos retroespalhadores ao absorvedor, determinam a estrutura local. A qualidade dos resultados estruturais de $X A F S$ depende muito da qualidade dos padrões de $X A F S$ de referência utilizados na análise de dados. Geralmente, utilizam-se dois tipos de espectros de referência: experimentais e teóricos. O primeiro é extraído dos dados de $X A F S$ de um material padrão de estrutura conhecida e similar à do material em estudo. O segundo é calculado a partir da estrutura conhecida utilizando métodos computacionais.

Se os pares de átomos do composto padrão e da amostra real têm as vizinhanças químicas parecidas, o padrão experimental em geral funciona muito bem. Porém, nem sempre se encontram padrões experimentais com estas características. Devido ao avanço nos cálculos teóricos nos últimos 20 anos o uso dos espectros de referência teóricos nos últimos anos tem se tornado mais freqüente. Neste trabalho, utilizam-se espectros de referência teóricos.

Para análise de dados de $X A F S$, executou-se os seguintes programas:

$A T O M S 3.00$, que cria uma lista de coordenadas atômicas dada uma informação cristalográfica de um cristal. Escrito por Bruce Ravel e disponível na internet para as mais diversas plataformas. Pode ser obtido gratuitamente na internet em http : //feff.phys.washington.edu/ ravel.

FEFF 6.01, programa que calcula os espectros de $X A F S$ teóricos dada uma configuração espacial dos átomos, baseado na expansão de curvas esféricas e espalhamento múltiplo da equação de $X A F S$. Escrito por John Rehr e seus estudantes Jose Mustre de Leon, Steven Zabinsky e Alexei Ankudinov em colaboração com R. Albers (Rehr and Albers, 1990; Rehr, 1993) e tem mostrado ser uma ferramenta rápida e flexível para obter espectros de $X A F S$ confiáveis numa grande variedade de sistemas experimentais (Vaarkampe et al., 1994; O’Day et al., 1994; Frenkel et al., 1993). Pode ser obtido mediante pagamento de uma licença, na internet em http : //feff.phys.washington.edu/feff.

12 No caso de espalhamento simples considera-se somente a onda que sai do átomo absorvedor e a que é retroespalhada, sendo assim o ângulo de $\pi$ radianos. 
$A U T O B K$, que separa a absorção medida experimentalmente nos espectros de absorção do elemento absorvedor (ou central) no caso em que estivesse livre do caso real (as oscilações $X A F S \chi(k)$ ). Escrito por Matthew G. Newville, tem demonstrado ser útil e confiável na análise de vários sistemas. Encontra-se disponível gratuitamente na internet em http : //cars.uchicago.edu/ newville/AUTOBK/ e funciona em ambiente $D O S$.

$W I N X A S$, programa mais usado que calcula a tranformada de Fourier da função $\chi(k)$ e faz o ajuste entre o espectro teórico obtido por $F E F F$ e os dados experimentais. Escrito por Thorsten Ressler (Ressler T., 1997) para ambiente Windows sendo comercial (versão demonstração disponível na internet: http : //ourworld.compuserve.com/homepages/t_ressler).

\subsubsection{Isolamento e interpretação do sinal de $E X A F S$}

O sinal de $E X A F S$ é definido na equação 3.31 como a modificação do coeficiente de absorção do átomo "isolado", $\mu_{0}(k)$ devido ao espalhamento dos f.e.'s pelos átomos vizinhos no sólido, i.é,

$$
\chi(k)=\frac{\mu(k)-\mu_{0}(k)}{\mu_{0}(k)}
$$

onde $k$ é o número de onda dos f.e.'s em relação ao nível de Fermi. Deve ser notado que nesta definição $\mu_{0}(k)$ é a contribuição à absorção de uma dada esfera interna de excitação de elétrons $(1 s, 2 p 3 / 2, \ldots$, dependendo da borda de absorção em questão) para um dado átomo absorvedor isolado (no caso o átomo central ou absorvedor). O coeficiente de absorção medido experimentalmente $(\mu)$, porém, pode conter contribuições da absorção de outras bordas de absorção do átomo em estudo e de outros átomos presentes na amostras se existirem. Essas contribuições precisam ser subtraídas do coeficiente de absorção medido $(\mu)$ para uma normalização adequada das oscilações de XAFS $(\chi(k))$. Justamente por este motivo, se determina $\mu$ experimentalmente num grande intervalo de energia $\Delta E$ abaixo da borda de interesse $(\Delta E \sim 100 \mathrm{eV}$ ) no qual a contribuição à absorção dos elétrons da camada $K$ do átomo absorvedor é zero. Nessa faixa todas as outras contribuições de absorção (provenientes de outras bordas como $L, M, N, \ldots$ ) não desejadas aparecem. Já que todas as outras contribuições se manifestam em $\mu$ de forma contínua (sem quebras abruptas) em torno da borda de interesse, elas são subtraídas ajustando a região "pré-borda" com uma linha (reta, polinômio de segundo grau, ...) e se extrapolando a mesma após a borda (linha em vermelho na figura 13). 


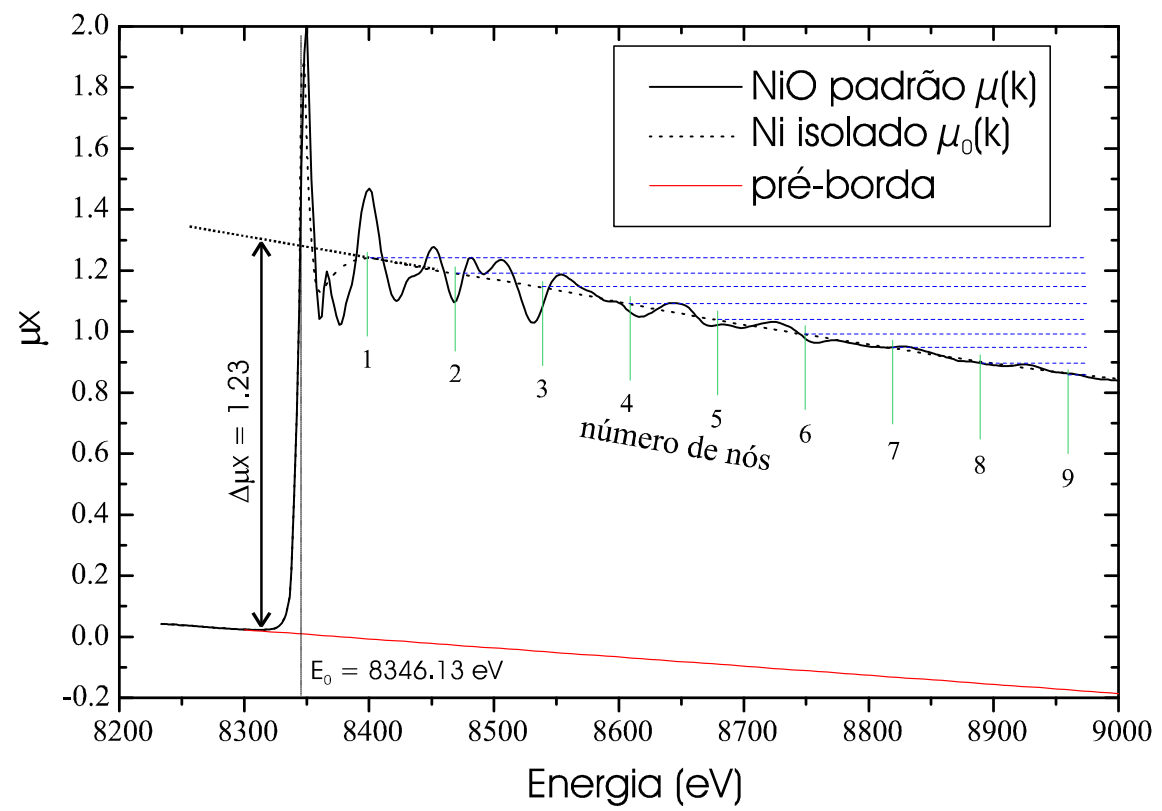

Figura 13.Procedimento utilizado pelo $A U T O B K$ para obter a função $\chi(k)$. As linhas verdes (numeradas na vertical) representam os nós da função spline que são igualmente espaçados e são definidos pelo intervalo de energia em que foi feita a medida. As linhas azuis (na horizontal e tracejadas) representam o ajuste na vertical determinado pela minimização entre a diferença da $\widetilde{\chi}_{\text {tentativa }}(r)$ e $\widetilde{\chi}_{\text {padrão }}(r)$ para $r \leq R_{\text {fundo }}$. 
Para isolar $\chi(k)$ se utilizou o programa $A U T O B K$. Ele é baseado na distinção entre componentes de freqüência presentes devido somente ao átomo isolado (freqüências de fundo) daquelas presentes na $\chi(k)$. Como pode ser visto na equação 3.32 , as oscilações na $\chi(k)$, dadas pelo termo senoidal, tem "frequiências" que são relacionadas a duas vezes as distâncias interatômicas, $2 r_{j}$ (as fases de espalhamento $\delta_{j}(k)$, dependem de $k$ e tem um efeito menor, porém significante nas "frequiências"). A contribuição não-espalhadora à $\mu$ varia suavemente com $k$, já que o fundo é definido como a contribuição das componentes de frequiência abaixo daquelas que contêm sinal $X A F S$, isto é, abaixo de $2 r_{1}$, a "freqüência" da primeira camada $X A F S^{13}$. Como um vazamento da primeira esfera de coordenação dentro da região de baixo $R(<1 \AA)$ afetando a $\chi(k)$ é possível, uma aproximação melhor é utilizar um padrão teórico ou experimental e assim minimizar a diferença na região de baixo $R$. O $\chi(k)$ teórico é utilizado para dar uma estimativa do vazamento na região de baixo $R$.

O fundo é determinado utilizando-se uma função "spline" que é composta por $N_{\text {fundo }}+1$ polinômios de $4^{\circ}$ grau igualmente espaçados. O número de nós $\left(N_{\text {fundo }}\right)$ é determinado, igualando-se o número de pontos independentes na região de fundo, $N_{\text {fundo }} \approx 2 \Delta k R_{\text {fundo }} / \pi$, onde $\Delta k$ é a região usada para determinar $\mu_{0}(k)$ e $R_{\text {fundo }}$ é o valor máximo da região de baixo $R$ sobre o qual o fundo será ajustado.

Considera-se que o fundo é aceitável, quando a transformada de Fourier ( $T F$ ) da $\chi(k)^{14}$, obtida pela eq. 3.30, é similar à do padrão na faixa abaixo de um valor de $R$ menor que a menor distância interatômica $\left(R_{\text {fundo }}\right)$. Os parâmetros da função de fundo são ajustados até que a diferença seja minimizada. Para algumas estruturas, especialmente naquelas onde a distância dos primeiros vizinhos é pequena, a TF da $\chi(k)$ pode vazar na região de fundo e neste caso a minimização com respeito a um padrão é mais apropriada do que simplesmente remover todos as componentes de freqüência abaixo de $R_{\text {fundo }}$.

Nesta dissertação, escolheu-se os valors de $R_{\text {fundo }}$ da ordem da metade da distância do primeiro vizinho, região onde o sinal de $X A F S$ é desprezível ou pequeno.

\subsubsection{Medida de $\mu(E)$}

Alguns cuidados são necessários na determinação de $\mu(E)$ para que as oscilações $X A F S$ possam ser consideradas confiáveis, já que uma pequena quantidade do sinal de absorção total é o que realmente contêm informação relevante. Assim, a relação

13 A distinção entre estes dois regimes não é tão fácil de determinar. Por este motivo alguns pesquisadores não utilizam programas de subtração de fundo automático.

14 A transformada de Fourier da $\chi(k)$ é representada por $\widetilde{\chi}(k)$. 
sinal/ruído precisa ser melhor que $10^{-3}$. Esse tipo de estatística de contagem é facilmente conseguida, usando-se uma fonte de luz síncrotron, mesmo em tempos de aquisição da ordem de 1s por ponto. Quando o número de fótons na câmara de ionização é da ordem de $10^{8}-10^{9}$ fótons/s, tem-se uma relação sinal/ruído da ordem de $10^{-4}-10^{-5}$ (sendo a relação sinal/ruído nas oscilações de $X A F S$ da ordem de $\left.10^{-3}\right)^{15}$. Isto corresponde a correntes típicas na câmara de transmissão $I_{t}$ da ordem de $I \approx$ (\#fótons $/ s)\left(E_{d} / E_{\text {ionização }}\right)(e) \approx 0,5 n A$, para $E_{d} \sim 8 k \mathrm{eV}^{16}$ e $E_{\text {ionização. }} \sim 30 \mathrm{eV}^{17}$. Além de erros decorrentes de eventuais baixas correntes, outros erros fatores podem também contribuir de forma apreciável, tais como a não uniformidade na amostra e/ou a presença de harmônicos no feixe suposto "monocromático" em uma certa faixa de energia. Assim, minimizando esses erros sistemáticos, podem-se obter medidas confiáveis do coeficiente de absorção $\mu(E)$.

\subsection{Descrição da linha de $X A F S$ do $L N L S$}

Utilizando-se feixes de raios $X$ produzidos por fontes de luz síncrotron, dispomos de fótons com uma ampla faixa de energia, desde o infra - vermelho até raios $X$ duros, com a intensidade crescendo até aproximadamente o valor da energia crítica $E_{c}(\mathrm{eV})=2218 E_{e^{-}}^{3}\left(G \mathrm{eV}^{3}\right) / \rho(m)$, onde $E$ é a energia dos elétrons no anel e $\rho$ é o raio de curvatura dos dipólos, depois da qual descresce exponencialmente (veja figura 15). A energia dos elétrons armazenados no anel do $L N L S$ é de $1,37 G e V$ e a curvatura dos dipólos é de $2,735 \mathrm{~m}$ resultando em $E_{c}=2,08 k \mathrm{eV}^{18}$. Acima de $E=E_{c}$, o fluxo de fótons decai rapidamente. A $10 k \mathrm{eV}$, o fluxo já é mais de 50 vezes inferior a seu valor máximo, e a $20 k \mathrm{eV}$ mais de 5000 vezes, sendo o fluxo quase desprezível acima de $30-40 k \mathrm{eV}$.

\footnotetext{
15 Lembrando novamente que estes valores dependem da fonte de luz síncrotron utilizada, bem como da amostra, tipo de aquisição, etc.

$16 E_{d}$ é a energia em torno da borda de absorção do elemento em estudo, por exemplo, a energia de absorção da borda $K$ do $N i$ é $8333 \mathrm{eV}$.

$17 E_{\text {ionização }}=$ energia de ionização. Para ionizar um átomo de argônio são necessários em torno de $30 \mathrm{eV}$. Com $70 \mathrm{eV}$ é possível ionizar qualquer átomo da tabela periódica (arrancar um elétron da última camada do átomo).

18 Descrições detalhadas sobre o funcionamento e informações técnicas da fonte de luz síncrotron utilizada podem ser encontradas no "Activity Report" do $L N L S$.
} 


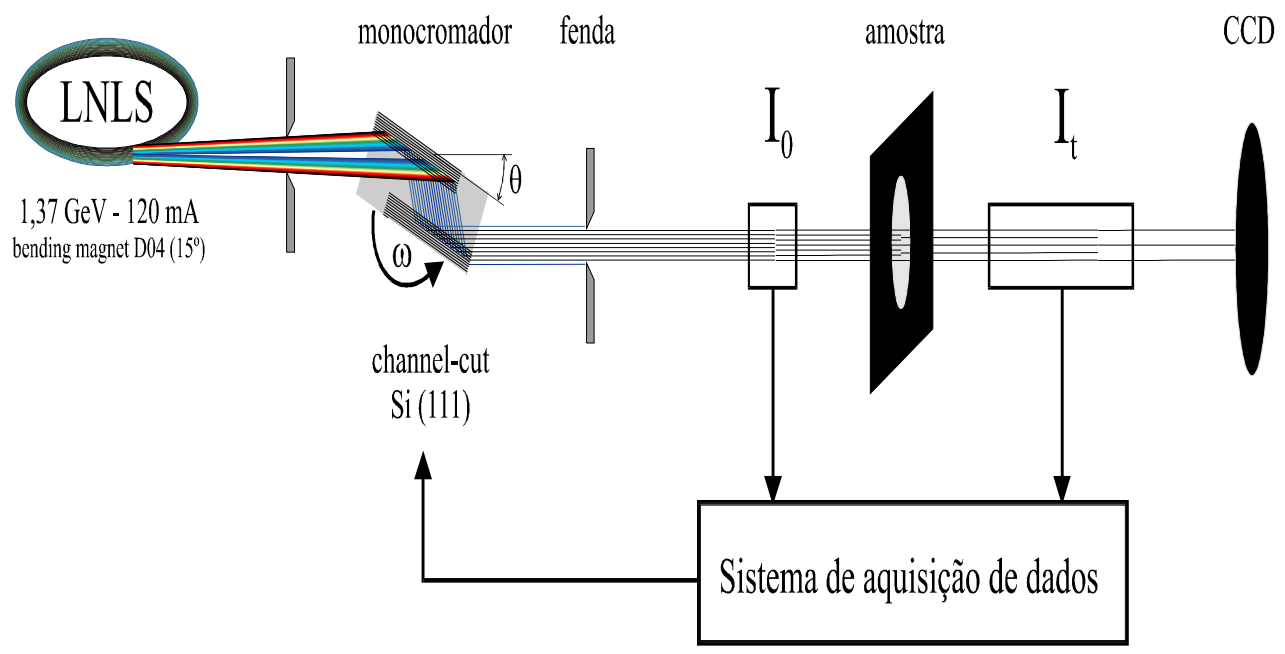

Figura 14.Esquema experimental para determinar o coeficiente de absorção das amostras em função da energia, na geometria de transmissão utilizada neste trabalho.

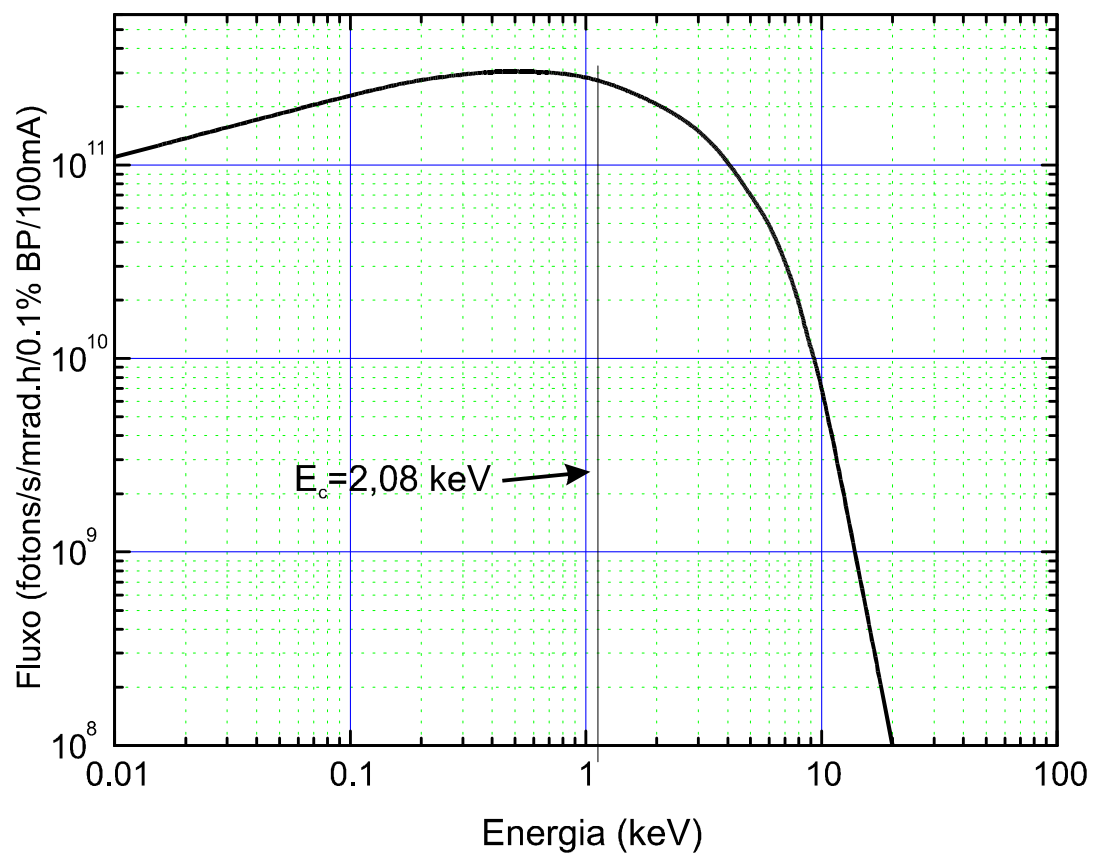

Figura 15.Fluxo de fótons emitido pela fonte de luz síncrotron do $L N L S$. 


\subsubsection{Monocromador e fendas horizontais}

Numa medida de $X A F S$, para se variar a energia dos fótons incidentes para determinar $\mu(E)$, necessita-se de um monocromador que permite selecionar a energia desejada, permitindo assim uma varredura em torno da borda de absorção do elemento. $\mathrm{Na}$ linha de $X A F S$ do $L N L S$, usa-se um monocromador de cristal único ("channel cut"), onde se faz um sulco num bloco de $S i$ (ver figura 14). Como nas experiências dessa dissertação a energia mínima utilizada foi de $4900 \mathrm{eV}$ e a máxima de $9100 \mathrm{eV}$, empregou-se um cristal de Si com corte nos planos (111) que é apropriado para essa faixa de energias. A geometria do monocromador na linha de XAFS do $L N L S$ permite utilizar a reflexão (111) do $S i$ na faixa de $2010 \mathrm{eV}<E<11390 \mathrm{eV}$. Então, tem-se dois cristais num só bloco. O primeiro cristal é usado para selecionar a energia desejada, geralmente em torno da $E_{b . a .}$, fazendo com que os planos deste cristal com o feixe incidente satisfaçam a lei de Bragg, expressa por

$$
2 d_{h k l} \sin \theta=\lambda_{b . a .}=\frac{h c}{E_{d}} .
$$

Aqui $h$ é a constante de Plank, $2 d_{h k l}=6,271 \AA$, quando $h=k=l=1\left(d_{111}\right.$ é a distância interplanar dos planos (111) do cristal de Si) e $c$ é a velocidade da luz no vácuo e $E_{d}$ a energia dos fótons refletidos (ver figura 14).

O segundo cristal, sendo paralelo ao primeiro, satisfaz igualmente a lei de Bragg para o mesmo ângulo e assim reflete o feixe monocromatizado na mesma direção do feixe incidente no primeiro cristal em direção à amostra. A medida que o experimento avança, o ângulo de Bragg varia continuamente fazendo com que a altura (ou "offset") do feixe monocromático mude um pouco. Este efeito é grande para energias baixas, quando a mudança de ângulo necessária para uma dada energia é maior. Este efeito pode ser visto pela equação abaixo:

$$
\Delta \theta=\frac{\Delta E_{d}}{E_{d} \cot \theta}
$$

Nas experiências realizadas durante a dissertação não se obteve variações de altura do feixe maiores de $0,2 \mathrm{~mm}$ na amostra, devido ao fato da varredura ter sido feita num espaço reduzido de energias. A tabela abaixo ilustra todas as varreduras realizadas e o efeito da variação de altura do feixe na posição da amostra.

\begin{tabular}{|c|c|c|c|c|}
\hline Material & $E_{i}(\mathrm{eV})$ & $E_{f}(\mathrm{eV})$ & $\Delta E_{d}(\mathrm{eV})$ & $\Delta h_{\alpha}(\mathrm{mm})^{19}$ \\
\hline $1 \mathrm{~mol} \mathrm{NiCl}_{2}+0,1 \mathrm{~mol}$ de ácido acético (aa) & 8230 & 9000 & 770 & 0,088 \\
\hline $\left.0,8 \mathrm{~mol} \mathrm{NiCl}_{2}+0,2 \mathrm{Ti}\left[\mathrm{O}\left(\mathrm{CH}_{2}\right) \mathrm{CH}_{3}\right]_{4}\right)+0,1 \mathrm{~mol}$ aa & 8230 & 9000 & 770 & 0,088 \\
\hline $\left.0,8 \mathrm{~mol} \mathrm{NiCl}_{2}+0,2 \mathrm{Ti}\left[\mathrm{O}\left(\mathrm{CH}_{2}\right) \mathrm{CH}_{3}\right]_{4}\right)+0,1 \mathrm{~mol}$ aa & 4900 & 5200 & 300 & 0,178 \\
\hline
\end{tabular}

19 Onde $\Delta h_{\alpha}$ é a variação da altura do feixe na posição da amostra $\left(\Delta h_{\alpha}=2 * d_{m} *\left(\cos \left(\theta_{f}\right)-\cos \left(\theta_{i}\right)\right)\right)$ 
Tabela 1: Material estudado, $E_{i}=$ energia inicial, $E_{f}=$ energia final, $\Delta E_{d}=$ intervalo de energia medido $\left(E_{f}-E_{i}\right)$ e $\Delta h_{a}=$ variação total da altura do feixe monocromatizado na direção vertical.

Como as amostras tinham em torno de $2,5 \mathrm{~cm}^{2}$ e sendo de espessura bem uniformes não foi necessário acompanhar o movimento na vertical para evitar efeitos de heterogeneidades de espessura.

Como pode ser visto também pela eq. 3.40, a resolução em energia do feixe monocromático é principalmente determinada pela divergência vertical da radiação incidente no monocromador e amostra (para divergências angulares $\leq 0,1 \mathrm{mrad}$, a largura angular intrínsica do pico de difração de Bragg, isto é, a largura de Darwin, pode corresponder a um valor de $\Delta E$ comparável). O objetivo das fendas horizontais, ilustrado na fig. 14 é de limitar a divergência vertical do feixe (assim há perda de fluxo) para aumentar a resolução.

Para fótons de alta energia, isto é, $E>>E_{c}$, a divergência vertical do feixe produzido pela frente de luz síncrotron é dado por (Wiedemann, 1999):

$$
\sigma_{\theta}(\operatorname{mrad})=\frac{7,124}{[\rho(m) E(\mathrm{eV})]^{1 / 3}} .
$$

No $L N L S$ para energia da ordem de $8 k \mathrm{eV}$ temos uma divergência da ordem de 0,25mrad resultando num feixe com dimensão vertical (FWHM) da ordem de $2,7 \mathrm{~mm}$ na posição do monocromador situado $11,28 \mathrm{~m}$ longe da fonte. Nas condições experimentais utilizadas, as fendas pré-monocromador tinham uma abertura de $1 \mathrm{~mm}$. Como a fonte de fótons também tem uma secção de tamanho não nulo (a secção do pacote de elétrons tem uma dimensão vertical de $0,7 \mathrm{~mm}$ ), tem-se uma contribuição adicional para a divergência angular. Assim, com uma fenda pré-monocromador de $1 \mathrm{~mm}$ e uma fonte de $0,522 \mathrm{~mm}$ se tem uma divergência angular vertical da radiação entrando no monocromador da ordem de $\delta \theta \sim 1,522 \cdot 10^{-3} / 11 \sim 1,4 \cdot 10^{-4}$. Como a largura de Darwin intrínsica para os planos (111) do Si é da ordem de $\delta E / E \sim 1,3 \cdot 10^{-4}$, tem-se uma resolução em energia para fótons de $8 k \mathrm{eV}$ em torno de $4,8 \mathrm{eV}$. Já para uma fenda e $0,5 \mathrm{~mm}$ se teria uma resolução em energia para fótons de mesma energia uma resolução de $3,5 \mathrm{eV}$ (ver figura16). Como o $\Delta E$ devido ao tempo de vida finito da vacância gerada na camada $K$ do $N i$ contribui em torno de $1,5 \mathrm{eV}$ para o alargamento da energia concluí-se que a maior contribuição é devida à parte instrumental. A abertura vertical do segundo par de fendas horizontais é reduzida para melhorar ainda mais a resolução em energia e diminuir a dimensão vertical do feixe no plano da amostra. Assim para as medidas de $E X A F S$ a dimensão vertical

e $d_{m}$. é a distância entre os dois planos refletores do monocromador $(9 \mathrm{~mm})$. 


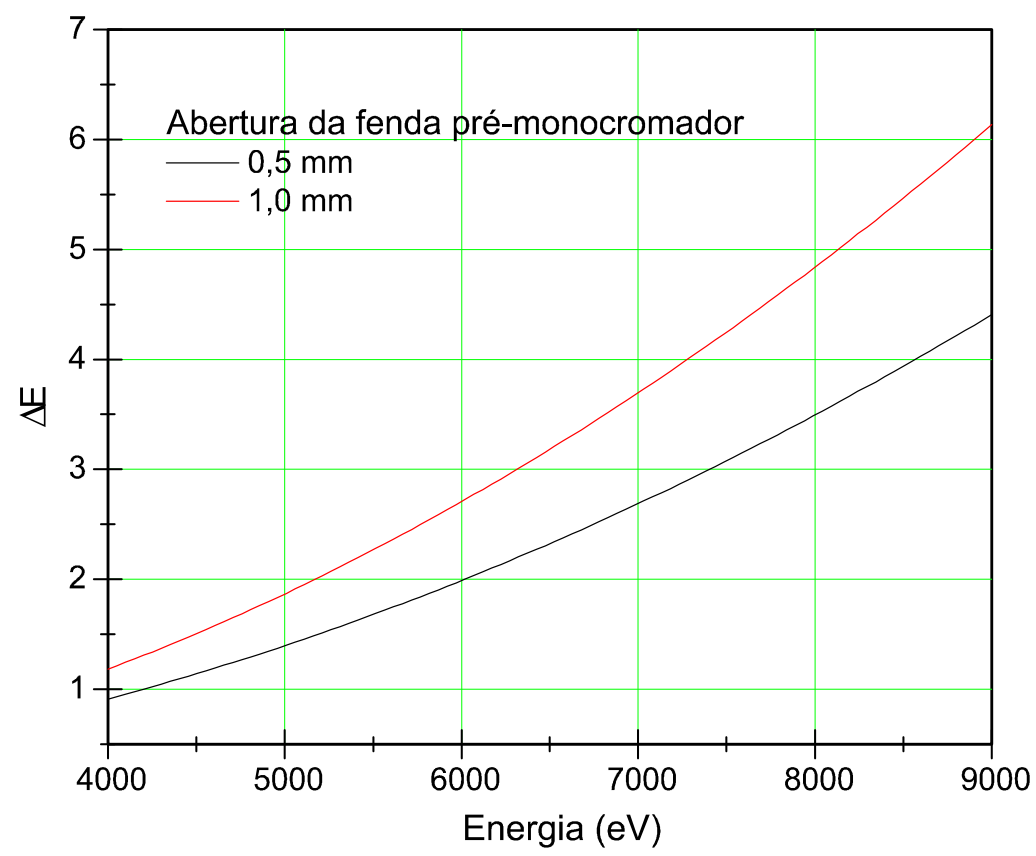

Figura 16.Resolução em energia do feixe. Tamanho da fonte $\left(0,5 x 0,7 \mathrm{~mm}^{2}\right)$. A distância da fonte (dipolo) ao monocromador foi de $11,28 \mathrm{~m}$. Nota-se que quanto maior a abertura da fenda a resolução em energia diminui.

do feixe foi fixada em $2 \mathrm{~mm}$ na posição da amostra e para as medidas de XANES foi em $1 \mathrm{~mm}$. A dimensão horizontal do feixe foi mantida fixa em torno de $10 \mathrm{~mm}$. A técnica de preparação possibilitou uma boa homogeneidade na espessura das amostras. Desta forma eventuais efeitos de alargamento nos espectros de EXAFS devido a heterogeneidades de espessura foram considerados desprezíveis. Dois espectros obtidos em regiões distintas com certa heterogeneidade aparente não apresentaram nenhuma diferença visível entre si. Com efeito, fazendo um ajuste com o programa WinX $A S$ utilizando fase e amplitude téorica calculada por $F E F F$ não se observaram diferenças apreciáveis em nenhum parâmetro estrutural (número de coordenação, fator Debye Waller, distância entre primeiros vizinhos, etc.). Utilizou-se uma câmara $C C D$ sensível a raios $X$ para determinar a região iluminada da amostra, procurando sempre a região com transmitância o mais homogênea possível.

Outro fator importante de erros sistemáticos é a presença de harmônicos de mais alta energia no feixe "monocromático". Para um espaçamento interplanar $d_{h k l}$, a condição de Bragg é satisfeita em $\theta_{1}$ para $\lambda_{1}$, assim ordens de maior reflexão da mesma família de planos $\left(222,333\right.$, etc.) são possíveis para energias $\lambda_{1} / 2, \lambda_{1} / 3$, etc, no mesmo ângulo (desde que o fator de estrutura não se anule). Esses harmônicos devem 
ser eliminados do feixe "monocromático" pois a sua existência produz distorções na determinação do coeficiente de absorção $\mu(E)$.

$\mathrm{O}$ fator de estrutura do segundo harmônico do $S i(111), h k l=(222)$ se anula visto que somente reflexões do tipo $h+k+l=2 n$ (com $n$ par) e $h+k+l=n$ (com $n$ ímpar) são permitidas. Este é um bom motivo para utilizar este tipo de cristal. Porém, os terceiros, quartos, quintos, etc. harmônicos são permitidos. Assim um certo cuidado precisa ser tomado para remover os harmônicos maiores do feixe. E já que a largura angular intrínsica dos harmônicos de energia maior é menor que o fundamental, fazendo-se um pequeno desvio de paralelismo entre os planos das duas partes refletoras do cristal monocromador. Dessa forma a maior parte da contribuição dos harmônicos de maior energia são rejeitados, permanecendo somente a radiação fundamental. Geralmente há uma perda de $10-20 \%$ no fluxo, quando se faz isto. O terceiro harmônico correspondente a fótons de $24 k \mathrm{eV}$ é no caso da fonte do $L N L S$ de intensidade muito menor que $5 \%$ da intensidade dos fótons de $8 k \mathrm{eV}$. Em particular foi verificado que a contaminação por harmônicos é desprezível acima de $4 k \mathrm{eV}$. Por isso, em nosso caso, não foi necessário o procedimento de desvio de paralelismo dos planos refletores do cristal.

\subsubsection{Câmaras de ionização}

Os detetores utilizados (figura 14) são câmaras de gás preenchidas com ar. Podem ser preenchidas também com outros gases dependendo da energia dos fótons com os quais se lida. Quanto maior a energia dos fótons, maior o número atômico dos átomos do gás que deve ser utilizado, pois quanto maior a energia dos fótons mais penetrante e conseqüentemente menos absorvidos eles são. Portanto, aumentando-se o número atômico, a secção de choque é maior e se tem maior absorção do feixe. Nossa experiência foi realizada em modo de transmissão. Para isto foram necessárias duas câmaras de ionização como mostra a figura 14, uma para medir o fluxo incidente de fótons e a outra para medir o fluxo transmitido. Tipicamente, $10-15 \%$ do fluxo de fótons incidente é absorvido pela câmara que mede $I_{0}\left(\mu_{I_{0}} x_{0} \sim 0,1-0,15\right)$ enquanto que $90 \%$ do feixe transmitido pela amostra é absorvido na câmara que mede $I_{t}\left(\mu_{I_{t}} x_{t} \sim 0,25\right)$. Onde $x_{0}$ e $x_{t}$ são os comprimentos das câmaras.

Desta forma, tem-se que

$$
I_{0}=\Omega\left(I_{0}\right) I_{i}\left(1-e^{-\mu_{I_{0}} x_{0}}\right),
$$

onde $\Omega\left(I_{0}\right)$ é o ganho do amplificador de corrente da câmara $I_{0}$ e $I_{i}$ é a intensidade do feixe incidente. Após passar pela amostra a intensidade se reduz a $I_{i} e^{-\mu_{I_{0}} x_{0}} e^{-\mu_{a} x_{a}}$, onde 
$\mu_{a}=\mu(E)$. Justamente a quantidade que interessa. Por fim, a intensidade detectada na câmara $I_{t}$ é:

$$
I_{t}=\Omega\left(I_{t}\right) I_{i} e^{-\mu_{I_{0}} x_{0}} e^{-\mu_{a} x_{a}}\left(1-e^{-\mu_{I_{t}} x_{t}}\right),
$$

multiplicando e dividindo a eq. 3.43 pela equação $3.42, I_{t}$ pode ser reescrito como:

$$
I_{t}=I_{0} e^{-\mu_{a} x_{a}} \frac{\Omega\left(I_{t}\right)}{\Omega\left(I_{0}\right)} \frac{\left(1-e^{-\mu_{I_{t}} x_{t}}\right)}{\left(e^{\mu_{I_{0}} x_{0}}-1\right)} .
$$

Invertendo e tomando o logaritmo natural, obtem se finalmente:

$$
\ln \frac{I_{0}}{I_{t}}=\mu_{a} x_{a}+\ln \frac{\Omega\left(I_{t}\right)}{\Omega\left(I_{0}\right)}+\ln \frac{\left(e^{\mu_{I_{0}} x_{0}}-1\right)}{\left(1-e^{-\mu_{I_{t}} x_{t}}\right)} .
$$

Pode se notar que na eq. ??, tem se dois termos adicionais à quantidade de interesse $\left(\mu_{a} x_{a}\right)$. O primeiro é uma constante que contém a razão dos ganhos de $I_{0}$ e $I_{t}$ e simplesmente desloca o espectro $\ln I_{0} / I_{t}$. O segundo termo é função da energia já que $\mu_{I_{0}}$ e $\mu_{I_{t}}$ dependem da energia do fóton incidente. Esse termo varia suavemente em torno da borda de absorção de interesse (para isto gases ou misturas de gases apropriadas precisam ser escolhidas). Assim esse termo contribui como um fundo dependente de energia e pode ser subtraído juntamente com as outras contribuições de fundo, ajustando a região de absorção da pré-borda e extrapolando esta região após a borda, subraindo a dos dados. Este procedimento supõe que a dependência em energia deste segundo termo é o mesmo antes e após a borda e sobre todo o espectro medido, o que não é necessariamente verdade. Como a subtração da parte extrapolada da préborda pode afetar o valor de absorção do átomo "isolado", normalizamos o espectro de $X A F S$ pela diferença de absorção antes e depois da borda, i.é, por $\Delta \mu x$ (ver figura 13), isto é:

$$
\chi(k)=\frac{\mu(k)-\mu_{0}(k)}{\Delta \mu x(k=0)} .
$$

A razão por não usar o fundo dependente da energia é que ele pode ser distorcido pelos motivos acima descritos. Outro possível erro é a variação na resposta do ganho em energia das câmaras $I_{0}$ e $I_{t}$, à medida que o experimento avança, produzindo mudanças dependentes da energia na medida de $\mu(k)$ e por conseguinte uma distorção na dependência da energia de $\mu_{0}(k)$. O valor relativo de $\mu_{0}(k)$ e $\chi(k)$ não é afetado preservando assim o numerador da eq. 3.46. 


\section{Resultados experimentais}

Neste capítulo, apresenta-se os estudos experimentais da estrutura de xerogéis obtidos a partir da secagem de organosóis a base de $\mathrm{NiO}$. As características estruturais dos diversos materiais resultantes foram estudados para diferentes concentrações iniciais de $i$ ) ácido acético (0,001, 0,003 e 0,1 $\mathrm{mol}$ de ácido acético/mol de $\mathrm{NiCl}_{2}$ ), ii) água (contendo $1,2,3,6$ e $9 \mathrm{~mol}$ de água/mol de $\mathrm{NiCl}_{2}$ ) e $\mathrm{iii}$ ) temperaturas de tratamento térmico $\left(150,300,500,700\right.$ e $\left.900^{\circ} \mathrm{C}\right)$.

\subsection{Preparação das amostras}

Métodos de baixa temperatura, como por exemplo os processos hidrotermais, emulsivos, eletroquímicos e de coprecipitação têm sido usados para a síntese de materiais cerâmicos. O processo sol - gel é um processo alternativo para fabricar vidros e materiais cerâmicos que não envolve processo de fusão a alta temperatura.

Compostos orgânicos, como alcóxidos de silício, titânio, zircônio e outros

$$
M-\left(O-C_{2} H_{5}\right)_{x}
$$

são usados para a preparação de diversos tipos de materiais pelo método sol - gel. Adicionando água, estes componentes se decompõem na fase líquida em uma forma complexada (1) e álcool (2) num processo de hidrólise:

$$
M-\left(\mathrm{O}-\mathrm{C}_{2} \mathrm{H}_{5}\right)_{x}+\mathrm{H}_{2} \mathrm{O} \longrightarrow \underbrace{M-\left(\mathrm{O}-\mathrm{C}_{2} H_{5}\right)_{x-1} \mathrm{OH}}_{1}+\underbrace{\mathrm{C}_{2} \mathrm{H}_{5}-\mathrm{OH}}_{2} .
$$

Posteriormente, condensam segundo a reação

$$
M-\left(\mathrm{O}-\mathrm{C}_{2} \mathrm{H}_{5}\right)_{x}+\mathrm{M}-(\mathrm{OH})_{x} \longrightarrow \underbrace{-[M-O]_{x}-M}_{3}+x\left(\mathrm{OH}-\mathrm{C}_{2} \mathrm{H}_{5}\right),
$$

que conduz a uma estrutura na qual os átomos metálicos estão ligados aos átomos de oxigênio numa rede irregular não cristalina (3).

Após a agregação dos monômeros no sol, forma-se um gel úmido (contendo solvente entre os agregados). Mediante secagem, obtem-se um material poroso chamado xerogel que é posteriormente tratado a médias ou altas temperaturas (em nosso caso $150<T<900^{\circ} \mathrm{C}$ ) para produzir um material final consistente de um pó fino e poroso. Em condições particulares e controladas, podem ser obtidos materiais monolíticos e livres de porosidade. Variando as condições acima descritas, pode-se obter materiais com uma larga faixa de propriedades físicas. 
No total, preparou-se e estudou-se três series de sistemas. Na primeira série, utilizou-se na preparação do sol inicial cloreto de níquel puro $\left(\mathrm{NiCl}_{2} \cdot 6 \mathrm{H}_{2} \mathrm{O}\right)$ e variouse a concentração de ácido acético, mantendo o conteúdo de água constante. Na segunda série, também partiu-se de cloreto de níquel puro e variou-se o conteúdo de água, mantendo-se a concentração de ácido acético constante. Na terceira série utilizou-se $80 \%$ de cloreto de níquel $+20 \%$ butóxido de titânio $(\mathrm{IV})\left(\mathrm{Ti}\left[\mathrm{O}\left(\mathrm{CH}_{2}\right) \mathrm{CH}_{3}\right]_{4}\right)$, variando a concentração de água e mantendo a concentração de ácido acético fixa.

A concentração de ácido acético na primeira série de experiências variou de 0,001 a $0,1 \mathrm{~mol} / \mathrm{mol} \mathrm{NiCl}_{2} \cdot 6 \mathrm{H}_{2} \mathrm{O}$. Na segunda e terceira séries, a concentração de ácido acético se manteve fixa em $0,1 \mathrm{~mol}$.

A solução precursora foi preparada dissolvendo quantidades conhecidas de sal de cloreto de níquel (primeira e segunda série) em butanol. Na terceira série, dissolveuse $80 \%$ de cloreto de níquel $+20 \%$ butóxido de titânio $(I V)$ também em butanol. As soluções foram agitadas durante 30 minutos e logo depois o ácido acético foi adicionado. Em seguida foi feito refluxo à $70^{\circ} \mathrm{C}$ durante 30 minutos sempre sob constante agitação para assegurar uma perfeita homogeinização. Terminada esta etapa, foi adicionada a água. Na primeira experiência, adicionou-se 2 moles de água a todas as amostras. Na segunda, variou-se a concentração entre 1 e 9 moles (a solução total de cada amostra era de $20 \mathrm{~mL}$ ). Em seguida, fez-se o refluxo da solução final por três horas.

Secou-se a primeira série de amostras a temperatura ambiente, e manteve-se a temperatura constante $\left(60,250,450\right.$ e $\left.800^{\circ} \mathrm{C}\right)$ durante 1 hora.

A segunda e terceira série de amostras secas inicialmente em estufa à $70^{\circ} \mathrm{C}$ por uma semana e mantidas a $150^{\circ} \mathrm{C}$ por 60 dias, após este tempo as amostras foram tratadas térmicamente, mantendo se-as por uma hora a diferentes temperaturas finais $\left(150,300,500,700\right.$ e $\left.900^{\circ} \mathrm{C}\right)$.

As amostras da primeira série foram colocadas no forno em temperatura ambiente. Depois aquecidas dentro dele até a temperatura final. A segunda e terceira séries de amostras foram introduzidas no forno, quando este já tinha atingido a temperatura final.

$\mathrm{Na}$ figura 17, apresentou-se uma descrição esquemática do processo de preparação dos xerogéis estudados nesta dissertação.

\subsection{Primeira série de experiências}


Sal metálico

a) cloreto de níquel

b) cloreto de níquel + butóxido de titânio (IV)
Solvente

Butanol

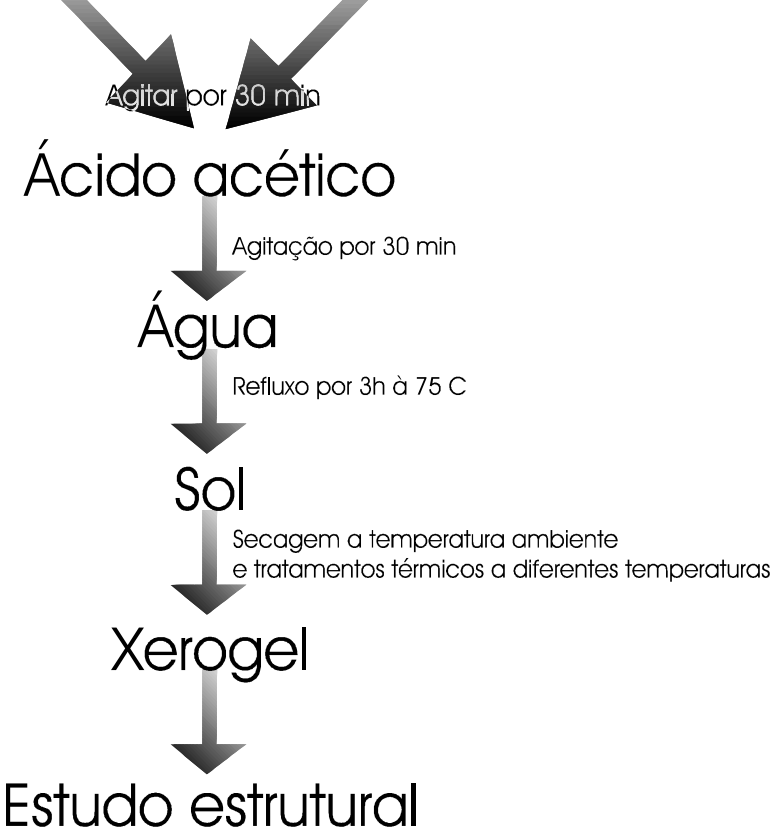

Figura 17.Descrição esquemática do processo de preparação das amostras. 


\subsubsection{Resultados experimentais de espalhamento de raios $X$ a baixos ângulos $(S A X S)$}

Os xerogéis finais com diversos conteúdos de ácido acético, tratados a temperaturas entre 60 e $800^{\circ} \mathrm{C}$ por uma hora, foram estudados por $S A X S$. Os espectros são apresentados em escala $\log I$ vs $\log q$ na figura 18.

Sabendo que os xerogéis são materiais porosos, que incluem em geral cavidades nanométricas, assumiu-se que o espalhamento é produzido pelo conjunto de poros e se supõe ainda que não estão espacialmente correlacionados. Esta última aproximação é em geral válida para sistemas nos quais os objetos espalhadores têm uma larga distribuição de tamanho ${ }^{20}$.

O comportamento linear em gráficos $\log$ - log das intensidades de espalhamento de todas as amostras no domínio de $q$ analizado, indica que o sistema não é composto por nanoporos de tamanho igual já que a lei de Guinier não é verificada. Isso nos conduziu a propor uma modelo pelo qual a intensidade de espalhamento é produzida por um conjunto de poros com uma certa distribuição de tamanhos. Assumiu-se ainda que são aproximadamente isodiamétricos e que a contribuição é descrita com precisão razoável pela intensidade produzida por esferas isoladas.

Nessas condições, pode-se aplicar o primeiro procedimento de tratamento de dados descrito na secção II.1.3.1. Lembre-se que um valor alto do módulo da inclinação das retas dos gráficos em escala $\log -\log ,(\alpha)$ é maior quanto mais estendida é a distribuição de tamanhos, como indicado na figura 5.

O efeito da temperatura no parâmetro $\alpha$ nas amostras com $[a . a]^{21}=0.001,0.003$ e 0.1 mol é mostrado na Figura $18 a, b$ e $c$ respectivamente. A figura $18 a$ mostra que os valores dos módulos da inclinação das retas nos gráficos $\log I(q)-\log q, \alpha$, são 2, 09 e 2, 43 para temperaturas de tratamento térmico de 60 e $450^{\circ} \mathrm{C}$ respectivamente. Já para temperatura superior $\left(800^{\circ} C\right)$, o valor é de 2,23 . Um comportamento similar foi observado para todas as concentrações de ácido acético como ilustra a figura 19.

Os resultados de $S A X S$ mostrados na figura 20 indicam que o parâmetro $\alpha$ diminui com o aumento da concentração de ácido acético. Portanto, aplicando a equação 2.26, conclui-se que amostras com maior concentração de ácido acético contêm poros menores ou seja que a estrutura resultante é mais compacta.

\footnotetext{
20 Neste caso, mesmo em sistemas relativamente concentrados, não existe uma correlação significativa entre os "centros de massa" da função $\Delta \rho$ das partículas/poros espalhadores.

21 [a.a.] é a razão molar do ácido acético em relação ao sal precursor.
} 

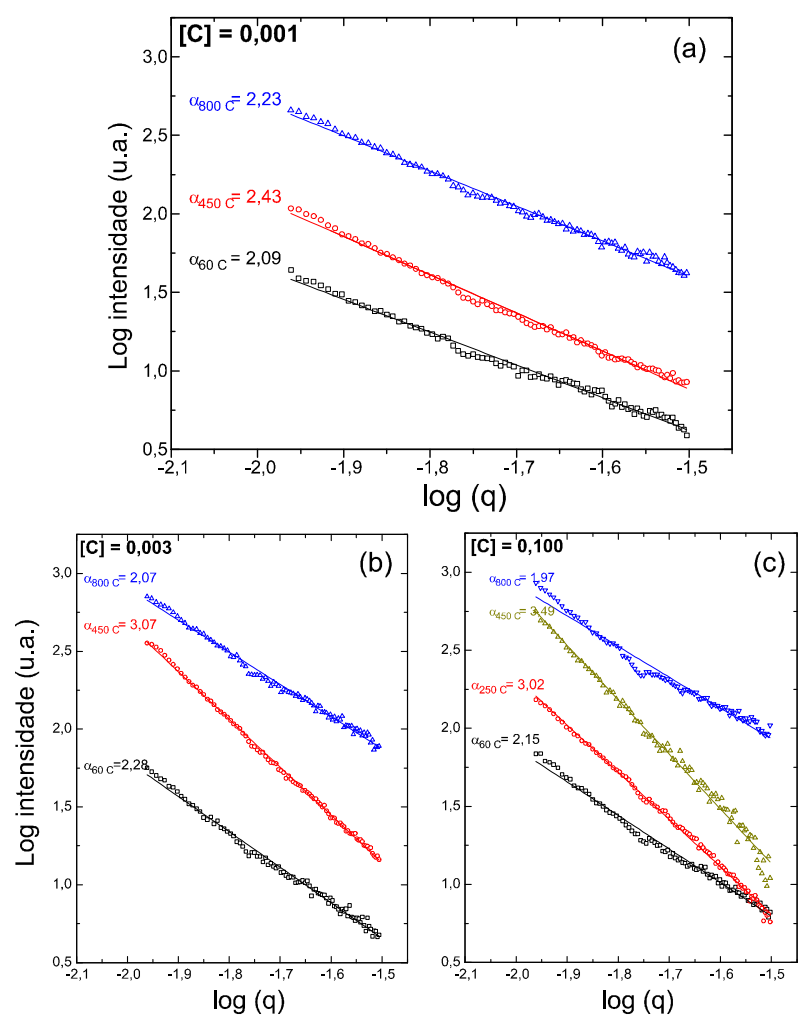

Figura 18.Gráfico $\log I(q)$ - $\log q$ para amostras tratadas a diferentes temperaturas com concentrações de ácido acético $(a) 0,001,(b) 0,003$ e (c) 0,1. Os erros estatísticos variam de $1 \%$ a baixo $q$ até $3 \%$ a alto $q$. (u.a. indica unidades arbitrárias).

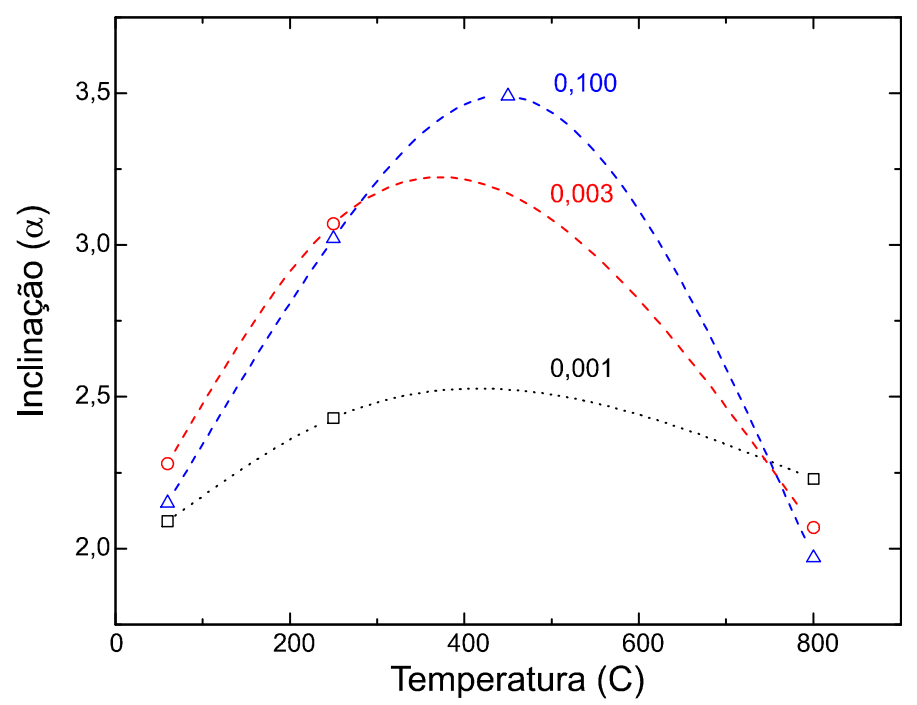

Figura 19.Parâmetro $\alpha$ (inclinação das retas em gráficos $\log$ - log) versus temperatura para as concentrações de ácido acético indicadas. As barras de erro são menores que os símbolos. 


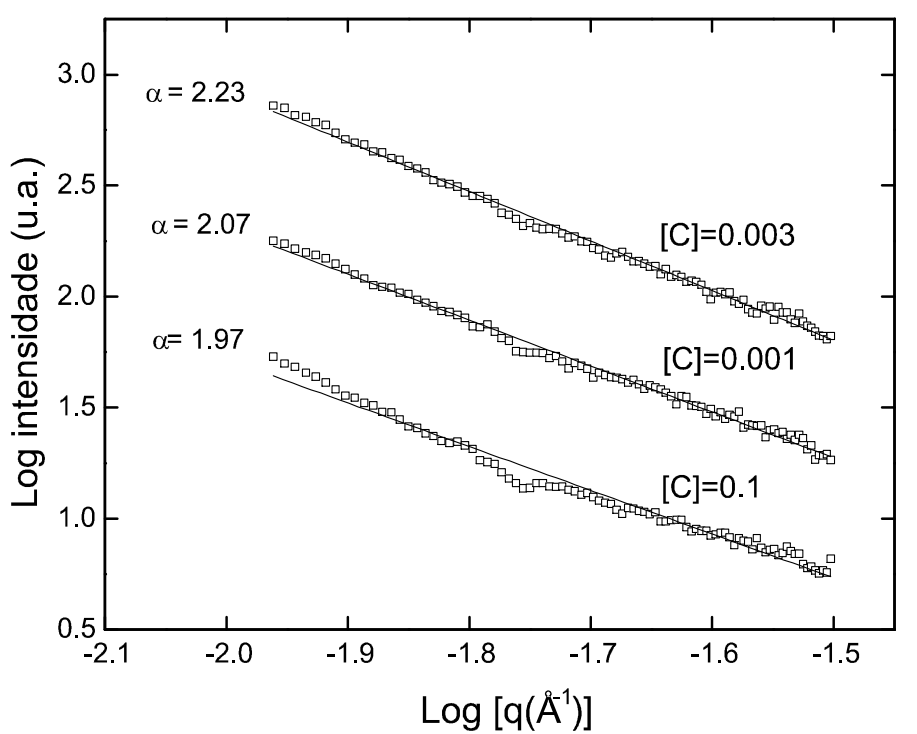

Figura 20.Gráfico $\log I(q)-\log q$ para amostras tratadas à $800^{\circ} \mathrm{C}$ com diferentes concentrações de ácido acético. Os erros estatísticos variam de $1 \%$ a baixo $q$ até $3 \%$ a alto q. (u.a. indica unidades arbitrárias). 
O efeito das diferentes concentrações de ácido acético na densidade dos xerogéis tratados até $800^{\circ} \mathrm{C}$ durante 1 hora é indicado na tabela 1 (figura 21a). A densidade dos pós aumenta com o aumento da concentração do ácido acético.

Em função da temperatura, tem-se um mínimo de densidade em torno de $450^{\circ} \mathrm{C}$, e um máximo aos $800^{\circ} \mathrm{C}$, como mostrado na tabela 2 (figura 21b). Para o conjunto de temperaturas utilizadas, o valor máximo de $\alpha$ ocorre a $450^{\circ} \mathrm{C}$, independentemente da concentração de ácido acético. Isto indica que materiais tratados em torno desta temperatura contêm poros maiores ( $<R>$ maior) do que a temperaturas menores.

$\mathrm{O}$ alto valor de $<R>$ para amostras tratadas a $250^{\circ} \mathrm{C}$ é devido ao crescimento dos poros produzido pela evaporação de água física e químicamente adsorvida. $\mathrm{O}$ valor ainda maior do tamanho médio dos poros em xerogéis tratadas a $450^{\circ} \mathrm{C}$ é consequiência da evaporação do restante de compostos orgânicos que permanecem na amostra (como ácido acético não reagido e butanol). Esta observação também foi experimentalmente verificada por espectroscopia de infravermelho $(F T I R)$ em amostras com $[a . a]=$. $0,001 \mathrm{~mol}$, como se vê mais adiante. O menor valor de $<R>$ para $800^{\circ} \mathrm{C}$ sugere que a esta temperatura se produz um rearranjo estrutural, que leva a uma densificação da matriz inorgânica. Estes seriam os primeiros estágios do processo de sinterização.

\begin{tabular}{|c|c|c|}
\hline Concentração de ácido acético $(\mathrm{mol})$ & Densidade $\left(\mathrm{g} / \mathrm{cm}^{3}\right)$ & $\langle R\rangle / R_{\min }(a . u)$. \\
\hline 0.001 & 6.35 & 1.36 \\
\hline 0.005 & 6.42 & 1.34 \\
\hline 0.1 & 6.55 & 1.33 \\
\hline
\end{tabular}

Tabela 1 : Efeito da concentração do ácido acético na densidade e tamanho médio dos poros dos xerogéis tratados a $800^{\circ} \mathrm{C}$.

\begin{tabular}{|c|c|c|}
\hline Temperatura $\left({ }^{\circ} \mathrm{C}\right)$ & Densidade $\left(\mathrm{g} / \mathrm{cm}^{3}\right)$ & $\langle R\rangle / R_{\min }$ (a.u.) \\
\hline 60 & 5.85 & 1.34 \\
\hline 450 & 5.36 & 1.39 \\
\hline 800 & 6.36 & 1.36 \\
\hline
\end{tabular}

Tabela 2 : Efeito da temperatura na densidade e tamanho médio dos poros de xerogéis com concentração de ácido acético de $0,001 \mathrm{~mol} / \mathrm{mol}$ de $\mathrm{NiCl}_{2}$.

Os resultados apresentados na tabela 1 indicam que os xerogéis com [a.a.] = $0,1 \mathrm{~mol}$ têm uma densidade maior que a dos xerogéis com $[a . a]=0,$.001 mol. Pode se entender isto como consequiência da formação de uma estrutura mais compacta, composta por poros menores, para maiores concentrações de ácido acético. Este resultado concorda com os resultados de $S A X S$ e, como se verá, também com os de 

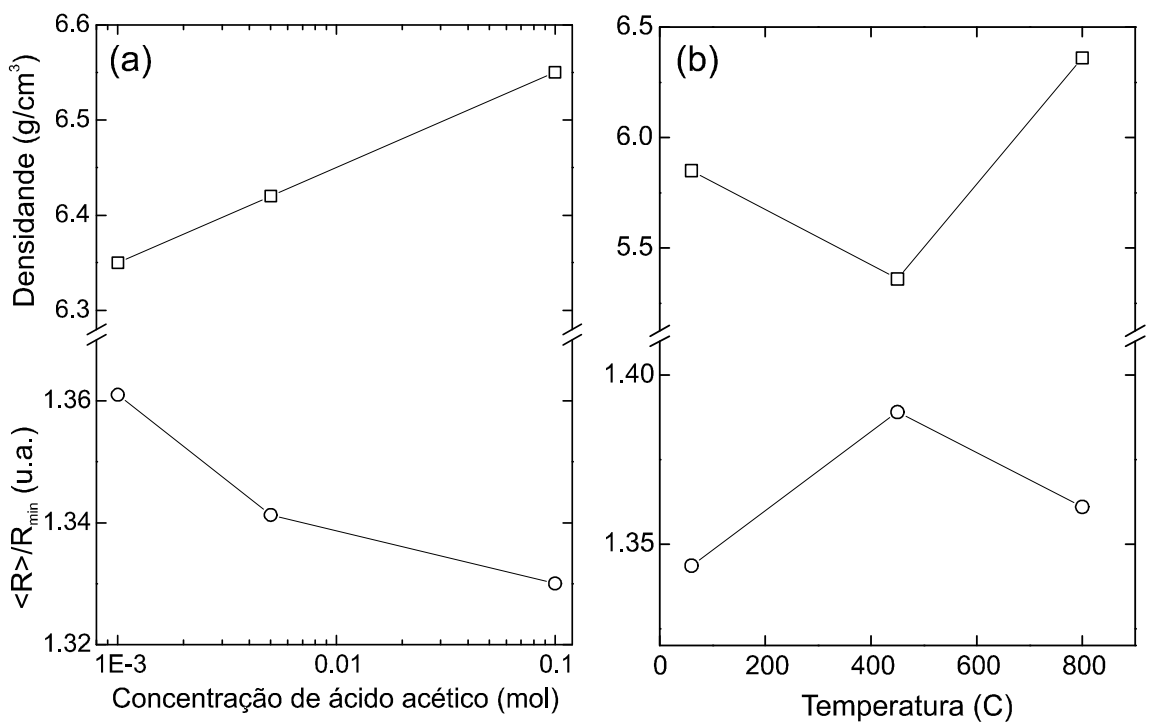

Figura 21.(a) Efeito da concentração do ácido acético e (b) Efeito da temperatura. 
FTIR e DSC. O aumento da densidade deve ser uma conseqüência do aumento do número de ligações do $N i$ com o ácido acético.

A tabela 2 mostra um valor relativamente alto da densidade dos xerogéis tratados a $800^{\circ} \mathrm{C}$ se comparado com a densidade das amostras tratadas a $450^{\circ} \mathrm{C}$. Esta observação pode ser atribuída ao mesmo efeito de início de sinterização já mencionado na discussão dos resultados de $S A X S$.

\subsubsection{Resultados de difração de $\operatorname{raios} X(X R D)$}

Para caracterizar a ordem a longo alcance e o grau de cristalinidade dos xerogéis, as mesmas amostras estudadas por $S A X S$ foram analizadas por $X R D$ (Sharma et al., 1999). Com esta técnica, pretendeu-se estabelecer se a estrutura atômica do xerogel é amorfa ou cristalina e, em caso de ter parte cristalina, determinar o tipo de estrutura cristalográfica e eventualmente o tamanho médio dos cristalitos. Para isso foram comparados os espectros de difração obtidos com os espectros de referência correspondente a padrões de cloreto de níquel $\left(\mathrm{NiCl}_{2}\right)$, hidróxido de níquel $\left(\mathrm{Ni}(\mathrm{OH})_{2}\right)$ e óxido de níquel cristalinos $\left(\mathrm{Ni}_{2} \mathrm{O}_{3}\right.$ ou $\left.\mathrm{NiO}\right)$.

Em estudos prévios (Sharma et al., 1999), foi detectada a fase cristalina de $\mathrm{Ni}(\mathrm{OH})_{2}$ em xerogéis tratados a $300^{\circ} \mathrm{C}$. Para tratamentos acima desta temperatura se observa a formação de uma fase de $\mathrm{Ni}_{2} \mathrm{O}_{3}$. Para temperaturas maiores de $450^{\circ} \mathrm{C}$, foi observado somente uma fase de $\mathrm{NiO}$ puro.

A morfologia das partículas de $\mathrm{Ni}(\mathrm{OH})_{2}$ foi estudada mediante microscopia eletrônica de varredura $(S E M)$. Uma micrografia de um xerogel tratado a $250^{\circ} \mathrm{C}$ revelou a presença de partículas aproximadamente esféricas.

\subsubsection{Resultados de espectroscopia de infravermelho por transformada de Fourier $(F T I R)$}

Realizou-se também análises dos xerogéis mediante técnica de FTIR. Os espectros obtidos apresentam em geral picos associados a transições vibracionais e rotacionais dos sistemas estudados. Pela presença de picos em números de onda dos fótons incidentes correspondentes a ligações conhecidas, pode-se determinar a eventual existência e quantidade destas nos materiais estudados.

Os espectros de FTIR das amostras tratados a $200^{\circ} \mathrm{C}$ estão ilustrados na figura 22 para diferentes concentrações de ácido acético $[a . a$.$] . O espectro que corresponde$ ao pó com $[$ a.a. $]=0,1 \mathrm{~mol}$ exibe uma larga banda de absorção em torno de $3555 \mathrm{~cm}^{-1}$ e picos mais estreitos entre $1000-1600 \mathrm{~cm}^{-1}$. O pico de absorção em $1570 \mathrm{~cm}^{-1}$ se 


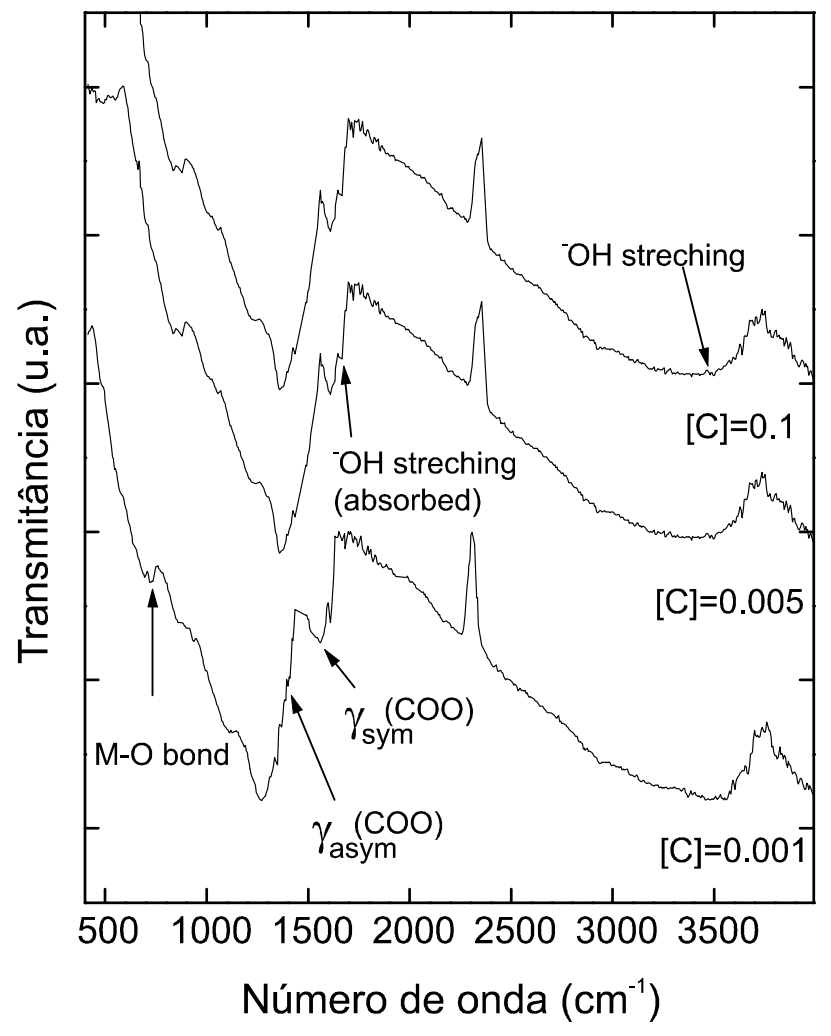

Figura 22.Espectros de FTIR de xerogéis sintetizados na presença de ácido acético com a concentração indicada e tratados a $200 C$. 


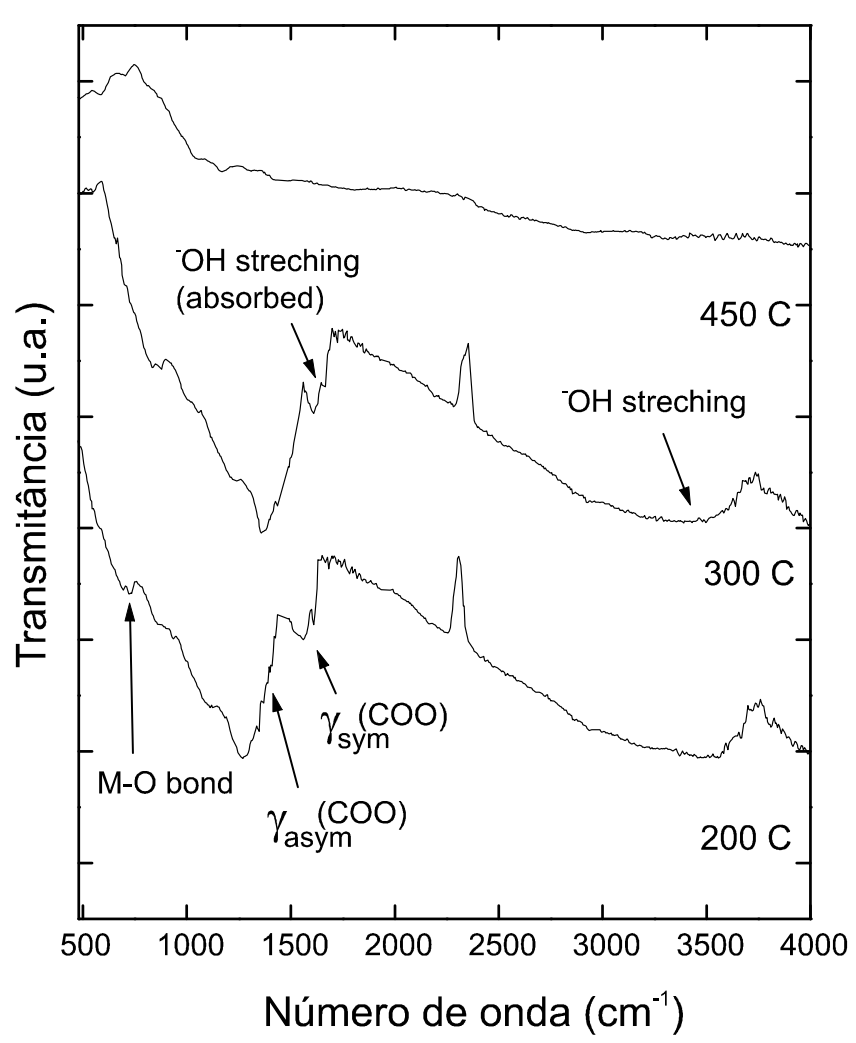

Figura 23.Espectros de FTIR dos xerogéis correspondentes a $[C]=0,001 \mathrm{~mol}$ e tratados nas temperaturas acima indicadas.

desloca para maiores números de onda (em torno de $1600 \mathrm{~cm}^{-1}$ ), à medida que [a.a.] aumenta de 0,001 para $0,1 \mathrm{~mol}$. Similarmente, o pico à $1440 \mathrm{~cm}^{-1}$ se desloca para $1450 \mathrm{~cm}^{-1}$.

Os picos de absorção na região de $1000-1600 \mathrm{~cm}^{-1}$ estão presentes em xerogéis tratados a 200 e $300^{\circ} \mathrm{C}$, porém não aparecem em amostras tratadas à $450^{\circ} \mathrm{C}$, como ilustra a figura 23. O alargamento do pico a $3555 \mathrm{~cm}^{-1}$ é menor para temperaturas maiores.

A larga banda de absorção em $3555 \mathrm{~cm}^{-1}$ no espectro da figura 22 para diferentes concentrações de ácido acético foi atribuído ao modo de vibração do $O H^{-}$("stretching mode") (Livage et al., 1988).

Os picos no intervalo de $1000-1600 \mathrm{~cm}^{-1}$ foram atribuidos a ligações de matéria orgânica e a ligações de $O H^{-}$da água adsorvida (Sanchez et al., 1988).

Os picos na região de $1450 \mathrm{e} 1530 \mathrm{~cm}^{-1}$ foram atribuídos às ligações de $C-C \mathrm{e}$ $C-O$ respectivamente correspondentes às espécies orgânicas do solvente e catalizador.

A separação entre os picos de absorção do $\gamma_{\text {sym }}(C O O)$ à $1570 \mathrm{~cm}^{-1}$ e o ombro do $\gamma_{\text {asym }}(C O O)$ à $1440 \mathrm{~cm}^{-1}$ e $140-170 \mathrm{~cm}^{-1}$ indica que o $\mathrm{CH}_{3} C O O$ age como um 


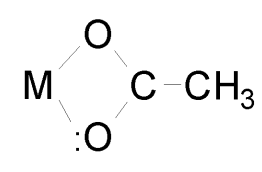

Figura 24.Ilustração da forma bidentada de ligação entre o ácido acético e o níquel.

ligante bidentado com o átomo de níquel da forma indicada na figura 24 (Sharma, et al., 1998; Doeuff et al., 1987; Deacon et al., 1980; Nakamoto, 1997).

O deslocamento do pico $\gamma_{s y m}(C O O)$ de $1570 \mathrm{~cm}^{-1}$ para maiores números de

onda (i.é, $1600 \mathrm{~cm}^{-1}$ ) bem como o deslocamento do ombro de $\gamma_{\text {asym }}(C O O)$ para $1450 \mathrm{~cm}^{-1}$ é esperado, porque o aumento no valor de $[$ a.a. $]=0,001$ para $0,1 \mathrm{~mol}$ aumenta o número de ligações metal-ligante (Chaibi et al., 1994). O espectro de FTIR representado na figura 22 mostra claramente que os ânions acetato atuam como ligantes que modificam o precursor em nível molecular mediante uma hidrólise e condensação controlada durante a evolução do processo de agregação. (Sharma et al., 1998).

O decréscimo na intensidade dos picos de absorção na região compreendida entre $1000-1550 \mathrm{~cm}^{-1}$ e o estreitamento do pico de vibração do $O H^{-}$à $1600 \mathrm{~cm}^{-1} \mathrm{com}$ aumento da temperatura de tratamento térmico (figura 23) são devidos à remoção de matéria orgânica durante o aquecimento.

\subsubsection{Resultados de calorimetria diferencial de varredura $(D S C)$}

Os xerogéis estudados foram analizados por $D S C$. Neste tipo de análise, a história térmica das amostras é diferente dos tratamentos isotérmicos correspondentes às técnicas experimentais precedentes. Em $D S C$ as amostras são aquecidas em velocidade de aquecimento constante $\left(\frac{d T}{d t}=10^{\circ} \mathrm{C} / \mathrm{min}\right)$.

Os picos endotérmicos (com absorção de calor) observados nos espectros de DSC podem ser atribuídos a efeitos de evaporação de constituintes voláteis $\left(\mathrm{H}_{2} \mathrm{O}\right.$, componentes orgânicos) e/ou a transformações estruturais em estado sólido produzidas no processo de aquecimento.

Os resultados de $D S C$ das amostras com 0,001 e $0,1 \mathrm{~mol}$ de ácido acético estão ilustradas na figura 25. A curva correspondente ao xerogel tratado com um valor inicial $[$ a.a. $]=0,001 \mathrm{~mol}$ indica três picos endotérmicos em 105,202 e $280^{\circ} \mathrm{C}$. Os picos à 202 e $280^{\circ} \mathrm{C}$ se deslocam para temperaturas maiores (i.e., 228 e $310^{\circ} \mathrm{C}$, respectivamente) para concentrações de ácido acético passando de 0,001 para 0,1 mol. $\mathrm{O}$ pico a $105^{\circ} \mathrm{C}$ permanece na mesma temperatura para todas as concentrações de ácido 


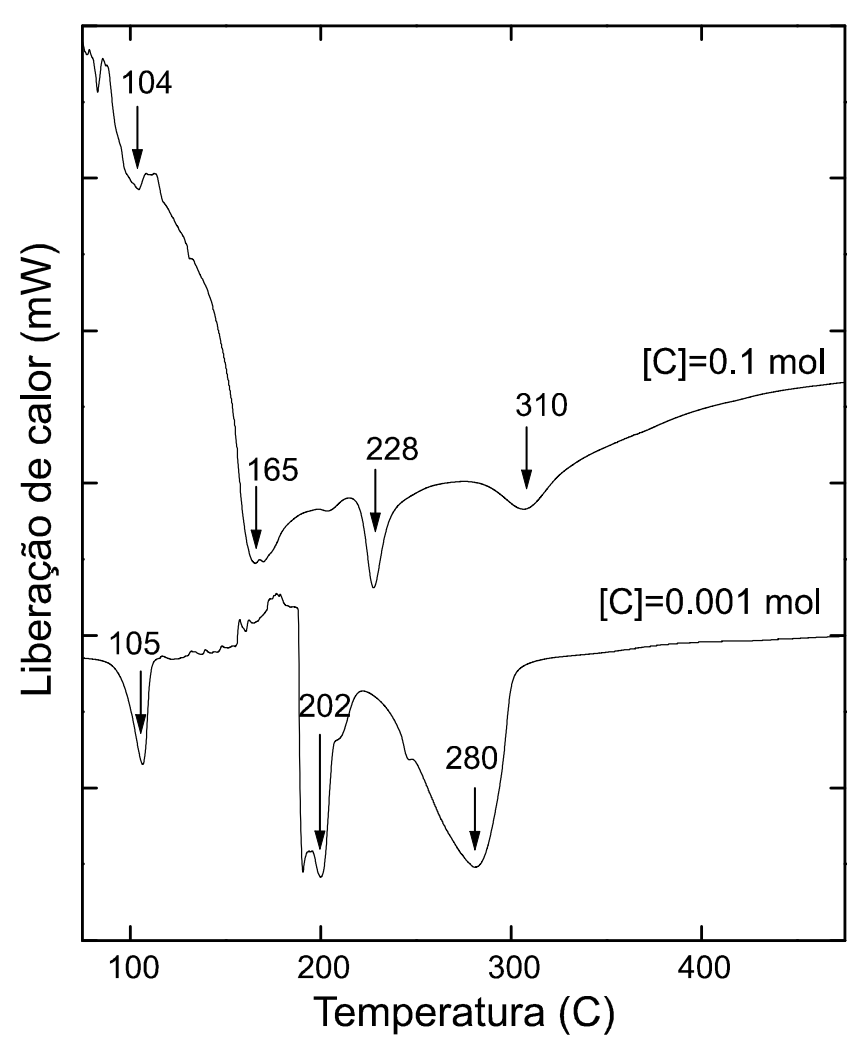

Figura 25.Curvas de $D S C$ do xerogel com concentrações indicadas na figura. As setas indicam a temperatura $(C)$ dos picos principais.

acético. Também se nota um pico a $165^{\circ} \mathrm{C}$ na curva de $D S C$ correspondente ao xerogel com a maior quantidade de ácido acético.

Os dois picos endotérmicos a 105 e $202^{\circ} \mathrm{C}$ da figura 25 foram atribuídos, respectivamente à água fisicamente adsorvida na superfície e quimicamente absorvida. Os picos endotérmicos a $280^{\circ} \mathrm{C}$ para baixos valores de ácido acético $(0,001 \mathrm{~mol})$ foram associados à transformação do hidróxido de níquel em óxido de níquel (ainda não estequiométrico). $\mathrm{O}$ deslocamento deste pico para uma temperatura maior $\left(310^{\circ} \mathrm{C}\right)$ no caso de xerogéis com $[$ a.a. $]=0,1 \mathrm{~mol}$ foi atribuído a um efeito de reforço da estrutura por terem sido produzidas mais ligações químicas entre o ligante e o níquel. Esta observação está em bom acordo com os resultados de nosso estudo de FTIR.

\subsection{Segunda série de experiências (precursor $100 \% \mathrm{NiCl}_{2} \cdot 6 \mathrm{H}_{2} \mathrm{O}$ )}




\subsubsection{Resultados de espalhamento de $\operatorname{raios} X$ a baixos ângulos $(S A X S)$}

Pelo fato das amostras serem higroscópicas, foram encapsuladas entre duas janelas de mica. Na primeira série de medidas, usou-se janelas de Mylar, porém, devido ao espalhamento parasita intenso deste polímero, preferiu-se usar na segunda e terceira série folhas de mica. A única desvantagem em usar janelas de mica é a imprecisão na medida da espessura, mas foi resolvida medindo uma por uma. Por fim, nem foi necessário fazer a correção devido ao espalhamento parasita por este ter sido desprezível diante do intenso espalhamento produzido pela amostra, assim subtrai-se somente uma constante para obter uma inclinação -4 no fim da curva (supõe-se válida a lei de Porod para altos $q$ ).

$\mathrm{Na}$ primeira série de experiências, estudou-se mediante $S A X S$ os efeitos da temperatura de tratamento térmico nos xerogéis preparados com diversas quantias de ácido acético na solução precursora. Lembre se de que o domínio de $q$ analisado nas primeiras experiências de $S A X S$ foi de $0,01 \AA^{-1}<q<0,03 \AA^{-1}$.

$\mathrm{Na}$ segunda série de experiências, estudou-se o efeito do conteúdo de água na solução precursora para uma quantidade fixa de ácido acético $(0,1 \mathrm{~mol})$. A intensidade de $S A X S$ foi determinada num domínio de $q$ bem maior, a fim de se obter informação sobre a porosidade em um domínio bem maior de tamanhos. A faixa de valores de $q$ na segunda série de experiências de $S A X S$ foi de $0,005 \AA^{-1}<q<0,14 \AA^{-1}$.

Os resultados de $S A X S$ foram representados em dois conjuntos de figuras em condições diferentes. Em cada figura do primeiro conjunto (figuras de 26 até 30) se apresentam os resultados para diversas temperaturas de tratamento térmico e concentrações de água fixa. Em cada figura do segundo conjunto (figuras de 31 até 35) se apresentam os resultados para diversas concentrações de água e temperatura fixa.

Nota-se na figura $26 a$ que as funções $I(q)$ para baixas temperaturas de tratamento térmico ( 150 e $300^{\circ} \mathrm{C}$, respectivamente) apresentam um comportamento não linear em escala $\log I(q)-\log q$. Já no caso de xerogéis tratados a altas temperaturas (500, 700 e $900^{\circ} \mathrm{C}$ ), os gráficos $\log$ - log apresentam comportamento linear. Estas mesmas características são observadas para as outras concentrações de água (figuras de 27 até 30). Estes resultados indicam que a função de distribuição de tamanhos dos poros depende da temperatura de tratamento térmico dos xerogéis.

Para analisar os resultados experimentais de $S A X S$, aplica-se o modelo estrutural simples de poros esféricos e não correlacionados embebidos em uma matriz homogênea descrito na introdução teórica de $S A X S$. Foi determinado o volume ocupado pelos 
poros como função do raio, $V(R)$, usando o programa $G N O M$ descrito na introdução teórica.

Aplicando o programa GNOM a todas as curvas de intensidade de $S A X S$ correspondentes à xerogéis com diferentes conteúdos de água e diferentes temperaturas de tratamento térmico obtivemos as funções $V(R)$ representadas na parte $b$ das figuras 26 até 35.

As funções $V(R)$ correspondentes às amostras tratadas a baixa temperatura (150 C) mostram uma distribuição de poros concentrada em torno de $10-150 \AA$ (figura 31), sendo $<R>$ em torno de $60 \AA$ A. Denominou-se os poros dentro deste limite de tamanho $(10-150 \AA$ ) de nanoporos. Os xerogéis com 1 mol de água apresentam um comportamento diferente, com uma distribuição mais larga que as demais.

Os xerogéis tratados à $300^{\circ} \mathrm{C}$ (figura 32) apresentam uma distribuição dos poros se estendem até $200 \AA$ com $<R>$ em torno de $90 \AA$ A. Nota-se também que a distribuição dos poros se desloca para a direita (poros maiores), à medida que a concentração de água aumenta, com excessão das amostras com $1 \mathrm{~mol}$ de água. Da mesma forma, a amostra com $1 \mathrm{~mol}$ de água apresenta uma distribuição bem larga, desviando-se mais da distribuição do tamanho de poros das amostras com maiores concentrações de água. Observa-se também um deslocamento na distribuição volumétrica para esquerda (poros menores) a medida que aumenta a concentração de água até $3 \mathrm{~mol}$. Para xerogéis com $\left[\mathrm{H}_{2} \mathrm{O}\right]=9 \mathrm{~mol}$ observamos dois picos um em torno de $80 \AA$ e outro ao redor de $170 \AA$.

Observa-se que em xerogéis tratados a $500^{\circ} \mathrm{C}$ os nanoporos são quase inexistentes, mas nota-se.a presença de poros maiores com raios na faixa de $100-400$ Å. Os poros com raios entre 150 - $400 \AA$ são denominados mesoporos (figura 33b).

Devido a inacessibilidade de valores experimentais de $q$ menores que $0,005 \AA^{-1}$, foi somente possível obter a função de distribuição de tamanho de poros até um valor máximo de $R=400 \AA$.

Para os xerogéis com $\left[\mathrm{H}_{2} \mathrm{O}\right]=6 \mathrm{~mol}$ não se obteve resultados da intensidade de espalhamento com uma estatística razoável o que prejudicou a determinação da função $V(R)$. Os picos das funções $V(R)$ na região de $10-50 \AA$ A correspondentes a xerogéis tratados a temperaturas iguais ou maiores que $500^{\circ} \mathrm{C}$ também não são precisos pois a estatística na região de altos valores de $q$ das funções $I(q)$ de quase todas amostras foi insuficiente. Observa-se também um deslocamento das funções de distribuição volumétrica $(V(R))$ para a esquerda a medida que a concentração de água aumenta (33b). Isto indica que a distribuição de poros é mais larga para maiores concentrações de água. 

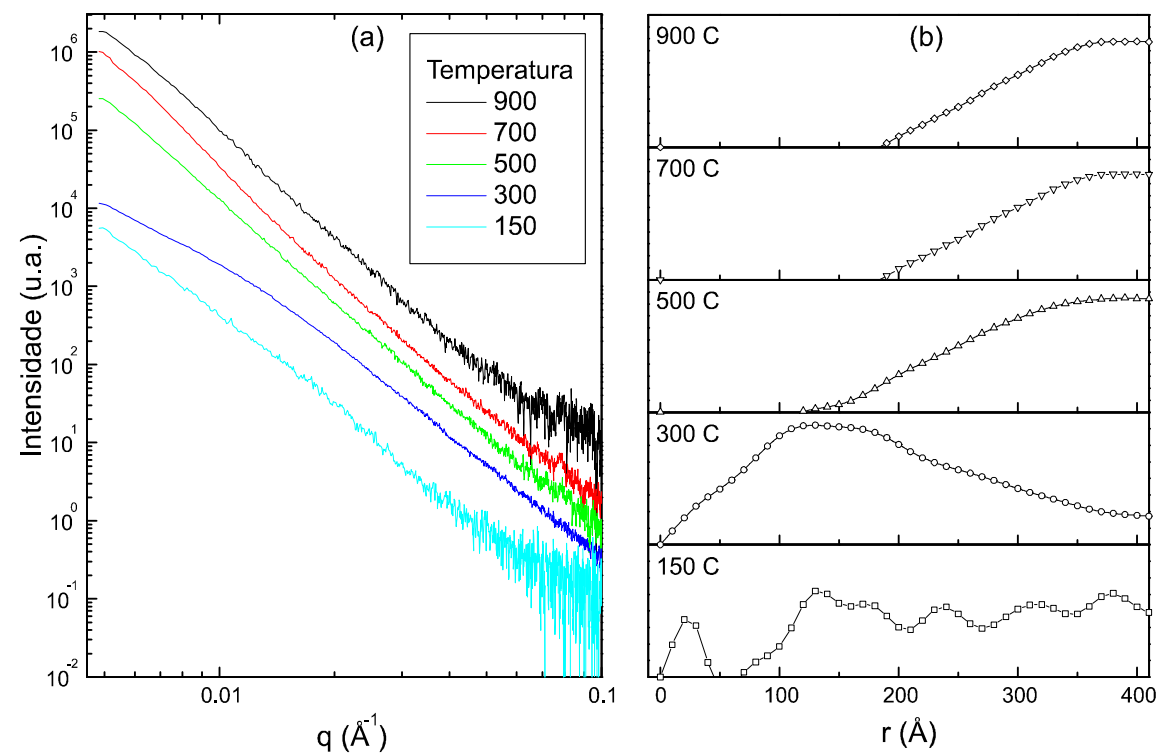

Figura 26.(a) Curvas de $S A X S$ correspondentes a xerogéis com $\left[\mathrm{H}_{2} \mathrm{O}\right]=1 \mathrm{~mol}$ tratados nas temperaturas indicadas. As curvas estão deslocadas verticalmente por motivos de clareza. (b) Funções de distribuição de volume de poros $V(R)$ associadas às diferentes curvas de espalhamento.

As funções de intensidade de espalhamento correspondentes aos xerogéis tratados a $500^{\circ} \mathrm{C}$ apresentam um comportamento quase linear nos gráficos $\log -\log$ (figura 33a). Este mesmo comportamento se observa para xerogéis tratados a 700 e $900^{\circ} \mathrm{C}$ como pode ser visto nas figuras $34 a$ e $35 a$ respectivamente. Isto significa, como pode ser observado nas figuras $34 b$ e $35 b$, que os xerogéis tratados a 700 e $900^{\circ} C$ não contêm nanoporos. Nos xerogéis tratados a $500^{\circ} \mathrm{C}$, há uma coexistência de nanoporos e mesoporos como pode ser observado na figura $33 b$.

A figura $33 b$ mostra um leve deslocamento do tamanho de poros para a esquerda para conteúdos de água crescente, o que indica que a medida que aumenta a concentração de água, aumenta o número relativo de nanoporos. Este efeito foi observado em xerogéis tratados à 700 e $900^{\circ} \mathrm{C}$ (figuras $34 b$ e $35 b$ respectivamente).

Pode-se observar claramente que o aumento da concentração inicial da água promove a formação de uma estrutura porosa mais fina em xerogéis tratados a $500^{\circ} \mathrm{C}$. As amostras tratadas a maiores temperaturas $\left(700\right.$ e $\left.900^{\circ} \mathrm{C}\right)$ têm uma estrutura basicamente composta por mesoporos. 

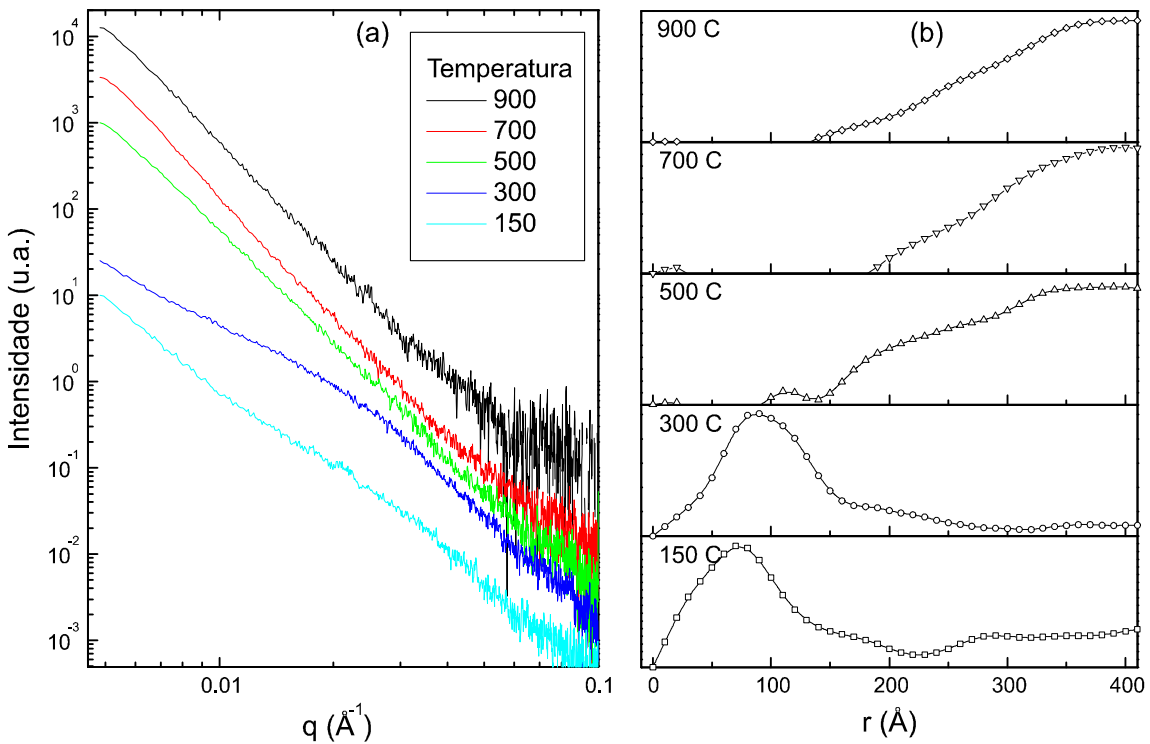

Figura 27.(a) Curvas de $S A X S$ correspondentes a xerogéis com $\left[\mathrm{H}_{2} \mathrm{O}\right]=2 \mathrm{~mol}$ tratados nas temperaturas indicadas. As curvas estão deslocadas verticalmente por motivos de clareza. (b) Funções de distribuição de volume de poros $V(R)$ associadas às diferentes curvas de espalhamento.
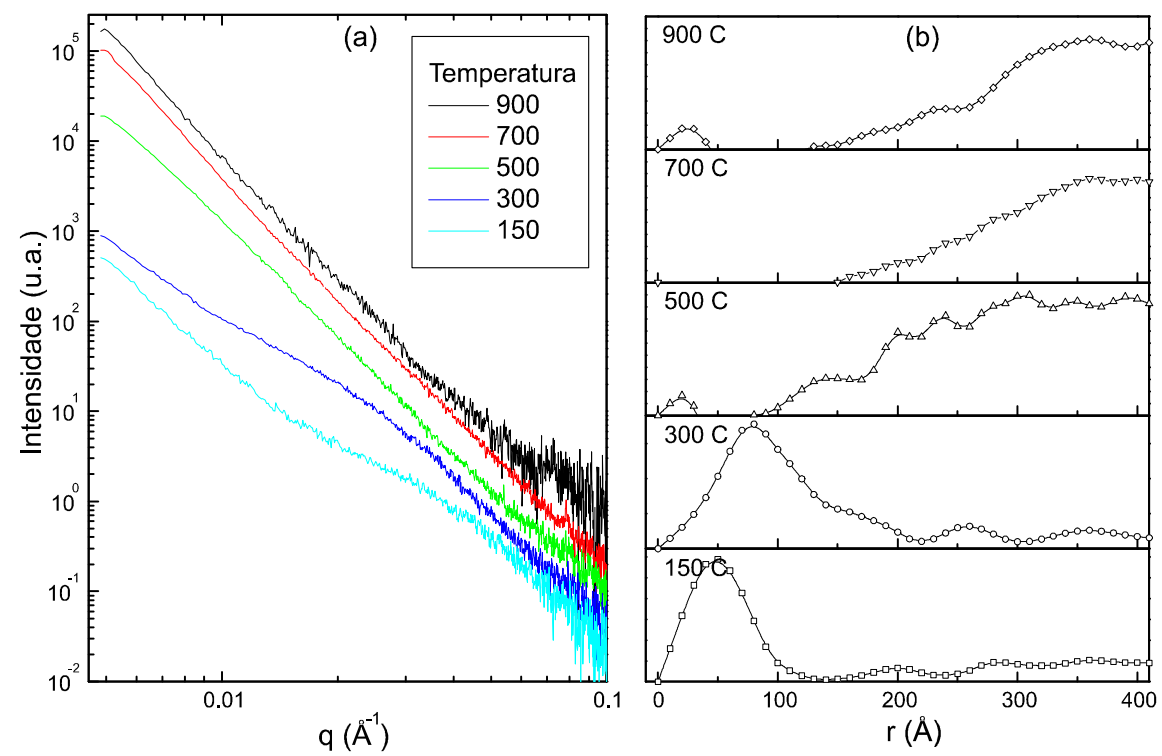

Figura 28. (a) Curvas de $S A X S$ correspondentes a xerogéis com $\left[\mathrm{H}_{2} \mathrm{O}\right]=3 \mathrm{~mol}$ tratados nas temperaturas indicadas. As curvas estão deslocadas verticalmente por motivos de clareza. (b) Funções de distribuição de volume de poros $V(R)$ associadas às diferentes curvas de espalhamento. 

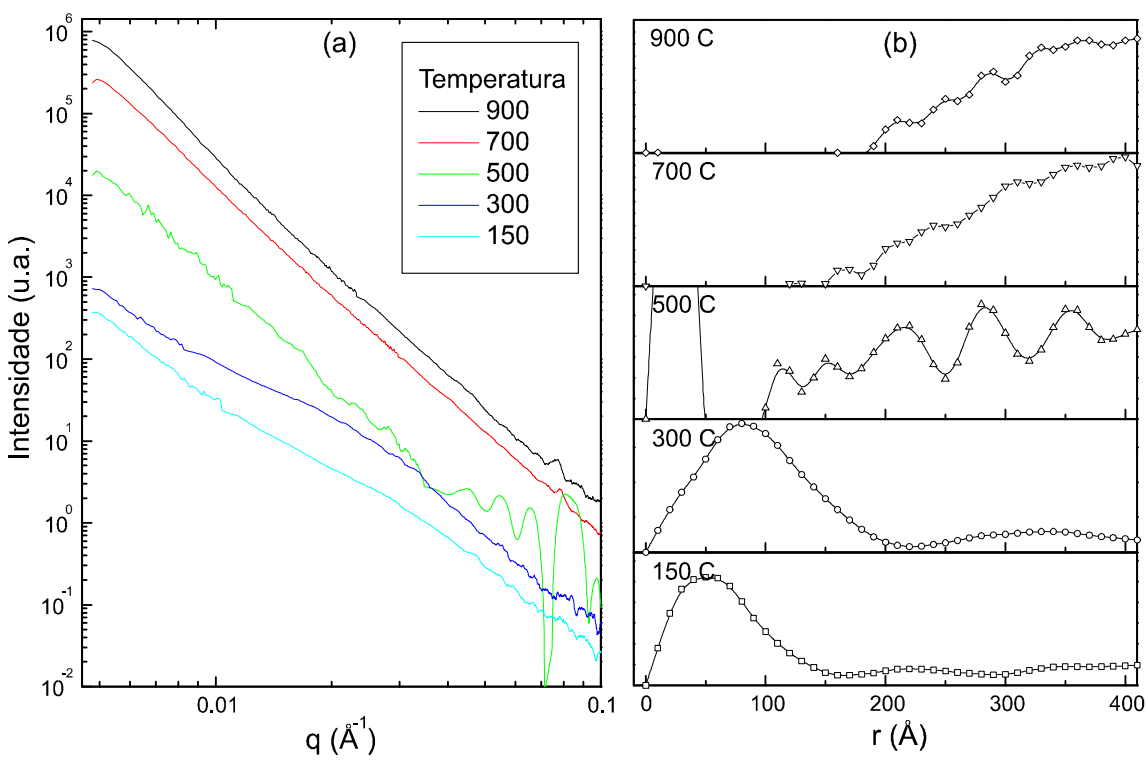

Figura 29.(a) Curvas de $S A X S$ correspondentes a xerogéis com $\left[\mathrm{H}_{2} \mathrm{O}\right]=6 \mathrm{~mol}$ tratados nas temperaturas indicadas. As curvas estão deslocadas verticalmente por motivos de clareza. (b) Funções de distribuição de volume de poros $V(R)$ associadas às diferentes curvas de espalhamento.
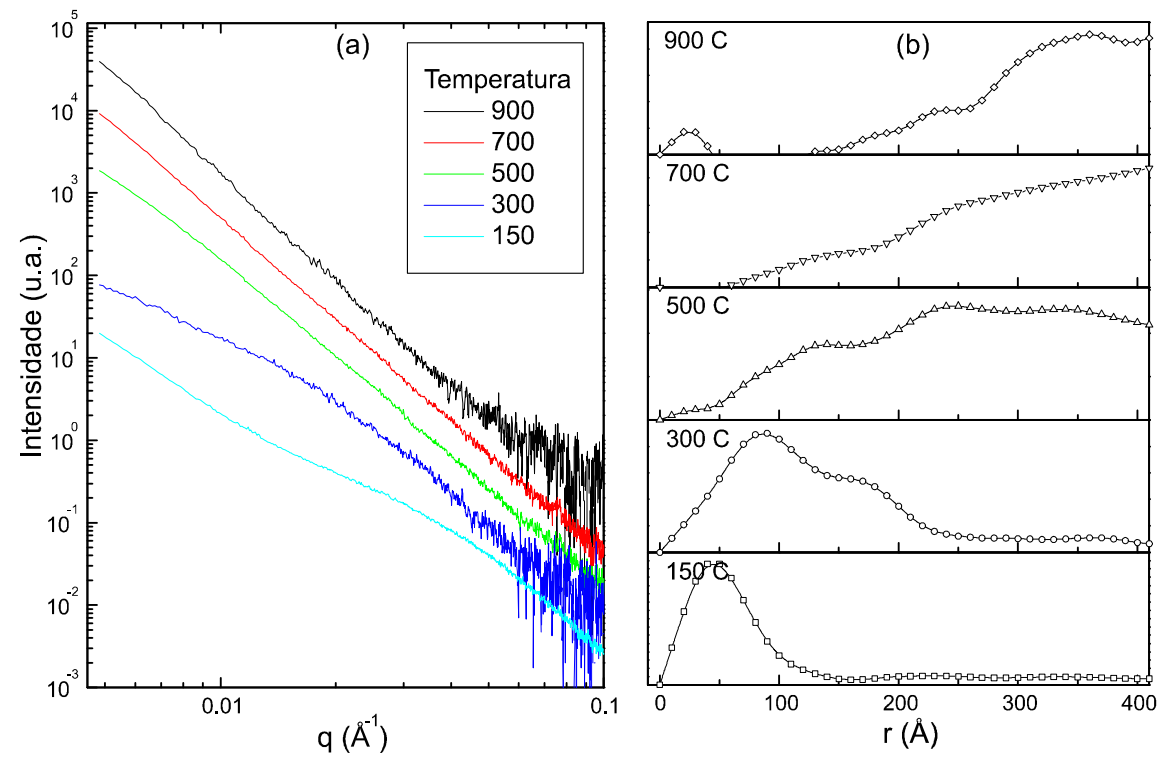

Figura 30.(a) Curvas de $S A X S$ correspondentes a xerogéis com $\left[\mathrm{H}_{2} \mathrm{O}\right]=9 \mathrm{~mol}$ tratados nas temperaturas indicadas. As curvas estão deslocadas verticalmente por motivos de clareza. (b) Funções de distribuição de volume de poros $V(R)$ associadas às diferentes curvas de espalhamento. 

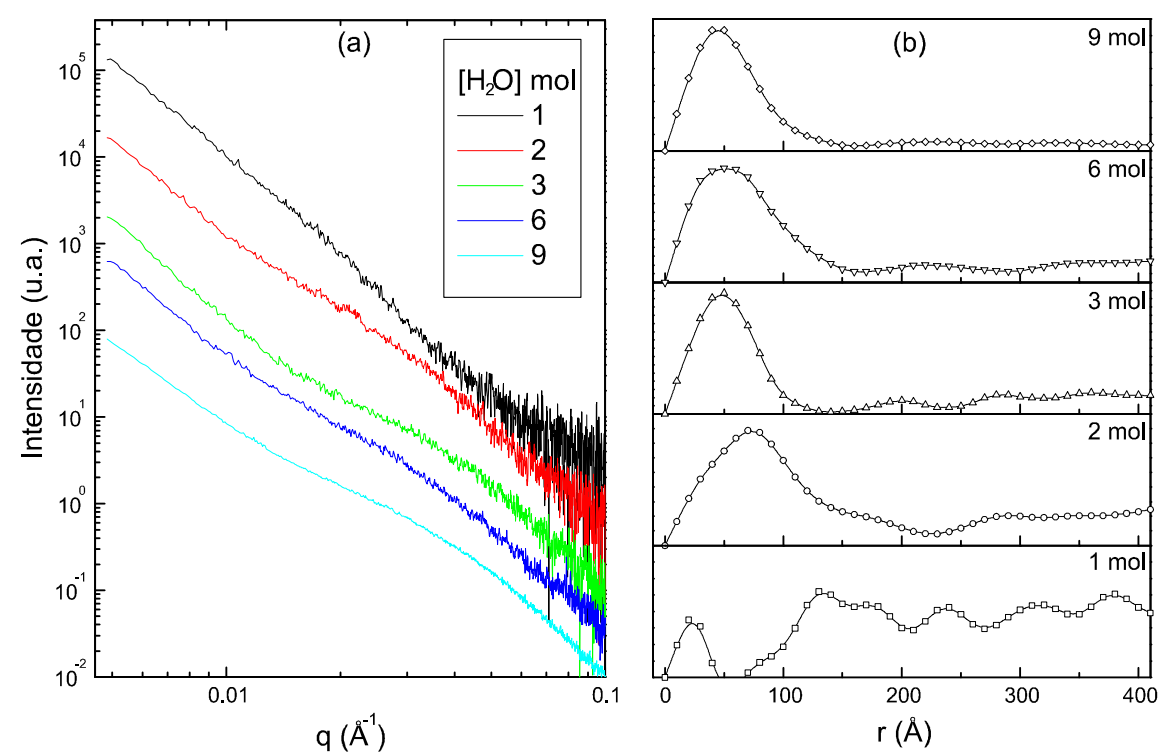

Figura 31.(a) Curvas de $S A X S$ correspondentes a xerogéis tratados a $150^{\circ} \mathrm{C}$ com as concentrações de água indicadas. As curvas estão deslocadas verticalmente por motivos de clareza. (b) Funções de distribuição de volume de poros $V(R)$ associadas às diferentes curvas de espalhamento.
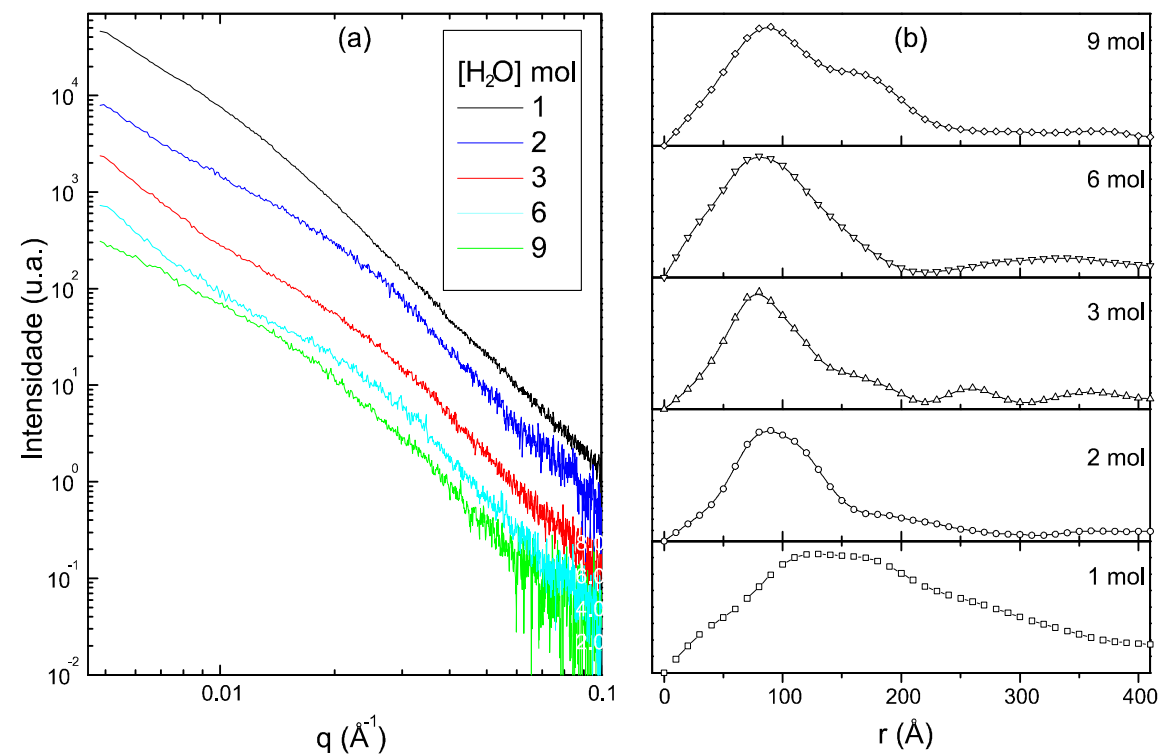

Figura 32. (a) Curvas de $S A X S$ correspondentes a xerogéis tratados a $300^{\circ} \mathrm{C}$ com as concentrações de água indicadas. As curvas estão deslocadas verticalmente por motivos de clareza. (b) Funções de distribuição de volume de poros $V(R)$ associadas às diferentes curvas de espalhamento. 

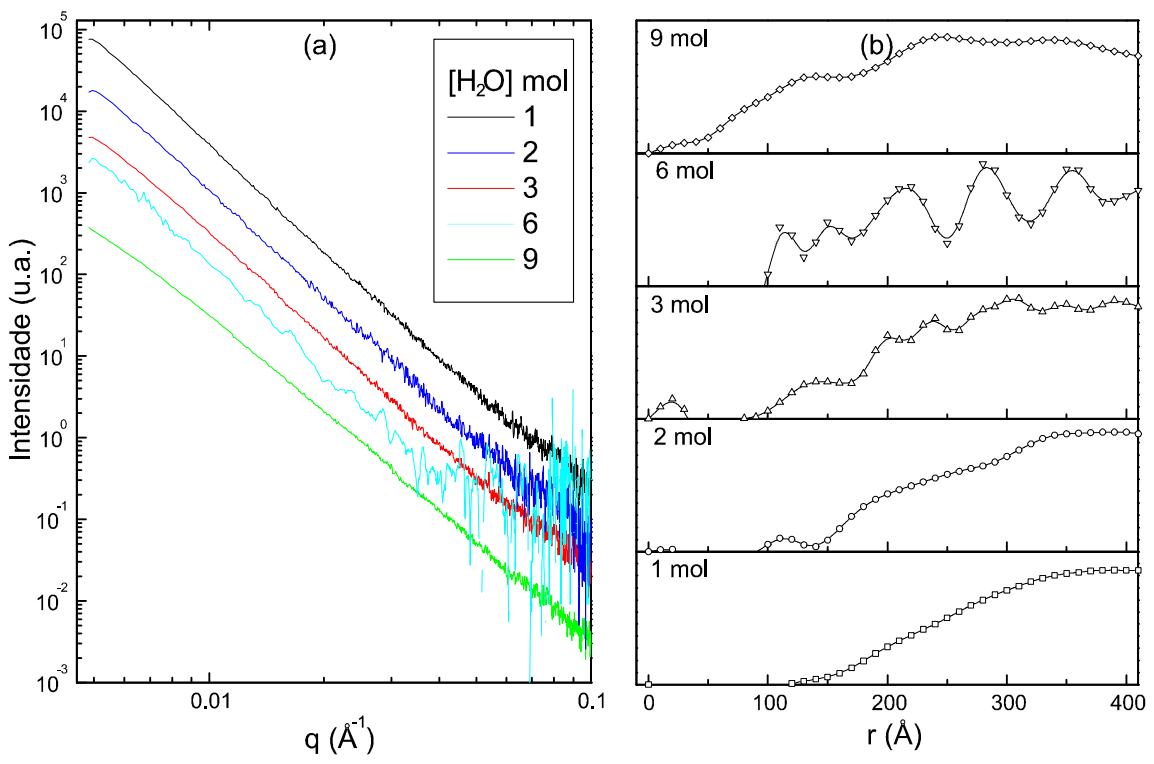

Figura 33. (a) Curvas de $S A X S$ correspondentes a xerogéis tratados a $500^{\circ} \mathrm{C}$ com as concentrações de água indicadas. As curvas estão deslocadas verticalmente por motivos de clareza. (b) Funções de distribuição de volume de poros $V(R)$ associadas às diferentes curvas de espalhamento.
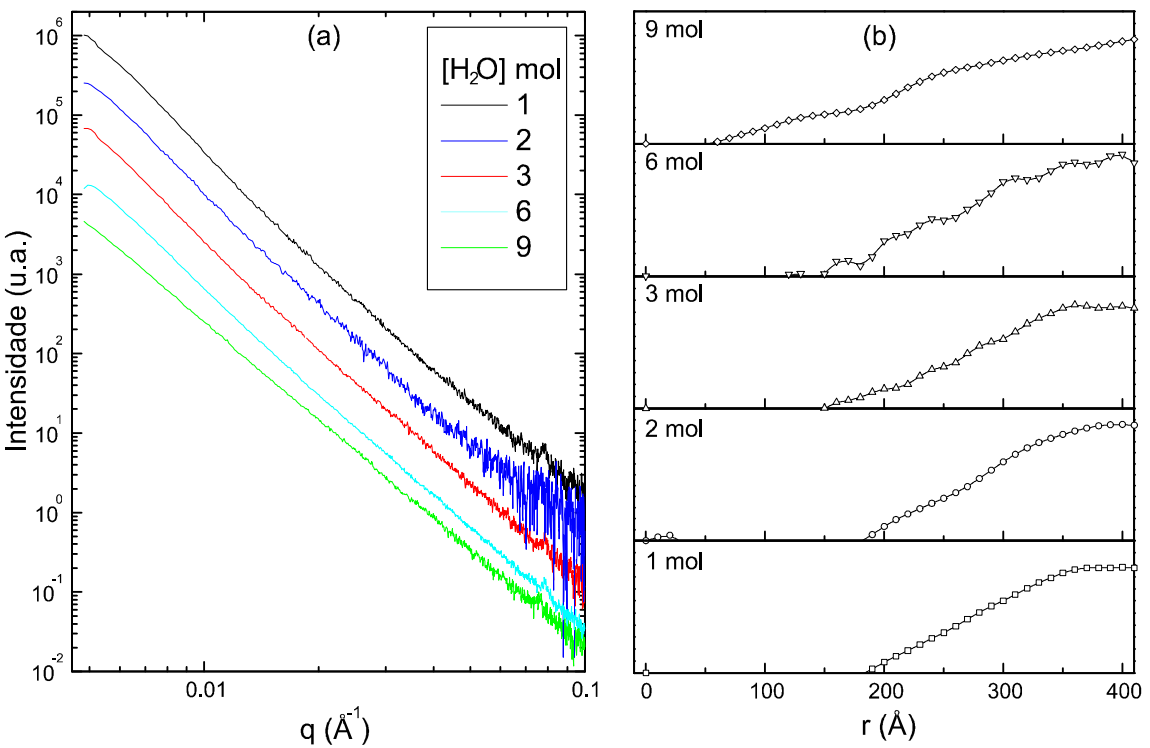

Figura 34. (a) Curvas de $S A X S$ correspondentes a xerogéis tratados a $700^{\circ} \mathrm{C}$ com as concentrações de água indicadas. As curvas estão deslocadas verticalmente por motivos de clareza. (b) Funções de distribuição de volume de poros $V(R)$ associadas às diferentes curvas de espalhamento. 

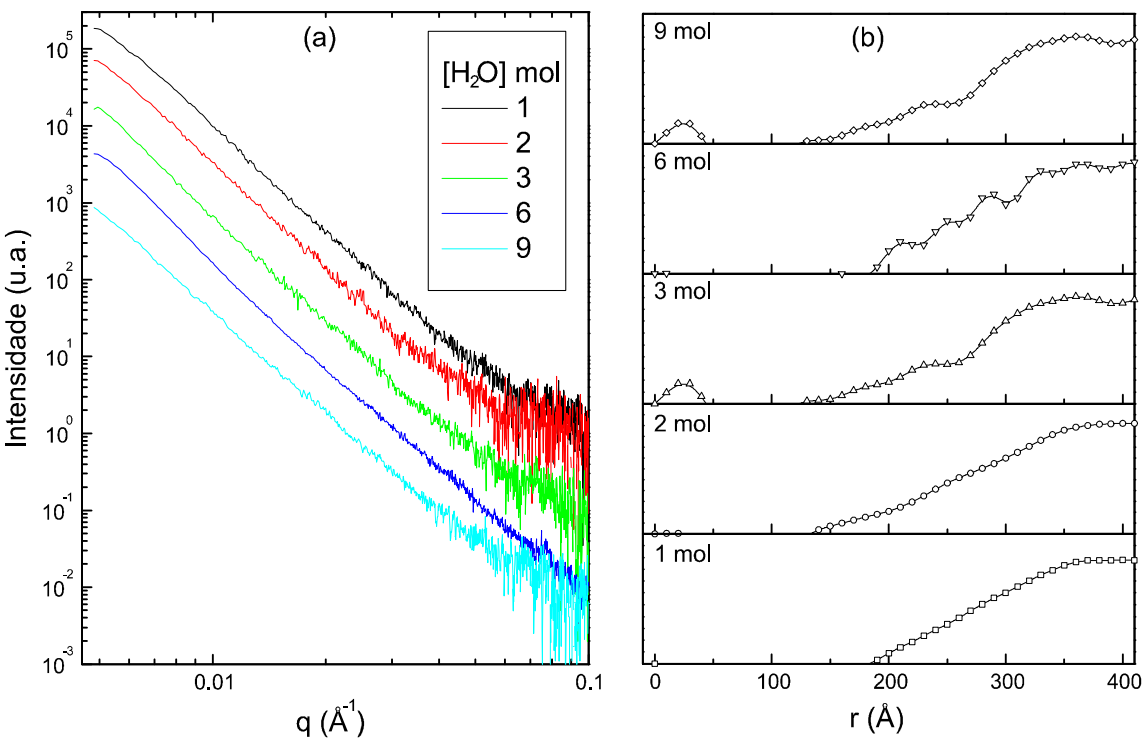

Figura 35. (a) Curvas de $S A X S$ correspondentes a xerogéis tratados a $900^{\circ} \mathrm{C}$ com as concentrações de água indicadas. As curvas estão deslocadas verticalmente por motivos de clareza. (b) Funções de distribuição de volume de poros $V(R)$ associadas às diferentes curvas de espalhamento. 


\subsubsection{Resultados de análise termogravimétrica $(T G A)$ e análise térmica diferencial $(D T A)$}

A variação de massa dos xerogéis durante aquecimento à velocidade constante $\left(\frac{d T}{d t}=\right.$ $5^{\circ} \mathrm{C} / \mathrm{min}$ ) foi determinada mediante $T G A$. A troca de calor devido à evaporação dos componentes voláteis e transformações estruturais durante o processo de aquecimento dos xerogéis foi determinada, utilizando-se a técnica de $D T A$. Neste caso, a velocidade de aquecimento constante foi de $10^{\circ} \mathrm{C} / \mathrm{min}$.

As curvas de TGA e DTA correspondentes a xerogéis com $\left[\mathrm{H}_{2} \mathrm{O}\right]=1$ e $9 \mathrm{~mol}$ são mostradas na figura $36 a$ e $b$ respectivamente.

Pode-se observar que as curvas de $T G A$ correspondentes às amostras com $\left[\mathrm{H}_{2} \mathrm{O}\right]=1 \mathrm{e} 9 \mathrm{~mol}$ apresentam três regimes de perda de massa correspondentes aos intervalos de temperatura de $20-200,200-400$ e $400-800^{\circ} \mathrm{C}$. A perda de massa na primeira região $\left(20-200^{\circ} \mathrm{C}\right)$ é pequena, com um pico em torno de $90^{\circ} \mathrm{C}$. Já na região de $200-400^{\circ} \mathrm{C}$ é a mais significativa. A perda de massa já esta quase finalizada a $400^{\circ} \mathrm{C}$.

As curvas de DTA apresentam três picos endotérmicos para xerogéis com $\left[\mathrm{H}_{2} \mathrm{O}\right]=1$ e $9 \mathrm{~mol}$ à $70-100,180-200$ e $200-400^{\circ} \mathrm{C}$ (figura 36). O pico principal está na terceira região $\left(200-400^{\circ} \mathrm{C}\right)$, sendo este o mais complexo. Inclue dois picos mais estreitos centrados a 390 e $400^{\circ} \mathrm{C}$ os quais são muito mais evidentes no xerogel com $\left[\mathrm{H}_{2} \mathrm{O}\right]=1 \mathrm{~mol}$. Os picos de $D T A$ centrados a 90 e $190^{\circ} \mathrm{C}$ foram atribuídos respectivamente à evaporação de água física e químicamente adsorvidas. $\mathrm{O}$ pico principal em torno de $335^{\circ} \mathrm{C}$ na curva de $D T A$ correspondente às temperaturas com maior taxa de perda de massa na curva de $T G A$ do xerogel com $\left[\mathrm{H}_{2} \mathrm{O}\right]=1 \mathrm{~mol}$ foi atribuído à transformação de hidróxido de níquel em óxido de níquel (Sharma, Fischer and Craievich, 1999).

Para xerogéis com $\left[\mathrm{H}_{2} \mathrm{O}\right]=1 \mathrm{~mol}$, o pico principal da curva de DTA está centrado em $335^{\circ} \mathrm{C}$, enquanto que para para $\left[\mathrm{H}_{2} \mathrm{O}\right]=9$ moles em $350^{\circ} \mathrm{C}$ (figura 36). Esta diferença sugere que para maiores concentrações de água ocorre uma hidrólise mais completa, favorecendo uma quantidade maior de hidróxidos. Como consequiência, a transformação de uma quantidade maior de hidróxido de níquel em óxido de níquel requer uma temperatura maior para ser completada. Este resultado concorda com o que já é bem estabelecido sobre a ação da água na química de sol-gel de óxidos metálicos (Brinker and Scherrer, 1990). A literatura mostra que a água afeta o curso da hidrólise (Strawbridge, Craievich and James, 1985). À baixa concentração de água, a hidrólise é lenta e não consegue converter totalmente os precursores $\left(\mathrm{NiCl}_{2}\right.$ ou $\left.\mathrm{NiCl}_{2-x}(\mathrm{OB})_{x}\right)$ aos seus respectivos hidróxidos. A posição do pico principal da curva de $D T A$ depende 


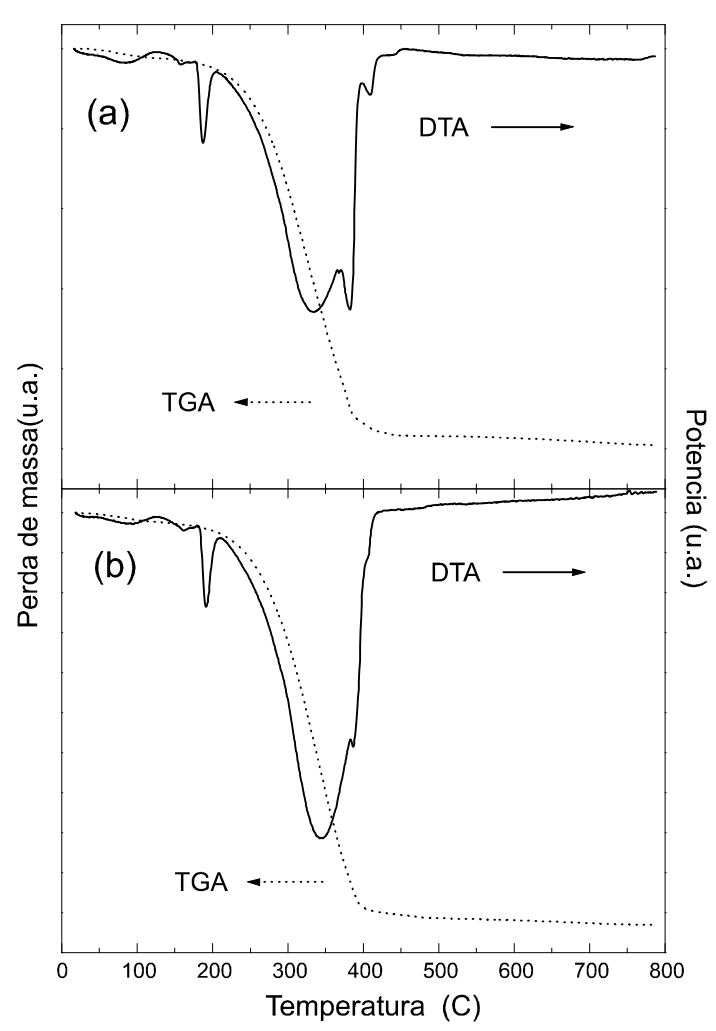

Figura 36.Curvas de $D T A$ e $T G A$ correspondentes a xerogéis com conteúdos iniciais de água de $(a) 1$ e (b) 9 mol.

da quantidade de hidróxido de níquel presente no pó. Para altas concentrações de água, mais e mais espécies ( $\mathrm{NiCl}_{2}$ ou $\mathrm{NiCl}_{2-x}(\mathrm{OB})_{x}$ por exemplo) se transformam no hidróxido de níquel, formando uma estrutura polimérica e entrelaçada, sendo necessária uma temperatura maior para completar a reação.

Não foi possível atribuir os picos estreitos da curva de DTA correspondente ao xerogel com $\left[\mathrm{H}_{2} \mathrm{O}\right]=1 \mathrm{~mol}$ centrados em 390 e $400^{\circ} \mathrm{C}$. A altura destes picos diminui, à medida que a $\left[\mathrm{H}_{2} \mathrm{O}\right]$ passa de 1 para 9 moles. Supõe-se que estes picos se relacionam com espécies que não reagiram e que existem em maior quantidade, quando a concentração de água é menor.

\subsubsection{Resultados de microscopia eletrônica de varredura $(S E M)$}

Imagens obtidas por microscopia eletrônica de varredura $(S E M)$ correspondentes a xerogéis tratados a 300 e $900^{\circ} C$ (figuras $37 a$ e $37 b$ respectivamente) exibem uma diferença bem visível em sua morfologia. Os xerogéis tratados a $300^{\circ} \mathrm{C}$ são compostos por um conjunto de grãos de diferentes tamanhos (em torno de alguns $\mu m$ ) com uma 


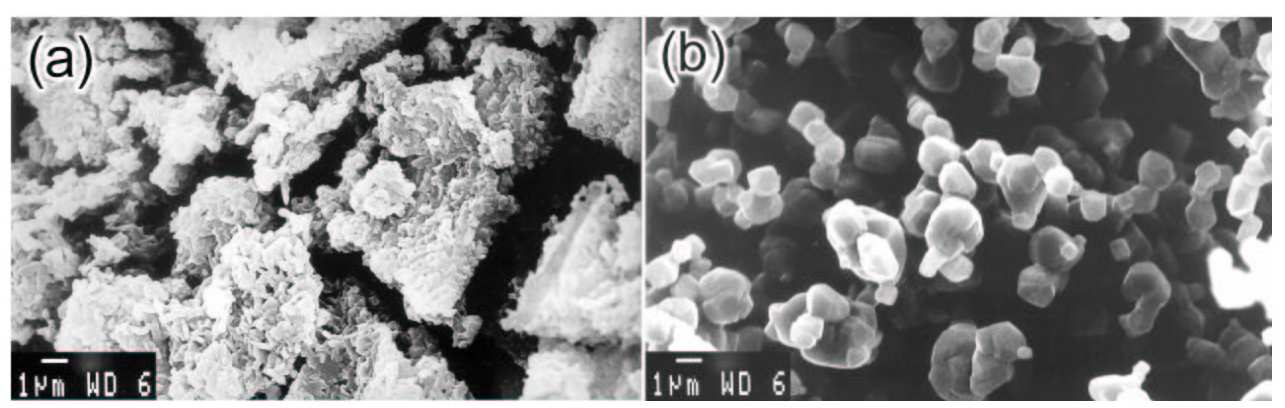

Figura 37.Microscopia eletrônica de varredura dos xerogéis com $\left[\mathrm{H}_{2} \mathrm{O}\right]=2 \mathrm{~mol}$ tratados a: (a) 300 e (b) $900 C$.

superfície exibindo uma rugosidade fina (figura 37a). A imagem correspondente aos xerogéis tratados à $900^{\circ} \mathrm{C}$ (figura 37b) é composta de grãos mais alisados e facetados da ordem de $1 \mu \mathrm{m}$ em tamanho e sem aparente microestrutura ou rugosidade.

\subsubsection{Resultados de difração de $\operatorname{raios} X(X R D)$}

Os mesmos xerogéis estudados por $S A X S$ foram analizados por $X R D$ para determinar o tipo de estrutura (cristalina ou amorfa) desses materiais. Em caso de materiais cristalinos, esta técnica fornece informação também sobre outras características estruturais (tipo de estrutura, tamanho médio dos cristalitos, microtensões). A determinação do tipo de estrutura cristalina se faz geralmente mediante comparação dos diagramas de difração obtidos da amostra policristalina com diagramas de substâncias cristalinas conhecidas.

Os diagramas de difração correspondentes a diferentes xerogéis tratados a 150, 410,500 e $900^{\circ} \mathrm{C}$ estão representados na figura 38. A curva inferior corresponde ao composto cristalino puro de $\mathrm{NiCl}_{2} \cdot 2 \mathrm{H}_{2} \mathrm{O}$ e a superior, a um policristal padrão de $\mathrm{NiO}$, ambos servindocomo referência de materiais conhecidos.

Observa-se que o diagrama de difração correspondente ao xerogel tratado a $150^{\circ} \mathrm{C}$ coincide com o do complexo $\mathrm{NiCl}_{2} \cdot 2 \mathrm{H}_{2} \mathrm{O}$. Por outro lado, o diagrama experimental correspondente a um gel tratado a $900^{\circ} \mathrm{C}$ é bem semelhante ao do policristal padrão de $\mathrm{NiO}$.

Os diagramas correspondentes a xerogéis com temperaturas de tratamento térmico intermediários podem ser descritos como superposições de diagramas de difração correspondentes às fases $\mathrm{NiCl}_{2} \cdot 2 \mathrm{H}_{2} \mathrm{O}$ (com estrutura de rede monoclínica e grupo espacial $I 12 / m 1$ ) e $\mathrm{NiO}$ (estrutura de rede cúbica de face centrada e grupo 


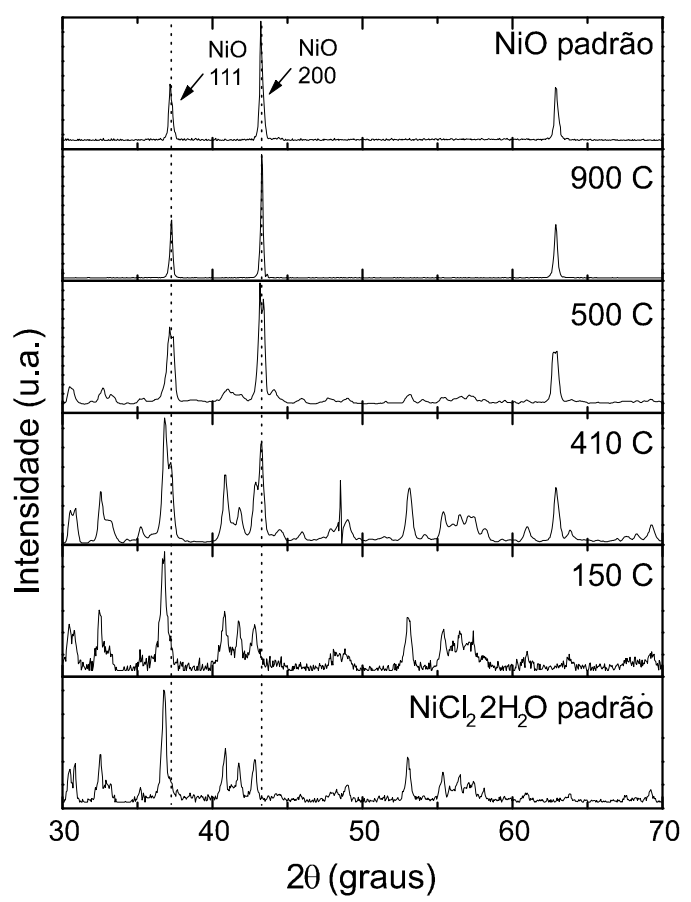

Figura 38.Padrão de difração de raios-X para xerogéis com $\left[\mathrm{H}_{2} \mathrm{O}\right]=2 \mathrm{moles} /(\mathrm{mol}$ $\mathrm{NiCl}_{2}$ ), tratados a diferentes temperaturas.

espacial $F 4 / m-32 / m$ ). Isso implica que os xerogéis tratados a temperaturas de 410 e $500^{\circ} \mathrm{C}$ possuem estrutura bifásica.

As larguras dos picos de difração de raios $X$ dos diagramas correspondentes às fases de $\mathrm{NiCl}_{2} \cdot 2 \mathrm{H}_{2} \mathrm{O}$ (omite-se $2 \mathrm{H}_{2} \mathrm{O}$ daqui para frente por simplicidade) e $\mathrm{NiO}$, dos xerogéis tratados a 150,410 e $500^{\circ} \mathrm{C}$, são maiores que a dos diagramas dos padrões correspondentes. Isso indica que os cristais são suficientemente pequenos para produzir um alargamento sensível do perfil dos picos de difração. Já as amostras tratadas a $900^{\circ} \mathrm{C}$ exibem uma largura de linha muito fina, indicando que nesta fase os cristais alcançam um tamanho maior.

\subsubsection{Resultados de espectroscopia de absorção de raios $X$ perto da borda de absorção ( $X A N E S$ )}

$X A N E S$ é uma técnica experimental de absorção de raios $X$ na qual se extrai informação a partir do coeficiente de absorção numa faixa de energia vizinha ( $E_{b o r d a} \pm$ $50 \mathrm{eV}$ ) à borda de absorção de um dos átomos constituintes do material em estudo. Os espectros de $X A N E S$ têm informações específicas das propriedades químicas do elemento absorvedor (como estado de oxidação por exemplo) e também da estrutura 
atômica local, já que nessa faixa de energia, há também contribuição de espalhamento múltiplo dos fóto-elétrons pelos átomos vizinhos.

Medidas de $X A N E S$ dos diversos tipos de xerogéis estudados foram realizadas perto da borda $K$ do $N i$. A varredura em energia foi realizada num intervalo que vai de 8280 até $8540 \mathrm{eV}$ com um passo de $0,8 \mathrm{eV}$. Os espectros correspondentes a xerogéis com $\left[\mathrm{H}_{2} \mathrm{O}\right]=1 \mathrm{~mol}$ e $[$ a.a. $]=0,1 \mathrm{~mol}$ tratados a $150,300,410,500$ e $900^{\circ} \mathrm{C}$ estão representadas na figura 39 juntamente com os dos materiais padrões $\mathrm{NiCl}_{2} \mathrm{e}$ $\mathrm{NiO}$ (primeiro e último espectro respectivamente). Pode-se notar que o espectro de $X A N E S$ associado à absorção dos átomos de $N i$ produzido pelo xerogel tratado a baixa temperatura $\left(150^{\circ} \mathrm{C}\right)$ é semelhante ao do padrão $\mathrm{NiCl}_{2}$. Do outro lado, o espectro correspondente a xerogéis tratados a $900^{\circ} \mathrm{C}$ é muito semelhante ao do padrão de $\mathrm{NiO}$. Isto implica que o estado químico (número de oxidação do $N i$ por exemplo) dos átomos de $N i$ das amostras tratadas a baixas e altas temperaturas são semelhantes aos dos padrões de $\mathrm{NiCl}_{2}$ e $\mathrm{NiO}$.

Nós assumimos que os xerogéis tratados a temperaturas intermediárias (300 $\leq$ $T \leq 500^{\circ} \mathrm{C}$ ) são bifásicos e que em cada uma das fases encontram-se os átomos de níquel de caráter químico diferente e/ou estrutura local diferente. Assim, para determinar a fração de cada uma das fases no material final foram ajustadas as oscilações de $X A N E S$ das amostras tratadas a temperaturas intermediárias mediante combinação linear dos espectros de referência (padrões de $\mathrm{NiCl}_{2}$ e $\mathrm{NiO}$ ) por:

$$
\chi(E)=c \chi(E)_{N i O}+(1-c) \chi(E)_{N i C l_{2}},
$$

onde $c(T)$ é a fração da fase de $\mathrm{NiO}$ no xerogel tratado a temperatura $T$.

Nessas condições, o efeito da temperatura de tratamento isotérmico por tempo fixo é induzir a formação de diferentes frações de fase $\mathrm{NiO}$ de tal forma a variar as frações de volume $c(T)$.

Os resultados do ajuste acima mencionado correspondentes a xerogéis com $\left[\mathrm{H}_{2} \mathrm{O}\right]=1$ e 9 moles e $[$ a.a. $]=0,1 \mathrm{~mol}$ tratados a $150,300,410,500$ e $900^{\circ} \mathrm{C}$ estão representados na figura 39 juntamente com os dos materiais padrões $\mathrm{NiCl}_{2}$ e $\mathrm{NiO}$. Os números em vermelho indicam o valor da percentagem de $c(T)$ que melhor ajusta os dados.

Uma análise mais apurada dos dados de XANES mostra que as amostras apresentam detalhes muito parecidos (figura 40). O pequeno pico observado abaixo da energia da borda de absorção, não apresenta deslocamento visível $(<0,6 \mathrm{eV}$, valor este dentro do erro experimental). 

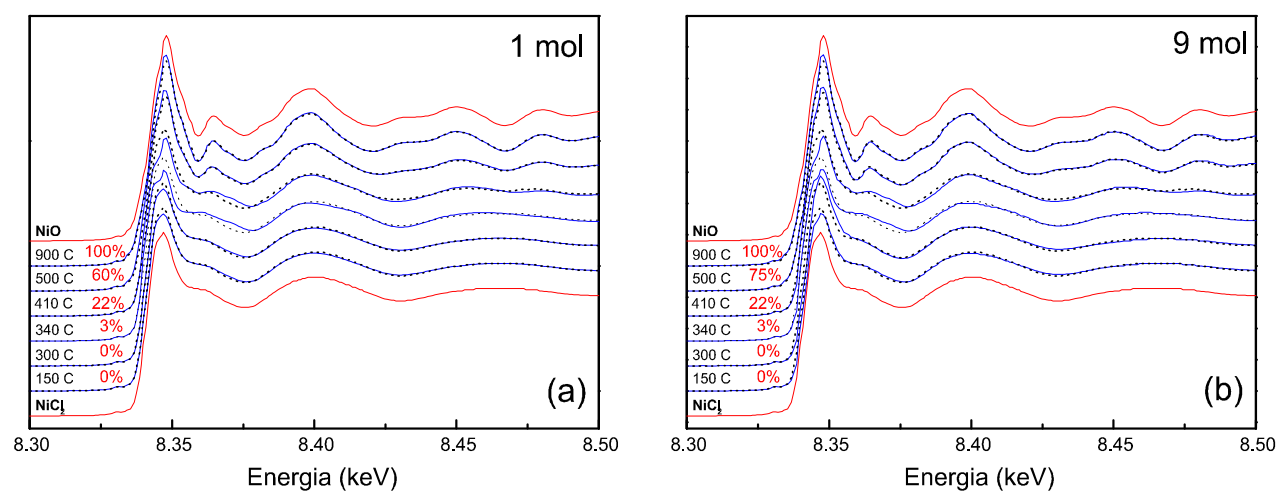

Figura 39.Ajuste linear na região de XANES para xerogéis de $N i$ com $(a) 1 \mathrm{~mol}$ de água e (b) 9 moles de água

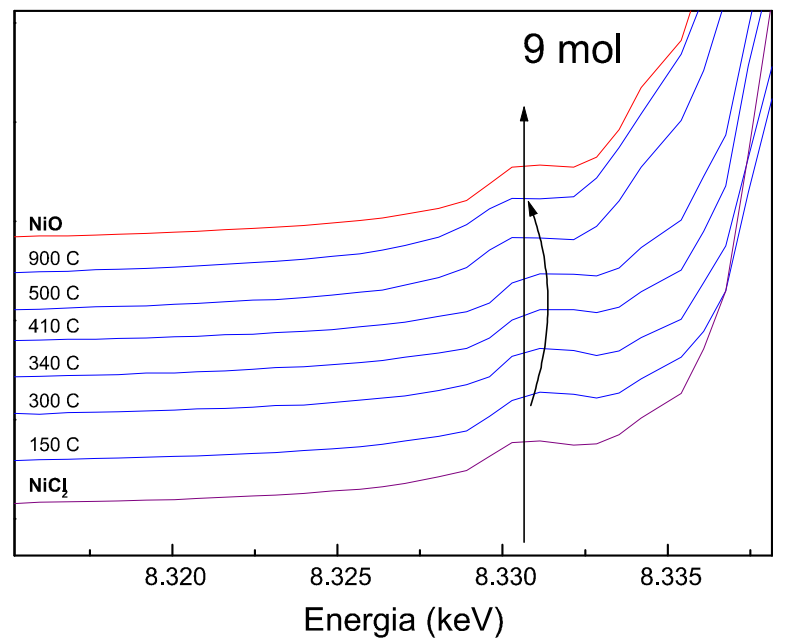

Figura 40.Região de XANES ampliada. O deslocamento deste "bump" está abaixo de $0,6 \mathrm{eV}$. 

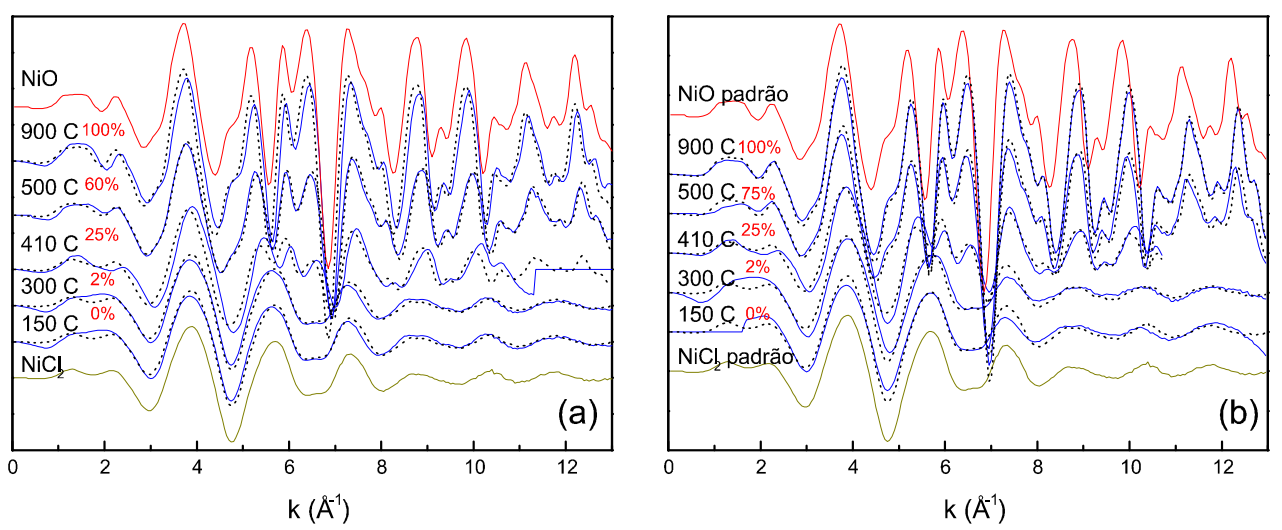

Figura 41.Ajuste dos espectros de $X A N E S$ correspondentes a xerogéis de $N i$ com (a) 1 (b) e 9 moles de água assumindo um modelo bifásico.

\subsubsection{Resultados de espectroscopia de raios $X$ longe da borda de absorção $(E X A F S)$}

\section{Interpretação dos espectros considerando o sistema bifásico}

Os espectros de $E X A F S$ foram primeiramente analisados da mesma forma que os espectros de $X A N E S$, supondo que os xerogéis têm estrutura bifásica.

As oscilações de $E X A F S \chi(k)$ foram determinadas a partir dos espectros de absorção utilizando o programa $A U T O B K$. As funções $\chi(k)$ correspondentes aos xerogéis bifásicos foram determinados mediante uma combinação linear das funções $\chi(k)$ dos padrões $\mathrm{NiCl}_{2}$ e $\mathrm{NiO}$, da mesma forma que se fez com os espectros $X A N E S$. Os resultados dos ajustes estão representados na figura 41. Observa-se nessa figura um bom acordo entre as funções $\chi(k)$ experimentais e modeladas a partir dos espectros de referência.

Note-se que as oscilações de EXAFS dos xerogéis tratados a baixa e alta temperatura $\left(150\right.$ e $\left.900^{\circ} C\right)$ apresentam oscilações muito próximas às amostras referência de $\mathrm{NiCl}_{2}$ e $\mathrm{NiO}$ cristalinos, respectivamente. Os ajustes para temperaturas intermediárias foram satisfatórios do mesmo modo que os de $X A N E S$.

Os resultados de XANES e EXAFS correspondentes a amostras com diferentes concentrações de água indicam claramente que a quantidade da mesma nos sóis precursores afeta a estrutura local em torno do átomos de $\mathrm{Ni}$ no xerogel final. As frações de fase de $\mathrm{NiO}$ presente nos xerogéis tratados a diferentes temperaturas $c(T)$ para diferentes conteúdos de água são representadas na figura 42. Esses valores 


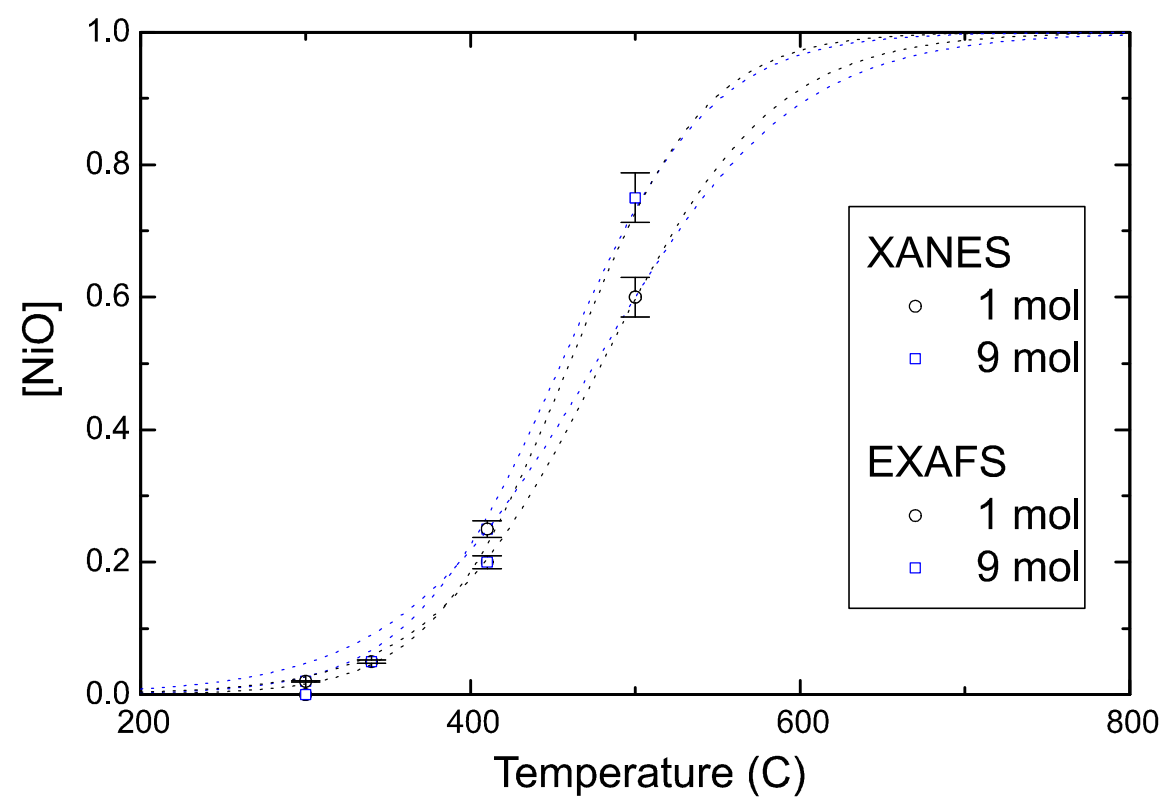

Figura 42.Fração de volume dos xerogéis transformados para $\mathrm{NiO}$.

experimentais de $c(T)$ foram ajustados por uma função sigmoidal

$$
c(T)=\frac{1}{1+e^{\left(T-T_{t}\right) / \Delta T}}
$$

onde $T_{t}$ e $\Delta T$ são parâmetros que dependem da quantidade de água. $T_{t}$ é a temperatura de tratamento dos xerogéis nos quais as duas frações de fase são iguais a $50 \%$. Com os ajustes, utilizando os resultados obtidos pelas técnicas de $X A N E S$ e $E X A F S$ foram obtidos os valores $T_{t}$ e $\Delta T$ como mostra a tabela 5 .

Um aumento da concentração de água desloca a temperatura $T_{t}$ para valores menores como pode ser visto na figura 42. Isso implica, que para uma certa temperatura de tratamento térmico, maior quantidade de água privilegia a transformação em direção à fase $\mathrm{NiO}$.

\begin{tabular}{ccccc} 
& \multicolumn{2}{c}{$1 \mathrm{~mol}$} & \multicolumn{2}{c}{9 moles } \\
& $T_{t}$ & $\Delta T$ & $T_{t}$ & $\Delta T$ \\
$X$ ANES & $480(10)$ & $48(3)$ & $460(10)$ & $37(3)$ \\
EXAFS & $476(10)$ & $57(3)$ & $455(10)$ & $41(3)$
\end{tabular}

Tabela 5 : Resultados obtidos pelo ajuste dos dados obtidos pela combinação linear das referências com as amostras usando a função sigmoidal (equação4.50).

Os xerogéis tratados a 150 e $900^{\circ} C$ têm os mesmos espectros de $X A N E S$ e $E X A F S$ que as amostras referência $\mathrm{NiCl}_{2}$ e $\mathrm{NiO}$, respectivamente. Isso nos permite 
concluir que o xerogel tratado a $150^{\circ} \mathrm{C}$ tem estrutura local idêntica ao $\mathrm{NiCl}_{2}$ e o tratado a $900^{\circ} \mathrm{C}$, igual ao $\mathrm{NiO}$. Estas conclusões concordam com as obtidas a partir das experiências de $X R D$.

\section{Interpretação dos espectros por simulação teórica $(F E F F)$}

As oscilações EXAFS dos xerogéis estudados foram isoladas previamente pelo programa $A U T O B K$ (ver figura 43). Deve-se ressaltar que se utiliza fase e amplitude teóricas (ver figura 49), calculadas por FEFF (utilizando clusters de $14 \AA$ de diâmetro no caso do $\mathrm{NiO}$ e $\mathrm{NiCl}_{2}$ que pode ser visto na figura 48), devido a impossibilidade de separar as esferas de coordenação correspondentes às distâncias $\mathrm{Ni}-\mathrm{O}$ e $\mathrm{Ni}-\mathrm{Cl}$ em amostras tratadas a baixas e médias temperaturas $\left(150-500^{\circ} \mathrm{C}\right)$. Somente no caso do xerogel tratado a $900^{\circ} C$, conseguiu-se separar as duas primeiras esferas de coordenação, sendo possível usar a fase e amplitude do padrão de $\mathrm{NiO}$ experimental. Por se ter apenas uma amostra para a qual a fase e a amplitude obtidas experimentalmente a partir de padrões experimentais são aplicáveis, prefere-se utilizar padrões de referência calculados teoricamente em todos os casos.

Para a análise da transformada de Fourier, usa-se o intervalo em $k$ de aproximadamente 3,3 a $12.5 \AA^{-1}$ (ver figura 43b). Para diminuir possíveis efeitos de descontinuidade nos extremos dos espectros (se bem que estes eram desprezíveis pois sempre se escolheu regiões onde o sinal de EXAFS se anulava - fig 43b) multiplicouse-os por uma função Bessel 2, 5 e todo o espectro por $k^{2}$ para ressaltar mais as regiões de alto valor de $k$ (compare a figura $43 a$ com a $43 b$ ).

Em seguida, isolou-se as primeiras esferas de coordenação, utilizou-se os arquivos gerados pelo programa $F E F F$ para estas esferas e usou-se a função de ajuste do programa WinXas (FEFFIF) para obter os valores dos parâmetros estruturais $N$, $\sigma$ e deslocamento de $E_{0}$.

A figura $43 a$ mostra, como exemplo, as oscilações de $E X A F S$ determinadas pelo programa $A U T O B K$ para o material de referência $N i O$. Em seguida, utilizando o programa WinXas, multiplicou-se este espectro por $k^{2}$ e isolou-se a região de interesse (figura 43b). Depois uma janela tipo Bessel 2, 5 é aplicada à região selecionada no passo anterior (figura 44) e finalmente determina-se a transformada de Fourier (figura 45). A figura 45 ilustra o efeito produzido por diferentes expoentes de $k$. Quanto maior o expoente de $k$ mais definida é a região de baixo $R$ e vice-versa. Em espectros com estatística ruim, não é recomendável usar expoentes de $k$ muito altos, já que neste caso o peso da região de alto $k$ pode resultar excessivo. 

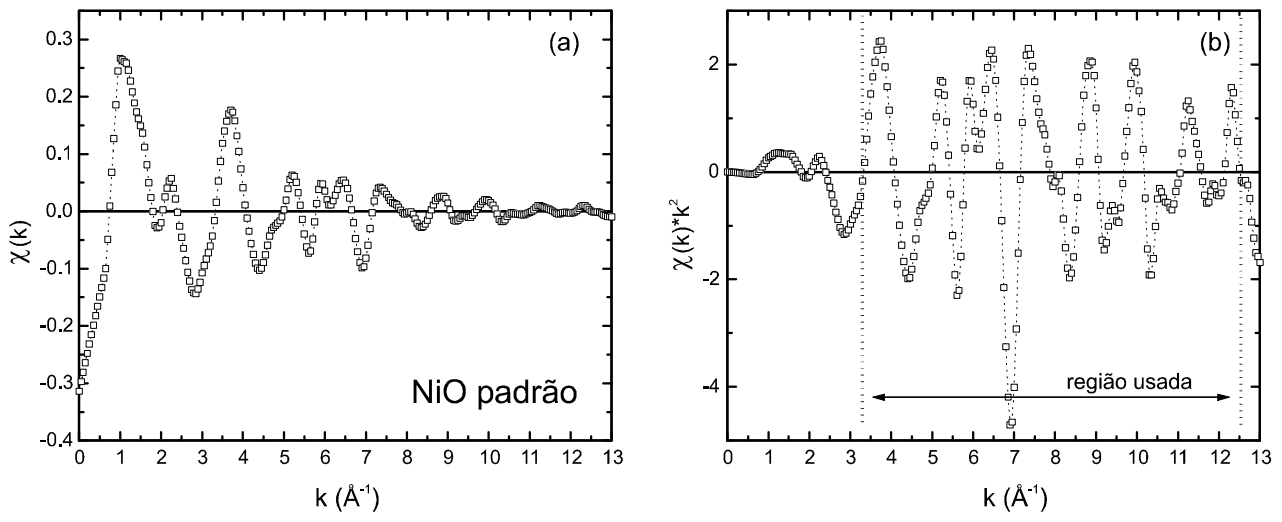

Figura 43.(a) Oscilações EXAFS obtidas pelo programa AUTOBK a partir do espectro bruto e (b) oscilações EXAFS multiplicadas por um fator $k^{2}$ para dar mais peso a regiões de alto $k$, também indicando a região utilizada para análise.

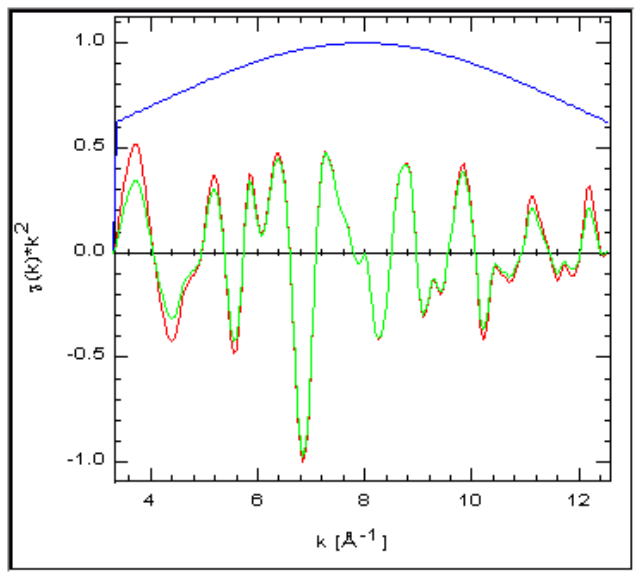

Figura 44.Multiplicando as oscilações EXAFS (vermelho) por uma função Bessel com peso 2,5 (azul) obtendo oscilações atenuadas nas extremidades (verde). 


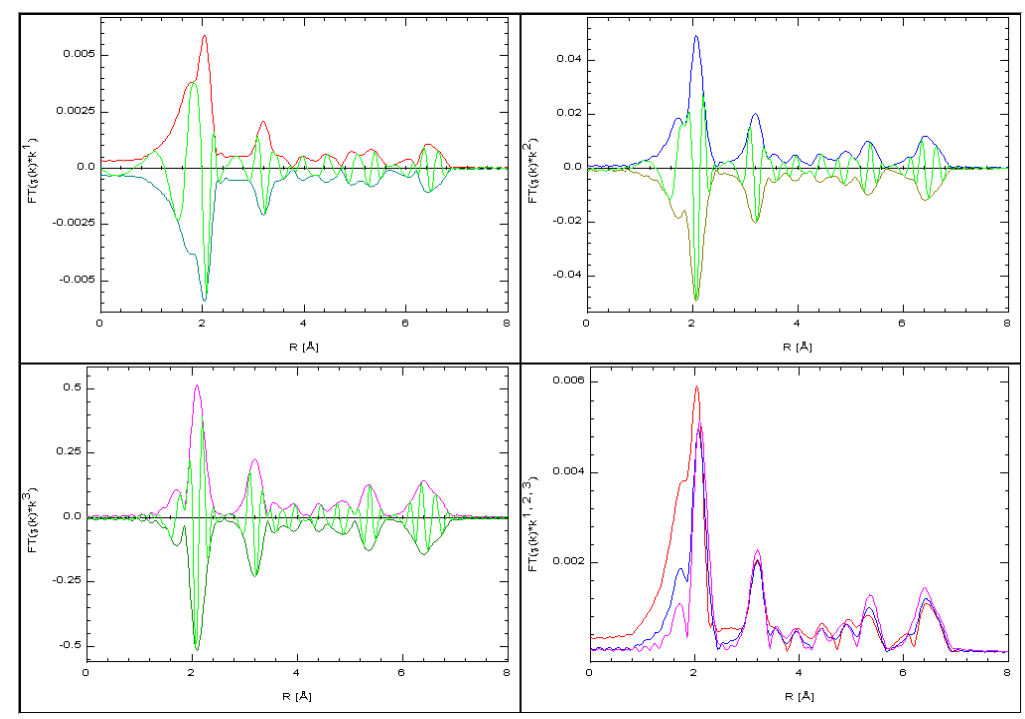

Figura 45.Gráfico ilustrando o efeito quando se pesa o espectro de diferentes formas $\left(k, k^{2}\right.$ e $k^{3}$ ). Note que quanto maior o $k$ mais definido a região de baixo $R$ e vice versa. Neste caso foi utilizado o $\mathrm{NiCl}_{2}$ calculado por $F E F F$. 

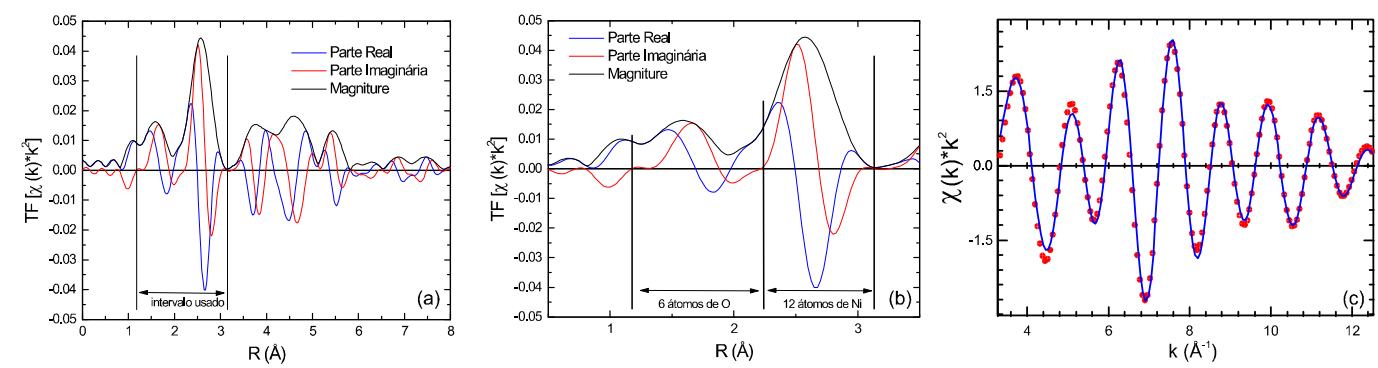

Figura 46.(a) Transformada de Fourier ( $T F$ ) das oscilações de $E X A F S$, em seguida (b) selecionou-se a região para fazer a $T F$ inversa obtendo por fim $(c)$ o sinal de $E X A F S$ (bolas abertas) e ajuste teórico correspondente.

Por fim, obtemos a transformada de Fourier $(T F)$ do sinal de $E X A F S$, como ilustrado na figura $46 a$ do material de referência. Depois de obtida a $T F$, isolam-se as esferas de coordenação de interesse (no caso da figura $46 a$ tem-se o $\mathrm{NiO}$, que tem 6 átomos de $O$ a 2, $09 \AA$ do $N i$ e 12 átomos de $N i$ a $2,95 \AA$ do $N i$ central, primeiro e segundo pico, respectivamente, como ilustrado na figura $46 b$ e aplica-se a $T F$ inversa obtendo-se o sinal de $E X A F S$ correspondente a somente às duas primeiras esferas de coordenação como indicado na figura 46c. A linha azul é o ajuste teórico aos dados experimentais. Na figura 47 está representada a $T F$ das oscilações da fig $46 c$, ilustrando que essas oscilações de fato correspondem às primeiras duas esferas de coordenação (as isoladas na figura $46 b$ ).

Na figura 51, temos as oscilações de $E X A F S$ para todas as amostras estudadas com $\left[H_{2} O\right]=1$. Também se ilustra em vermelho as oscilações de EXAFS obtidas por $F E F F$ sem correção no fator de atenuação de Debye-Waller.

Considera-se que a estrutura dos xerogéis tratados a diferentes temperaturas é descrita por um conjunto de átomos de $N i$ com diferentes vizinhanças dependendo da fase $\mathrm{NiCl}_{2}$ ou $\mathrm{NiO}$ na qual se encontra. Note-se que, mesmo num sistema bifásico, se os cristalitos que compõem o xerogel são pequenos e porosos o número médio de coordenação do $N i$ não é necessáriamente correlacionado às frações de volume das fases de $\mathrm{NiCl}_{2}$ e $\mathrm{NiO}$ obtidos a partir da figura 42 e ilustrados na figura 50.

\section{Resultado das simulações de EXAFS variando todos os parâmetros $\left(N, R, \sigma^{2}\right.$ e $E_{0}$ shift)}

Fizemos ajustes dos espectros de $E X A F S$ experimentais de todos os xerogéis com $\left[\mathrm{H}_{2} \mathrm{O}\right]=1$ e 9 moles e diferentes temperaturas de tratamento térmico. utiliza-se 


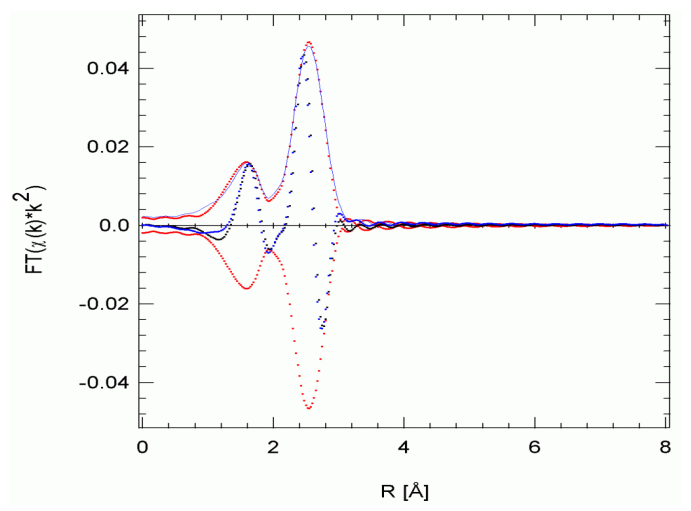

Figura 47.TF inversa das oscilações de $E X A F S$ da $c$ (vermelho) e correspondente ajuste (azul).
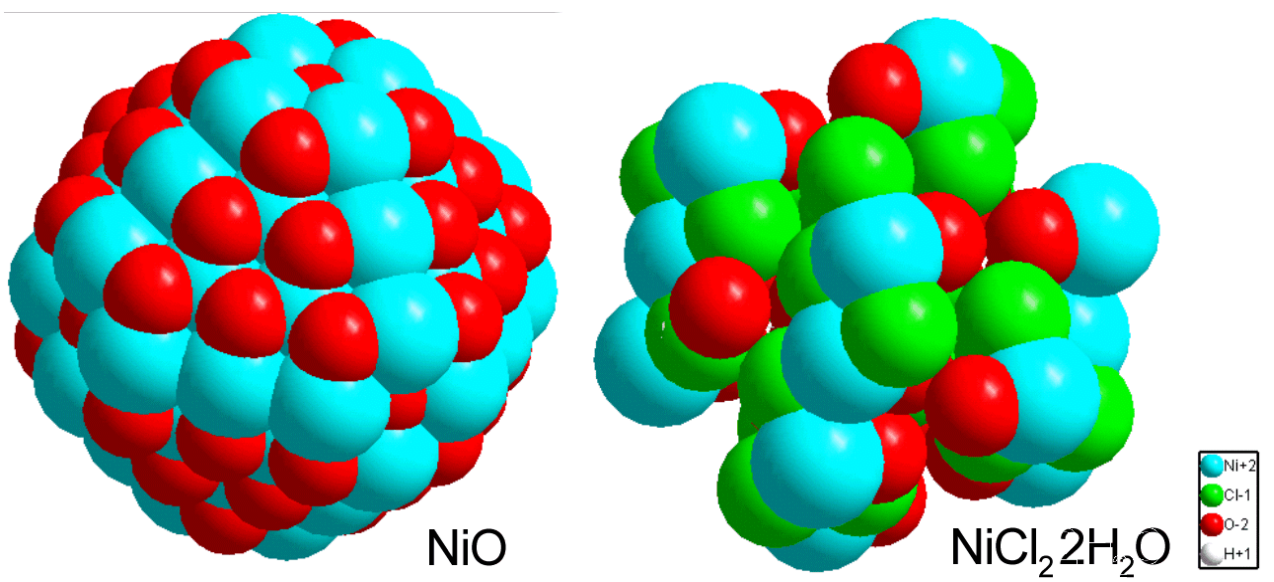

Figura 48.Clusters de $7 \AA$ de raio $\mathrm{NiO}$ (com 171 átomos) e $\mathrm{NiCl}_{2}$ (com 74 átomos) usados para obter as oscilação teóricas de $E X A F S$, bem como fases e amplitudes.
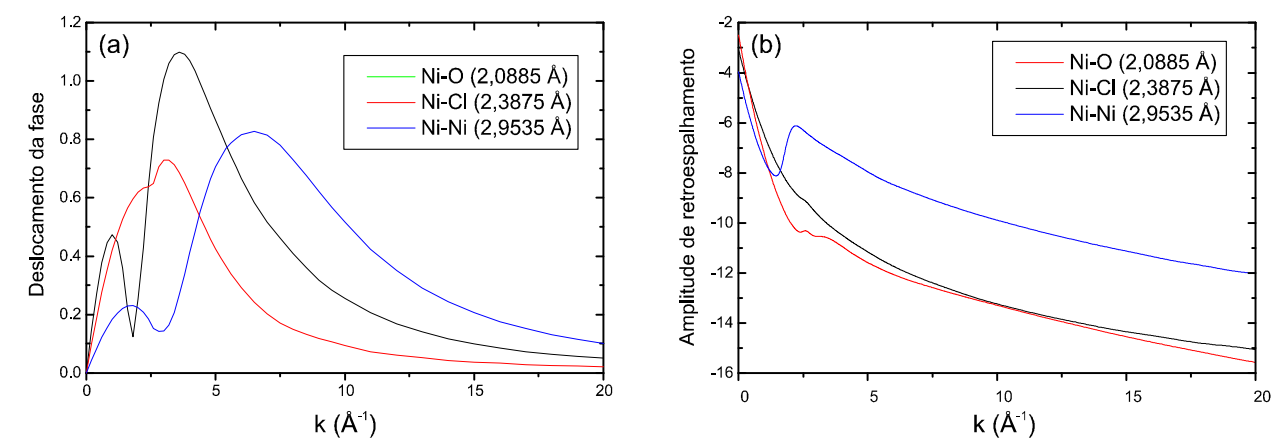

Figura 49.À esquerda, vê-se os cálculos realizados por $F E F F$ da amplitude de retroespalhamento dos átomos vizinhos ao átomo central $(N i)$ e à direita, encontram-se seus correspondentes deslocamentos de fases em função do número de onda $k$. 


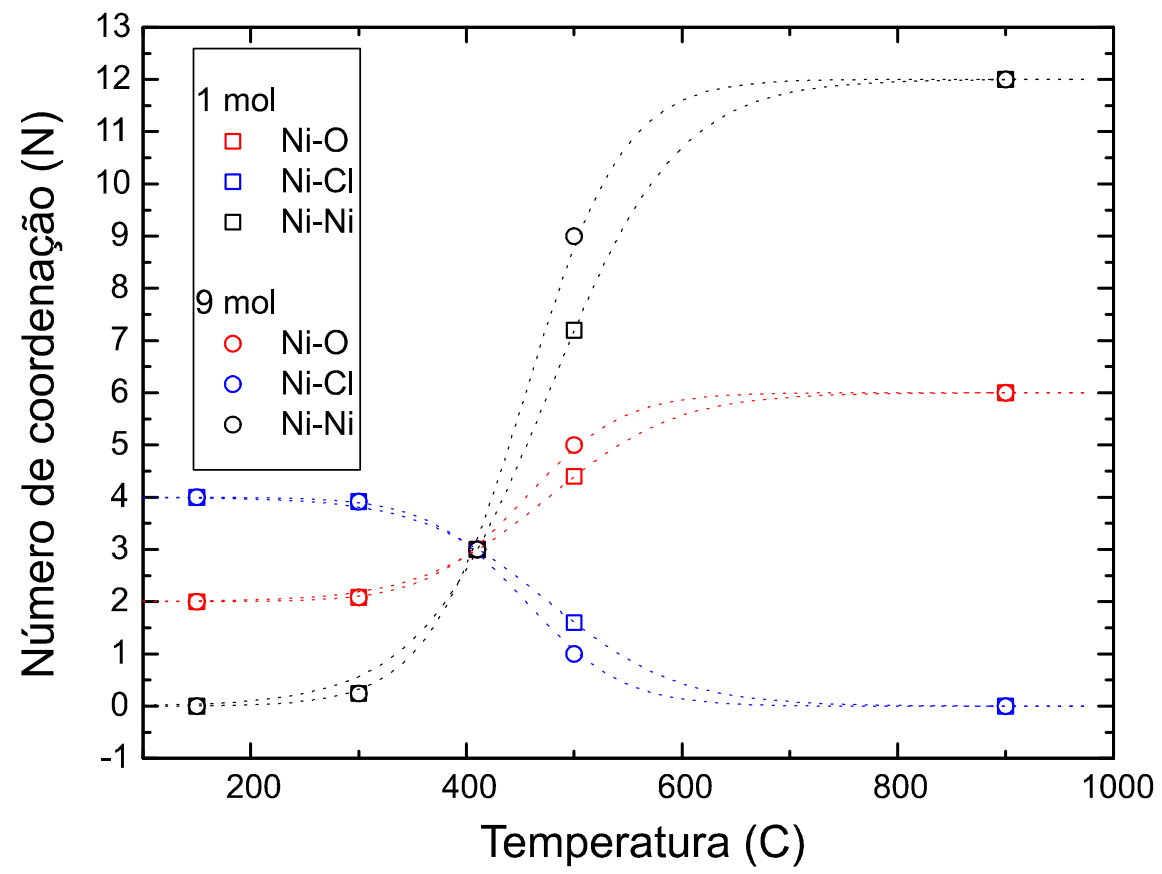

Figura 50.Números de coordenação obtidos supondo modelo bifásico.
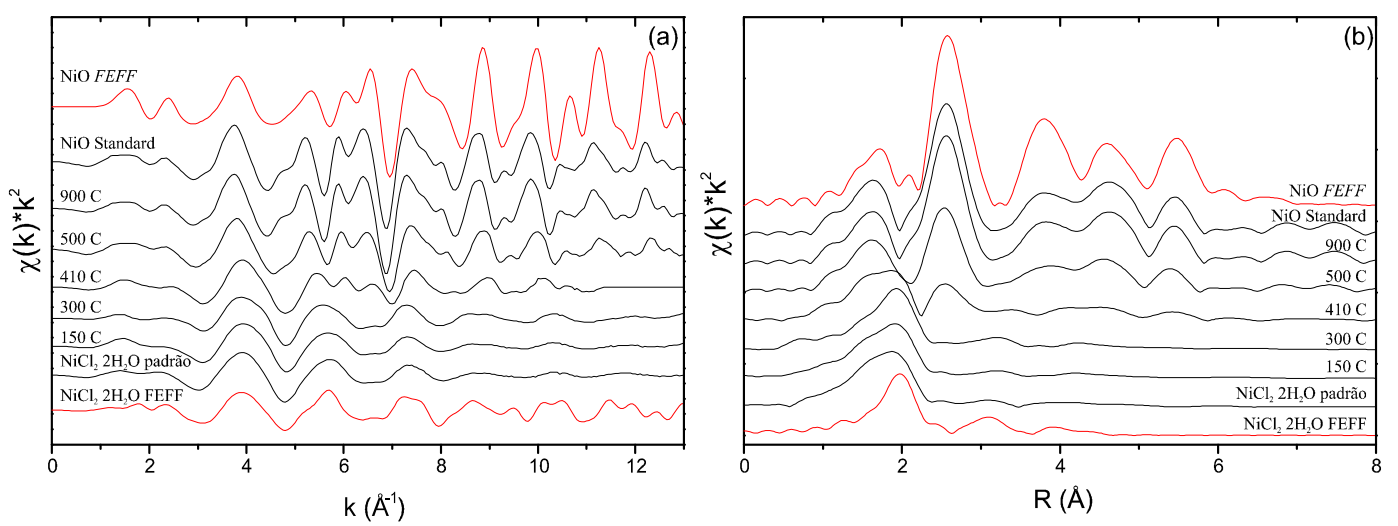

Figura 51.(a) oscilações $E X A F S$ e (b) respectivas transformadas de Fourier das amostras com $\left[\mathrm{H}_{2} \mathrm{O}\right]=1$ sem correção por deslocamento de fase (phase shift). Em vermelho, estão indicados os sinais de $E X A F S$ obtidos por $F E F F$ sem o fator de atenuação Debye-Waller. 

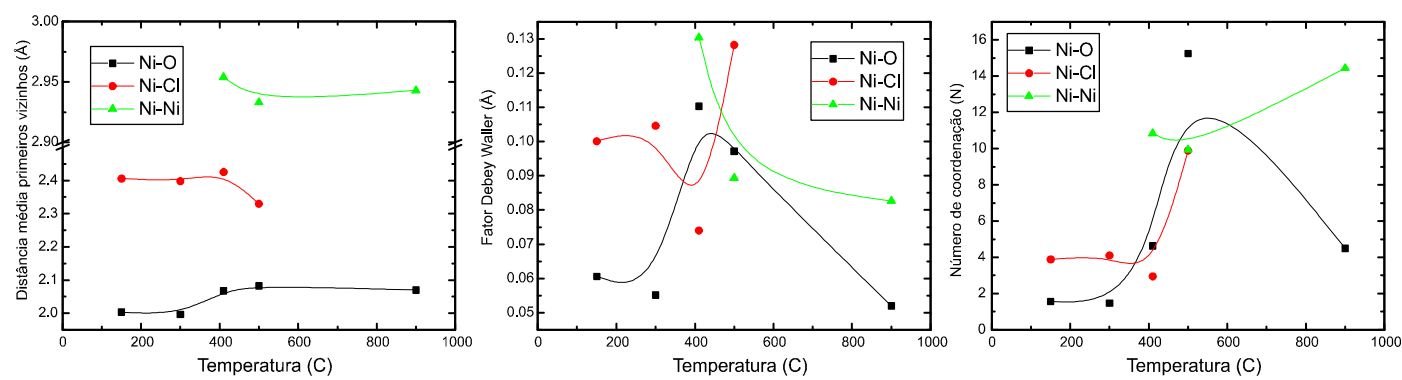

Figura 52.Amostras com $\left[\mathrm{H}_{2} \mathrm{O}\right]=1 \mathrm{~mol}$. Todos parâmetros foram ajustados

para isto padrões teóricos calculados com fases e amplitudes determinados por $F E F F$, permitindo a variação de todos os parâmetros estruturais ( $N, R, \sigma, E_{0}$ shift).

Os valores de $R, \sigma$ e $N$ estão representados nas figuras 52 e 53 para $\left[\mathrm{H}_{2} \mathrm{O}\right]=1 \mathrm{e}$ 9 moles, respectivamente.

Os resultados mostram que os valores do parâmetro de Debye-Waller apresentam um máximo em $410^{\circ} \mathrm{C}$. Por outro lado os diferentes valores de $N$ necessários para um ajuste satisfatório resultam extremamente altos e inaceitáveis do ponto de vista estrutural. No apêndice A, encontram-se os gráficos com detalhes dos numerosos ajustes realizados.

Pelo insucesso deste procedimento, passa-se a tentar um outro tipo de ajuste no qual alguns dos parâmetros foram fixados. Esse cálculo é descrito a seguir.

\section{Resultado das simulações de EXAFS mantendo alguns parâmetros fixos considerando-se um sistema bifásico}

Na segunda tentativa de ajuste, manteve-se fixa a distância dos primeiros vizinhos $\mathrm{Ni}-\mathrm{Cl}$ e $\mathrm{Ni}-\mathrm{Ni}$, sendo elas às correspondentes as amostras tratadas a $150 \mathrm{e} 900^{\circ} \mathrm{C}$ respectivamente. Permite-se variar a distância $N i-O$, pois esta esfera de coordenação está presente em amostras a baixa $(N=2)$ e alta temperatura $(N=6)$ e também o parâmetro de Debye-Waller $(\sigma)$. Este procedimento foi adotado para quantificar a variação da amplitude do sinal, que é função da ordem local, em termos da atenuação causada pelo fator de Debye-Waller.

Simulações do sinal $E X A F S$ por $F E F F$ foram realizadas, mantendo-se fixo o número de coordenação $(N)$ estabelecido pelo ajuste linear dos dados de $X A N E S$ e $E X A F S$ considerando um sistema bifásico, como ilustra a figura 50. A distância do $\mathrm{Ni}-\mathrm{Cl}$ e $\mathrm{Ni}-\mathrm{Ni}$ foi fixada em 2,41 e $2.93 \AA$ A respectivamente (valores correspondentes à estrutura de referência). Os resultados obtidos a partir deste ajuste se encontram na figura 54 e 55. 

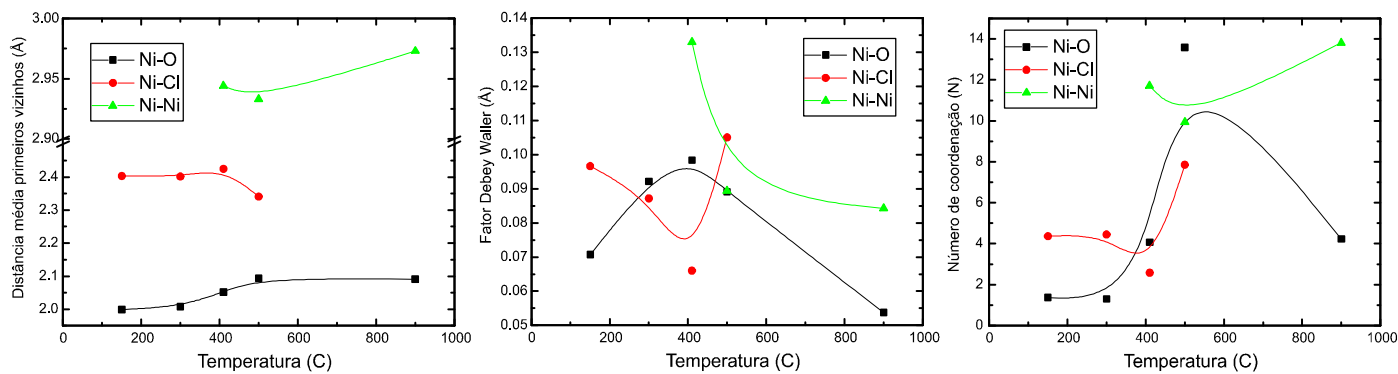

Figura 53.Amostras com $\left[\mathrm{H}_{2} \mathrm{O}\right]=9$ moles. Todos parâmetros foram ajustados
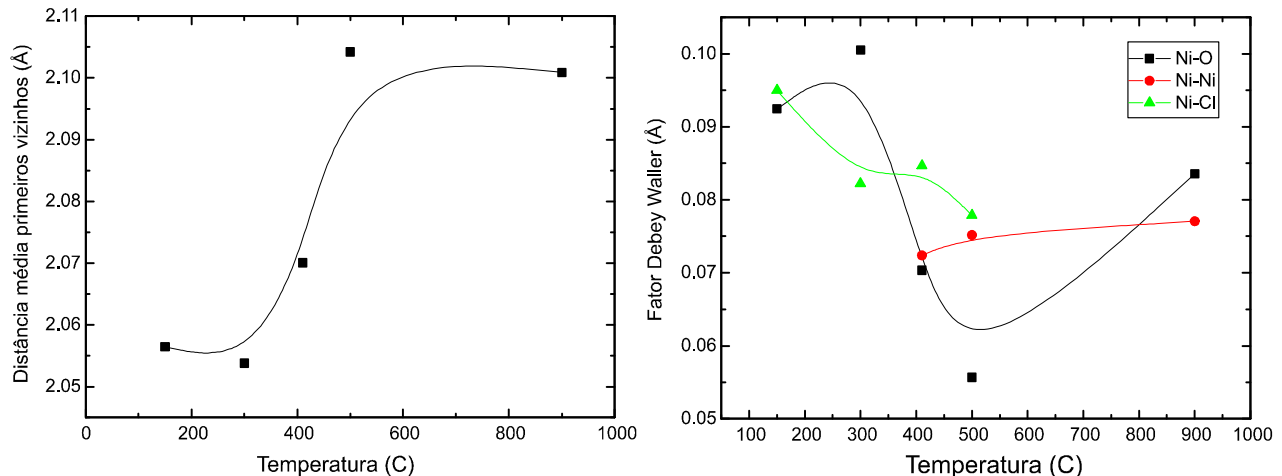

Figura 54.Resultados obtidos, fixando o número de coordenação do $\mathrm{Cl}$ e $\mathrm{Ni}$ pelos valores obtidos mediante ajuste linear. Variando somente distância da primeira esfera de coordenação (figura à esquerda) e o fator de $D W$ (figura à direita) e $E_{0}$ shift. Amostras com 1 mol de conteúdo de água inicial. Erro da ordem de $0,02 \AA$ para R e $0,01 \AA$ para $\sigma$.
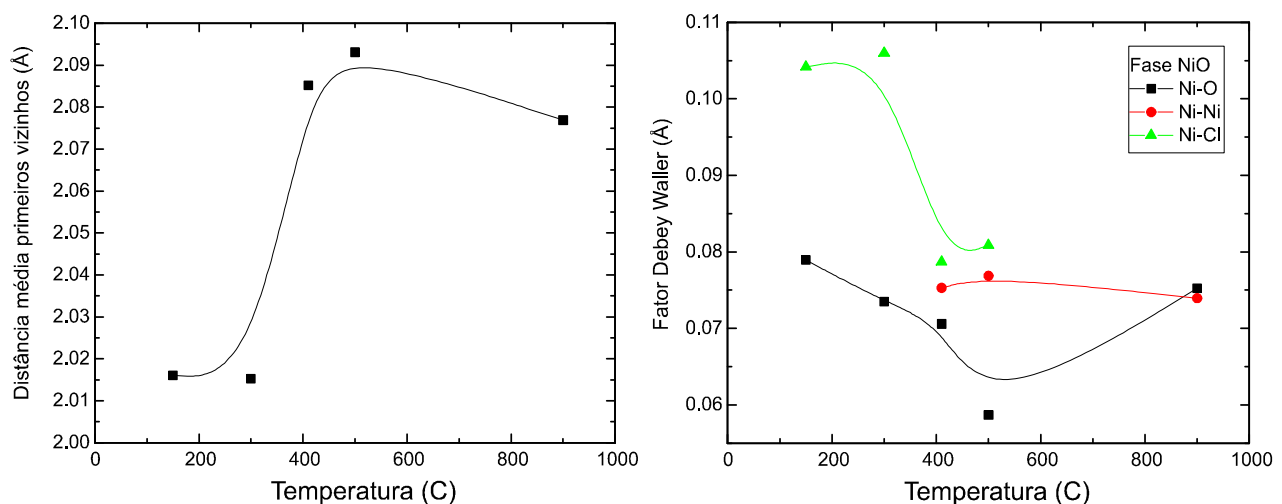

Figura 55.Resultados obtidos, fixando o número de coordenação do $\mathrm{O}, \mathrm{Cl}$ e $\mathrm{Ni}$ pelos valores obtidos mediante ajuste linear. Variando somente distância da primeira esfera de coordenação (figura à esquerda) e o fator de $D W$ e $E_{0}$ shift. Amostras com 9 moles de conteúdo de água inicial. Erro da ordem de $0,02 \AA$ para R e 0,01 $\AA$ para $\sigma$. 
Os valores da distância $N i-O$ obtidos pelos ajustes estão representados nas figuras 54 e 55. Resultados mais detalhados dos ajustes se encontram no apêndice A.

Pode-se observar que as distâncias do $N i$ aos primeiros vizinhos $O$ são mínimas em torno de $150^{\circ} \mathrm{C}$. Para $410^{\circ} \mathrm{C}$, essas distâncias são maiores e se mantêm constantes para temperaturas superiores (ver figuras 54 e 55). Pode-se observar que para $\left[\mathrm{H}_{2} \mathrm{O}\right]=$ $1 \mathrm{~mol}$ (figura 54) a distância mínima a $150^{\circ} \mathrm{C}$ é de $2,06 \AA$. Xerogéis tratados a maiores temperaturas apresentam uma distância $N i-O$ maior em torno de $2,10 \AA$.

Já para xerogéis com maiores quantias de água $(9 \mathrm{~mol})$, a distância $N i-O$ se reduz um pouco. Para $150^{\circ} \mathrm{C}$, essa distância é de $2,02 \AA$, ou seja, $0,04 \AA ̊$ menor que para os xerogéis com $1 \mathrm{~mol}$ de água inicial. Os xerogéis tratados a temperaturas superiores de $410^{\circ} \mathrm{C}$ com 9 moles de água a distância $N i-O$ é de aproximadamente $2,08 \AA$. Novamente em média $0,02 \AA$ menor que no caso das amostras contendo $1 \mathrm{~mol}$ de água.

O parâmetro de Debye-Waller $(\sigma)$ (ver figuras 54 e 55 lado direito) em relação à esfera de coordenação do $O$ em xerogéis com $\left[\mathrm{H}_{2} \mathrm{O}\right]=1 \mathrm{~mol}$ é em torno de $0,10 \AA$. Para xerogéis com $\left[\mathrm{H}_{2} \mathrm{O}\right]=9$ moles $\sigma$ é igual a $0,08 \AA$. Tanto as distâncias $\mathrm{Ni}-\mathrm{O}$ quanto os parâmetros $\sigma$ diminuem para conteúdos de água maiores. Este fato nos leva a crer que a adição de água no processo de obtenção dos xerogéis altera a esfera de hidratação em torno do $\mathrm{NiCl}_{2}$.

O parâmetro Debye-Waller $(\sigma)$ para a esfera de coordenação do $C l$ é maior a baixas temperaturas para $\left[\mathrm{H}_{2} \mathrm{O}\right]=$ 9moles. Os valores de $\sigma$ para $\left[\mathrm{H}_{2} \mathrm{O}\right]=1 \mathrm{e}$ 9 moles são iguais para amostras tratadas a 410 e $500^{\circ} \mathrm{C}$. Já parâmetro Debye-Waller $(\sigma)$ relacionado à coordenação $N i-N i$ independe da temperatura de tratamento térmico e do conteúdo de água.

O parâmetro Debye-Waller praticamente não depende do conteúdo de água e é independente da temperatura em amostras tratadas acima de $410^{\circ} \mathrm{C}$. Estes resultados sugerem que as transformações nos xerogéis tratados a altas temperaturas, sendo mais completas (incluindo até o início de um processo de sinterização) conduzem a estruturas cujo grau de perfeição não guarda memória de alguns detalhes das condições de preparação dos sóis precursores como no caso o conteúdo de água.

A figura 48 ilustra as estruturas das primeiras camadas ao redor dos átomos de $\mathrm{Ni}$ em cristais $\mathrm{NiCl}_{2} \cdot \mathrm{H}_{2} \mathrm{O}$ e $\mathrm{NiO}$. Note-se que a estrutura do $\mathrm{NiO}$ é muito mais compacta que a do $\mathrm{NiCl}_{2}$. Isto ajuda a entender qualitativamente, porque o parâmetro de Debye-Waller é menor em amostras tratadas a temperaturas maiores. 


\subsection{Terceira série de experiências (precursor $80 \%$ $\left.\mathrm{NiCl}_{2} \cdot 6 \mathrm{H}_{2} \mathrm{O}+20 \% \mathrm{Ti}\left[\mathrm{O}\left(\mathrm{CH}_{2}\right) \mathrm{CH}_{3}\right]_{4}\right)$}

Além dos estudos detalhados de xerogéis a base de $\mathrm{NiO}$ puro, descritos a pouco, foi pesquisado também um sistema no qual foram substituídos parcialmente os átomos de $N i$ por $T i$.

Neste estudo, procurou-se estabelecer o efeito da substituição de $N i$ por $T i$ na porosidade do material final produzido. As experiências de $S A X S$ foram realizadas com amostras nas quais se substituiu parte do alcóxido de $N i$ por $20 \%$ de $\mathrm{Ti}\left[\mathrm{O}\left(\mathrm{CH}_{2}\right) \mathrm{CH}_{3}\right]_{4}$.

Curvas de intensidade de espalhamento $I(q)$ e volume de poros $V(R)$ foram determinadas para diferentes xerogéis tratados a diferentes temperaturas contendo $\left[\mathrm{H}_{2} \mathrm{O}\right]=1,2,3,6$ e 9 moles $/\left(\mathrm{mol} 80 \% \mathrm{NiCl}_{2} \cdot 2 \mathrm{H}_{2} \mathrm{O}+20 \% \mathrm{Ti}\left[\mathrm{O}\left(\mathrm{CH}_{2}\right) \mathrm{CH}_{3}\right]_{4}\right) \mathrm{e}$ $0,1 \mathrm{~mol}$ de ácido acético. Os resultados estão representados nas figuras do apêndice $B$ (figuras $69 a$ até $73 a$ respectivamente). As conclusões a partir dos resultados experimentais obtidos, mostraram-se semelhantes com os da segunda série de medidas.

Para xerogéis tratados a baixa temperatura $\left(150\right.$ e $300^{\circ} C$ - figuras $74 a$ e $75 a$ respectivamente), pode-se observar novamente o comportamento não linear na região de $q$ dos gráficos $\log -\log$. A temperaturas maiores $\left(500,700\right.$ e $900^{\circ} C$ - figuras $76 a$ e $77 a$ e $78 a$ respectivamente), as funções $I(q)$ em escala $\log$ - $l o g$ têm uma dependência aproximadamente linear. Estes resultados indicam, como no caso anterior (segunda série de medidas), que a distribuição de tamanho de poros desses xerogéis depende da temperatura de tratamento térmico.

Uma diferença visível na porosidade entre os dois xerogéis estudados (com ou sem adição de $T i$ ) pode ser notada nas amostras tratadas a $500^{\circ} \mathrm{C}$. Enquanto que nas amostras sem a substituição parcial por $T i$, a presença de nanoporos é quase inexistente, naquelas onde houve substituição por $T i$ tem-se uma grande presença relativa de nanoporos, principalmente nas amostras com 1 e 2 moles de água (figura 76b).

Para amostras tratadas a $700^{\circ} \mathrm{C}$ (figura 77) e $900^{\circ} \mathrm{C}$ (figura 78), pode-se observar uma distribuição muito similar para todas concentrações de água. Nas amostras sem $T i$, observa-se pelo contrário um leve deslocamento para distribuições de poros menores, à medida que aumenta a concentração de água. 


\section{Discussão final e conclusão}

Os resultados da primeira série de experiências, em que se varia a concentração de ácido acético no processo de preparação dos xerogéis, permitem concluir que o ácido age como um catalisador na rota de obtenção do óxido e hidróxido de níquel. O ácido acético modifica o precursor metálico a um nível molecular e é capaz de controlar a reação de hidrólise e condensação durante a preparação do sol e transição sol - gel.

$\mathrm{O}$ aumento na temperatura de transformação do hidróxido de níquel em óxido de níquel para maiores concentrações de ácido acético, observado nas experiências de $D S C$, é coerente com a existência de uma maior quantidade de ligações níquel-ligantes. Por outro lado, xerogéis que têm sido preparados com maiores concentrações de ácido acético são mais densos e exibem uma porosidade menor. Estas propriedades também são conseqüentes do aumento do número de ligações níquel-ligantes.

Os resultados de $S A X S$ indicam que a porosidade fina existente nos géis secos e não tratados coalesce, quando a temperatura de tratamento térmico é maior que $\sim 400^{\circ} C$. Isso é devido à remoção da água e outras espécies orgânicas que promovem a redução da densidade do material. Tratamentos térmicos a maiores temperaturas $\left(800^{\circ} \mathrm{C}\right)$ levam a materiais óxidos mais densos com uma porosidade mais fina, indicando o início do processo de sinterização.

Os resultados da segunda série de experiências de $S A X S$ conduzem à conclusão de que a evaporação do solvente (butanol) e da água dos xerogéis durante o processo de secagem e consequiênte tratamento térmico a $150^{\circ} \mathrm{C}$ promove a formação de uma nanoporosidade fina com uma estreita distribuição de poros. $\mathrm{O}$ mesmo tipo de nanoporosidade também é observada em xerogéis tratados a $300^{\circ} \mathrm{C}$. As diferenças nas funções de distribuição de volume dos nanoporos das amostras tratadas a $150^{\circ} \mathrm{C}$ e aquelas tratadas a $300^{\circ} \mathrm{C}$ são devidas a diferentes condições para a formação e crescimento dos nanoporos como conseqüência de diferentes condições de evaporação de componentes orgânicos do xerogel. Uma pequena fração de volume de nanoporos coexiste com uma larga fração de volume ocupada pelos mesoporos nos xerogéis tratados a $500^{\circ} \mathrm{C}$. A maiores temperaturas de tratamento térmico $\left(700\right.$ e $\left.900^{\circ} \mathrm{C}\right)$ não foram observados nanoporos, ao invés disto verificada uma maior mesoporosidade.

As experiências de $X R D$ mostraram que a estrutura cristalográfica dos xerogéis tratados a $150^{\circ} \mathrm{C}$ consiste basicamente de cristais monoclínicos de $\mathrm{NiCl}_{2} \cdot 2 \mathrm{H}_{2} \mathrm{O}$. No outro extremo, ou seja para temperatura de tratamento térmico de $900^{\circ} \mathrm{C}$, observase uma fase cúbica pura de $\mathrm{NiO}$ que ocupa todo o volume da amostra. Xerogéis tratados a 410 e $500^{\circ} \mathrm{C}$ apresentam uma mistura binária de fases formada por cristais de 
$\mathrm{NiCl}_{2} \cdot 2 \mathrm{H}_{2} \mathrm{O}$ e de $\mathrm{NiO}$. Em xerogéis tratados a $500^{\circ} \mathrm{C}$, a fração dos cristais de $\mathrm{NiO}$ ocupa a maior parte do volume.

A diferença entre as estruturas cristalográficas correspondentes às amostras tratadas a diferentes temperaturas se correlaciona bem com as diferenças de nano e mesoporosidade. Em xerogéis tratados abaixo de $500^{\circ} \mathrm{C}$, tem-se os nanoporos embebidos numa matriz sólida consistindo de agregados de cristais de $\mathrm{NiCl}_{2} \cdot 2 \mathrm{H}_{2} \mathrm{O}$. Acima de $500^{\circ} \mathrm{C}$, surge uma mesoporosidade entre os pequenos grãos (sem poros) de $\mathrm{NiO}$. Isto implica que tratamentos térmicos a temperaturas acima de $500^{\circ} \mathrm{C}$ eliminam as espécies voláteis e promovem a formação de uma estrutura com pequenos cristais não porosos de $\mathrm{NiO}$ arranjados de tal forma que surgem mesoporos entre os mesmos. Nos xerogéis tratados a $500^{\circ} \mathrm{C}$, tem-se a formação de cristais de $\mathrm{NiO}$ apenas numa parte do volume total. Um esquema da estrutura final dos xerogéis tratados abaixo e acima de $500^{\circ} \mathrm{C}$ é ilustrada na figura 56 .

Diferenças na quantidade de água inicial adicionada à solução precursora no intervalo de 1 á 9 moles afetam as propriedades da nanoestrutura nas amostras tratadas a baixa temperatura $\left(150\right.$ e $\left.300^{\circ} \mathrm{C}\right)$, levando a uma distribuição de volume de poros mais estreita para 2 e 3 moles de água. Pelo contrário, a quantidade inicial de água não afeta significativamente a mesoporosidade em amostras tratadas a temperaturas maiores (700 e $900^{\circ} \mathrm{C}$ ).

Tanto os resultados das experiências de $X A N E S$ e as do modelo bifásico de $E X A F S$, quanto as de $X R D$ indicam a formação de um sistema bifásico composto por fase de $\mathrm{NiCl}_{2}$ e $\mathrm{NiO}$. Tratamentos a temperaturas superiores induzem a formação de uma maior fração de fase de $\mathrm{NiO}$.

Dos resultados de EXAFS se conclue que se deixando variar todos os parâmetros encontra-se um valor máximo para o valor de Debye-Waller em torno de $410^{\circ} \mathrm{C}$. Porém, sob esta suposição (não fixando nenhum parâmetro), os números de coordenação resultaram estruturalmente inaceitáveis e se afastaram muito daqueles obtidos pelo modelo bifásico. Por outro lado, mantendo-se fixo o número de coordenação de acordo com o modelo bifásico, o fator de Debye-Waller diminue constantemente. Isto sugere que a temperaturas mais baixas de tratamento térmico, os xerogéis possuem uma estrutura mais aberta (que é o caso do $\mathrm{NiCl}_{2}$ ), enquanto á temperaturas maiores, forma-se uma estrutura mais compacta $(\mathrm{NiO})$.

O modelo bifásico é o correto, já que é coerente com os resultados de várias técnicas experimentais ( $X R D, X A N E S$ e $E X A F S)$. $\mathrm{O}$ fato de obter valores incorretos dos parâmetros estruturais, quando todos são permitidos variar, sugere que se deve tomar em geral certos cuidados na análise de espectros de EXAFS. 


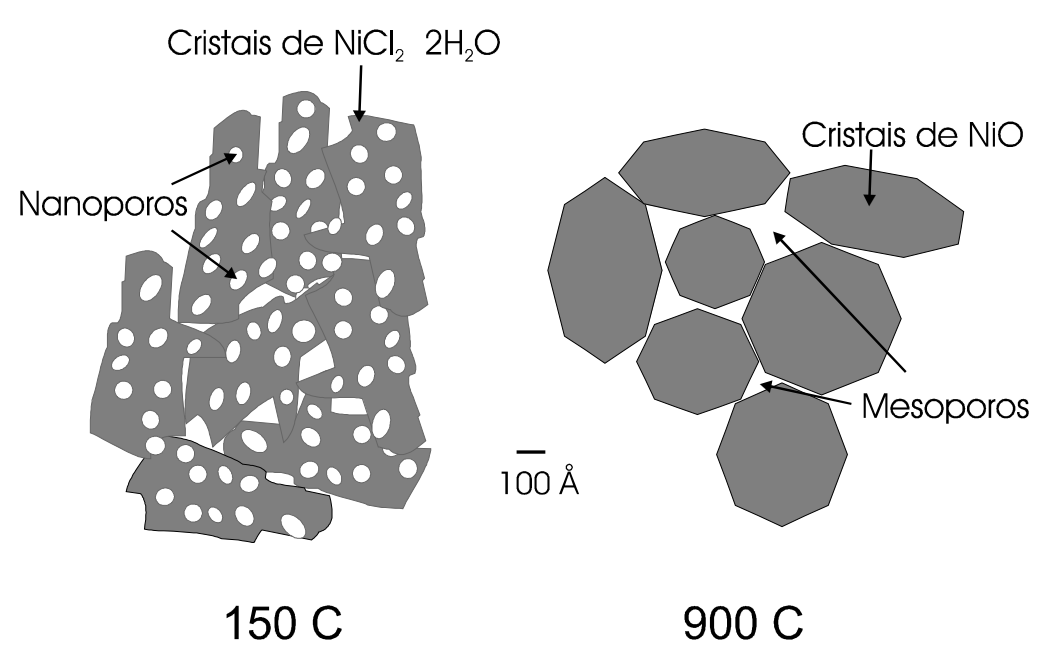

Figura 56.Representação esquemática da estrutura dos xerogéis estudados à baixa $(150 C)$ e alta $(900 C)$ temperatura. 
Para xerogéis com baixa quantidade de água, os átomos de $O$ se encontram mais afastados que naqueles com alto conteúdo tratados a baixas temperaturas. Isto sugere que a quantidade de água altera a esfera de hidratação do $\mathrm{NiCl}_{2}$ nesses xerogéis.

Deve-se resaltar que nas análises de $D T A$ realizadas, os xerogéis foram aquecidos continuamente a uma taxa constante, enquanto que no caso dos estudos de $X R D$, $X A F S$ e $S A X S$ as diferentes amostras foram mantidas a diferentes temperaturas constantes (entre 150 à $900^{\circ} \mathrm{C}$ ) durante 1 hora após a secagem. A difusão nas fases líquida e sólida dos xerogéis e a evaporação dos elementos voláteis durante o tratamento térmico deve ser bastante diferente, quando são aquecidos a velocidade $\left(\frac{d T}{d t}\right)$ constante do que quando são aquecidos bruscamente desde a temperatura ambiente até a de tratamento isotérmico. Portanto comparações de $X R D, S A X S$ e $X A F S$ com DTA podem fornecer conclusões apenas qualitativas. Isto explica por exemplo, porque a análise de $D T A$ indica que a transformação já se completou aos $310^{\circ} C$, enquanto que os padrões de difração de raios $X$ de xerogéis tratados isotermicamente por uma hora a $300^{\circ} \mathrm{C}$ ainda indicam a presença de uma quantidade significativa de $\mathrm{NiCl}_{2}$.

Sugere-se como trabalho futuro a realização de experiências, estudando os efeitos da porosidade, ordem local e a longa distância e os efeitos térmicos dos xerogéis tratando-os a temperaturas crescentes, variando a velocidade de tratamento térmico $(5,10,30 \mathrm{C} / \mathrm{min})$. Seria particularmente interessante determinar os espectros de $X R D$, $S A X S, E X A F S$ e $X A N E S$ in situ, durante o aquecimento dos xerogéis a velocidades $\left(\frac{d T}{d t}\right)$ iguais às utilizadas em experiências de $T G A$ e DTA. Estas experiências forneceriam informações mais confiáveis, já que permitiriam comparações quantitativas mais precisas entre os resultados das diferentes técnicas. 


\section{Referências}

\section{Teses}

- Tese de doutorado de Alain Michalowicz, Mèthodes et programmes d'analyse des spectres d'absorption des rayons $\mathrm{X}(E X A F S)$. Applications l'ètude de l'orde local et du dèsordre cristallin dans les matriaux inorganiques, Universite Paris Val de Marne (1990)

http : //www.lure.u-psud.fr/sections/chimie/xafsmac/xaf smac.htm

- Tese de doutorado de Matthew G. Newville, Local Thermodynamic Measurements of Dilute Binary Alloys Using $X A F S$, University of Washington (1995)

- Tese de doutorado de Andrei V. Sapelkin entitulada Structure of and Phase Transformations in Bulk Amorphous $(G a S b)_{1-x}\left(G e_{2}\right)_{x}$, Moscow Institute of Physics and Technology (1997)

http : //neuron.dmu.ac.uk/〜asn/Miscellaneous/thesis/

- Tese de doutorado de Bruce Ravel, Ferroelectric Phase Transitions in Oxide Perovskites Studied by $X A F S$, University of Washington (1997).

- Tese de doutorado de Daniel Haskel, Local Structural Studies of Oriented High Temperature Superconducting Cuprates by Polarized XAFS Spectroscopy, University of Washington (1998)

- Dissertação de mestrado de Júlio Griginski Cezar, Estudo por EXAFS de nanopartículas de cobalto imersas em uma matriz de cobre, LNLS (1998).

\section{Internet}

- Homepage do autor: http: //pagina.de/hannes

- The International XAFS Society: http : //ixs.iit.edu/

\section{Livros}

- Anais do Encontro. Técnicas e Aplicações da Radiação Sincrotron. Rio de Janeiro, $C B P F$, Área de Informação Científica, páginas 109-126 (1983).

- Brinker C.J. and Scherrer G.W. Sol - gel Science. Academic Press. San Diego (1990).

- Eisberg, R., Resnick, R. Física Quântica - Átomos, Moléculas, Sólidos, Núcleos e Partículas, - Editora Campus, Rio de Janeiro (1988).

- Feigin L. A. and Svergun D. I. Structure Analysis by Small-Angle $X-$ 
Ray and Neutron Scattering. Plenum Press. New York (1987).

- Glatter O. and Kratky O. Small Angle $X$ - ray Scattering. Academic Press. New York (1982).

- Guinier A. and Fournet G. Small-Angle Scattering of $X$ - rays. John Wiley \& Sons. New York (1955).

- Nakamoto K. Infrared and Raman Spectra of Inorganic Coordination Compounds, $3^{\text {rd }}$ ed. John Wiley. New York (1997).

- Schmidt H. Structure \& Bonding. Springer-Verlag. Berlin (1990).

\section{Artigos}

Bernardes, L. A. Projeto de estação experimental para espalhamento de raios $X$ a baixos ângulos usando radiação síncrotron. Dissertação de mestrado (UNICAMP), Campinas, São Paulo (1995).

Bordwehr R. S. A History of X-ray absorption fine structure. Annales de Physique 14: (4) 377 (1989).

Chaibi J., Henry M., Zarrouk H., Gharbi N. and Livage J. Structural characterization of hybrid materials obtained from zirconium N-propoxide and 1,2-ethanediol. J. Cryst. Solids. 170: (1) 1-10 (1994).

DeLeon J. M., Rehr J. J., Zabinsky S. I., Albers R. C. Ab-initio curved-wave X-rayabsorption fine-structure. Physical Review B 44: (9) 4146-4156 (1991).

Deacon G. B. and Phillips R. J. Relationships between the carbon-oxygen stretching frequencies of carboxylate complexes and the type of carboxylate coordination. Coord. Chem. Rev. 33: (3) 227-250 (1980).

Doeuff S., Henry M., Sanchez C. and Livage J. Hydrolysis of titanium alkoxides modification of the molecular precursor by acetic-acid. J. Non-Cryst. Solids. 89: (1-2) 206-216 (1987).

Fantini M. C. A., Bezerra G. H., Carvalho C. R. C. and Gorenstein A. Electrochromic properties and temperature dependence of chemically deposited $N i(O H)_{x}$ thin films. SPIE Proceedings 1536: 81-92 (1991).

Figlarz M., Gérand B., Delahaye-Vidal A., Dumont B., Harb F. and Coucou A. Topotaxy, nucleation and growth. Solid State Ionics. 43: 143-170 (1990).

Fischer, H. Relatório de atividades desenvolvidas durante o estágio da IX escola de verão no Laboratório Nacional de Luz Síncrotron ( $L N L S)$, Campinas, SP (1997). 
Fischer H., Sharma P.K. and Craievich A.F. - Porous structure of NiO based xerogels. Accepted. Journal of Applied Crystallography (1999).

Frenkel A. I., Stern E. A., Qian M. and Newville M. Multiple-scattering X-ray-absorption fine-structure analysis and thermal-expansion of alkali-halides. Physical Review B 48: (17) 12449-12458 (1993).

Glatter O. New method for evaluation of small-angle scattering data. J.Appl.Cryst. 10: 415-421 (1977).

Herman Winick, Dingchang Xian, Ming-ha Ye and Tao Huang, Applications of Synchrotron Radiation, Proceedings of the CCAST (World Laboratory), China (1988).

Kellermann, G., Vicentin, F. C., Tamura, E., Rocha, M., Tolentino, H., Barbosa, A. F., Craievich, A. F. and Torriani, I. J. The small-angle X-ray scattering beamline of the Brazilian Synchrotron Light Laboratory. J. Appl. Cryst. 30: 880-883 (1997).

Kronig R. L. Zur Theorie der Feinstruktur in den Röntgen-absorptionsspektren. ZS. $f$. Phys. 70: 317-323 (1931).

Kronig R. L. Zur Theorie der Feinstruktur in den Röntgen-absorptionsspektren. III. ZS. f. Phys. 75: 468-475 (1932).

Kumagai M. and Messing G. L. Enhanced densification of boehmite sol - gels by alpha-alumina seeding. J. Am. Ceram. Soc. 67: 11, C230-C231 (1984).

Lampert C. M., Granqvist C. G., editors; Potter R. F., general editor - Large-Area Chromogenics: Materials and Devices for Transmittance Control: 22-24 September, Hamburg, Federal Republic of Germany (1988).

Livage J., Henry M. and Sanchez C. Sol - gel chemistry of transition-metal oxides. Prog. Solid State Chem. 18: (4) 259-341 (1988).

Oday P. A., Rehr J. J., Zabinsky S. I. And Brown G. E. Extended X-ray-absorption finestructure (EXAFS) analysis of disorder and multiple-scattering in complex crystalline solid. J. Am.Chem. Soc. 116: (7) 2938-2949 (1994).

Orignac X., Vasconcelos H. C. and Almeida R. M. Structural study of $\mathrm{SiO}_{2}-\mathrm{TiO}_{2}$ sol - gel films by $X-$ ray absorption and photoemission spectroscopies. J. NonCryst. Solids 217: (2-3) 155-161 (1997).

Page R. A. Applications of Small-Angle Scattering in Ceramic Research, J. Appl. Cryst. 21: 798-804 (1988).

Ramamurthi S. D., Xu Z. K. and Payne D. A. Nanometer-sized $\mathrm{ZrO}_{2}$ particles prepared by a sol-emulsion-gel method. J. Am. Ceram. Soc. 73: (9) 2760-2763 (1990). 
Rehr J. J., Stern E. A., Martin R. L. and Da Vidson E. R. Extended X-ray-absorption fine-structure amplitudes - wavefunction relaxation and chemical effects. Physical Review B 17: (2) 560-565 (1978).

Rehr J. J., Albers R.C., Natoli C. R. and Stern E. A. New high-energy approximation for X-ray-absorption near-edge structure. Physical Review B 34: (6) 4350-4353 (1986).

Rehr J. J. and Albers R.C. Scattering-matrix formulation of curved-wave multiplescattering theory - application to x-ray-absorption fine-structure. Physical Review B 41: (12) 8139-8149 (1990).

Rehr J. J. Recent developments in multiple-scattering calculations of XAFS and XANES. Japanese Journal of Applied Physics 32: 8-12, Suppl. 32-2 (1993).

Ressler T. WinXAS: A new software package not only for the analysis of energydispersive XAS data. Journal de Physique IV 7: (C2) 269-270 (1997).

Sanchez C., Livage J., Henry M. and Babboneau F. Chemical Modification of Alkoxide Precursors. J. Non-Cryst. Solids. 100: (1-3) 65-76 (1988).

Sayers D. E., Stern E. A. and Lytle F. W. New Technique for Investigating Noncrystalline Structures: Fourier Analysis of the Extended X-Ray - Absorption Fine Structure. Phyical Review Letters 27: (18) 1204-1207 (1971).

Schmidt P. W. Interpretation of small-angle scattering curves proportional to a negative power of the scattering vector. J. Appl. Cryst. 15: 567 (1982).

Semenyuk A. V. and Svergun D. GNOM, a program package for small-angle scattering data-processing. J. Appl. Cryst. 24: 537-540 (1991).

Sharma P. K. and Ramanan A. The Role of N,N-dimethylaniline in the formation of titania gel monolith by sol - gel method. J. Mat. Sci. 31: (3) 773-777 (1996).

Sharma P. K., Fantini M. C. A. and Gorenstein A. Synthesis, characterization and electrochromic properties of $\mathrm{Ni}(\mathrm{OH})_{2}$ thin films derived from sol - gel method. Solid State Ionics. 115: 457-463 (1998).

Sharma P.K., Fischer H. and Craievich A.F. Chemical and structural properties of nickel hydroxide xerogels obtained by the sol-gel procedure in the presence of acetic acid. Journal of the American Ceramic Society 82: (4) 1020-1024 (1999).

Sharma P.K., Fantini M.C.A., Fischer H., Craievich A.F. and Gorenstein A.- Factors influencing the electrochromic properties of nickel oxide thin films derived from sol-gel method by dip coating. Mater. Res. Soc. Symp. Proc. 547: 351-356 (1999). 
Stern E. A. Theory of extended X-ray-absorption fine-structure. Physical Review B 10: (8) 3027-3037 (1974).

Stern E. A., Sayers D. E. and Lytle F. W. Extended X-ray-absorption fine-structure technique. III. determination of physical parameters. Physical Review B 11: (12) 4836-4846 (1975).

Strawbridge, I., Craievich, A. F. and James, P. F. The effect of the $\mathrm{H}_{2} \mathrm{O}$ TEOS ratio on the structure of gels derived by the acid-catalyzed hydrolysis of tetraethoxysilane. J. Non-Cryst. Solids. 72: 139-157 (1985).

Svergun D. I., Semenyuk A. V. and Feigin L. A. Small-angle-scattering-data treatment by the regularization method Acta Cryst. A44: 244-250 (1988).

Svergun D. I. Determination of the regularization parameter in indirect-transform methods using perceptual criteria. J. Appl. Cryst. 25: 495-503 (1992).

Svergun D. I. and Pedersen J. S. Propagating errors in small-angle scattering data treatment. J. Appl. Cryst. 27: 241-248 (1994).

Teo B. K. and Lee P. A. Abinitio calculations of amplitude and phase functions for Extended X-Ray Absorption Fine-Structure Spectroscopy. J. Am. Chem. Soc. 101: (11) 2815-2832 (1979).

Vaarkamp M, Dring I, Oldman R. J., Stern E. A. and Koningsberger D. C. Comparison of theoretical methods for the calculation of extended $X-$ ray-absorption finestructure. Physical Review B 50: (11) 7872-7883 (1994).

Wiedemann H. J. Electromagnetic Radiation from Relativistic Electron Beams, notas de aula da School on Synchrotron Radiation, Trieste, Itália (1999) 


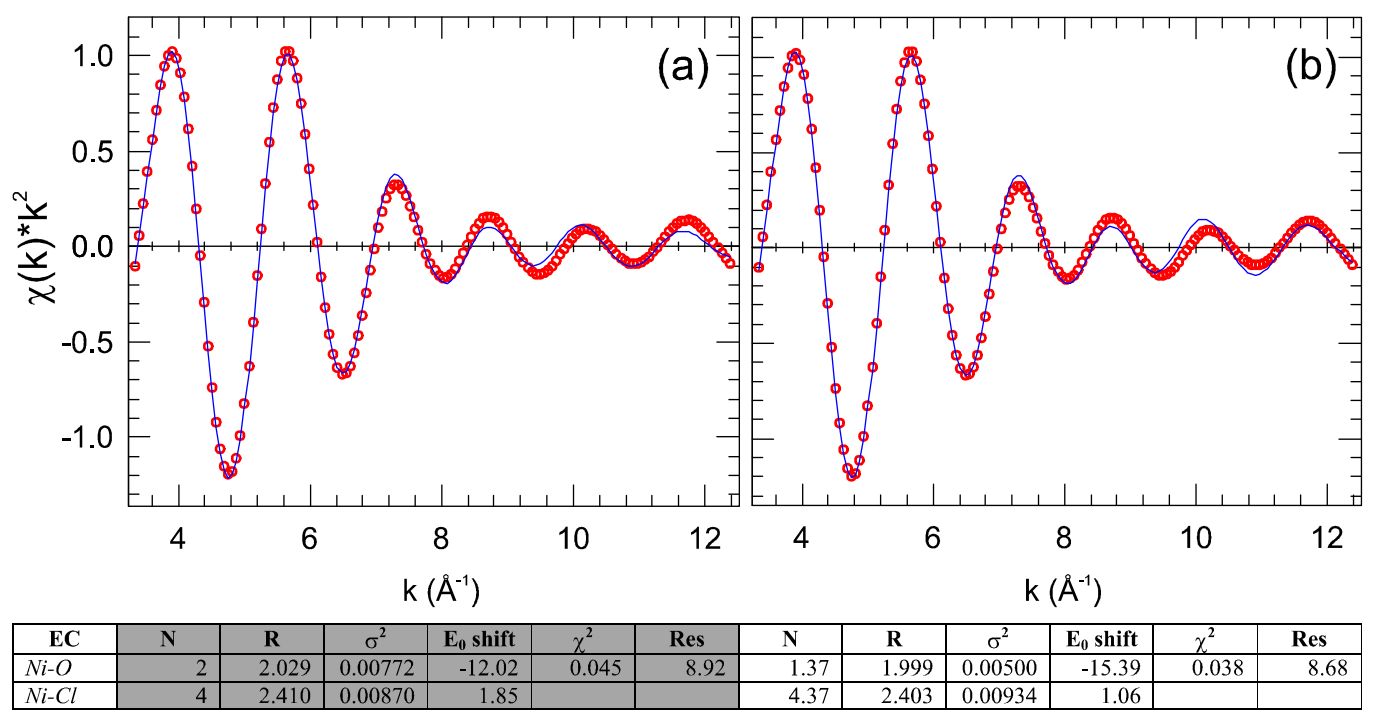

\begin{tabular}{|c|c|c|c}
\hline $\mathrm{E}_{0}=8343.76 \mathrm{eV}$ & $\mathrm{E}_{\mathrm{s}}=0.89$ & $\Delta \mathrm{E}=8343.94 \rightarrow 9001.91 \mathrm{eV}$ & $\Delta \mathrm{k}=0.20 \rightarrow 13.10 \AA^{-1}$
\end{tabular}

Figura 57. Amostra tratada á $150^{\circ} \mathrm{C}$. Ajuste teórico por $F E F F$ (linha azul) aos dados experimentais correspondentes ao xerogel com $\left[\mathrm{H}_{2} \mathrm{O}\right]=1 \mathrm{~mol}$ para as contribuições $\mathrm{Ni}-\mathrm{O}$ e $\mathrm{Ni}-\mathrm{Cl}$. (a) Parâmetros fixos: números de coordenação e $R_{N i-C l}(b)$ todos os parâmetros foram ajustados por mínimos quadrados.

\section{Appendix A \\ Apêndice A: Resultados dos ajuste dos dados de $E X A F S$ por $F E F F$ utilizando o programa WinXAS}

Em cada figura que se segue, está ilustrado o gráfico da transformada de Fourier das esferas de coordenação correspondentes aos átomos de $\mathrm{O}, \mathrm{Cl}$ e $\mathrm{Ni}$ (círculos), e seu correspondente ajuste (linha contínua). Em cada figura, encontram-se dois gráficos representados por $(a)$ e $(b)$. Na verdade são os mesmos, o que muda foram os parâmetros que foram permitidos variar para realizar o ajuste. No caso $(a)$ foi permitido variar somente a distância entre os átomos do $N i-O(\AA), \sigma^{2}\left(\AA^{2}\right)$ e $E_{0}$ shift, enquanto que no caso $(b)$ liberou-se todos os parâmetros.

A tabela abaixo de cada figura indica os parâmetros usados na obtenção das oscilações de $E X A F S$ (ver por exemplo figura 51) pelo programa $A U T O B K$, onde $E_{0}$ é o valor da borda de absorção, $E_{s}$ (energy step) é $\Delta \mu x, \Delta E$ é a região em energia usada no ajuste e $\Delta k$ o intervalo de $k$ obtido. 


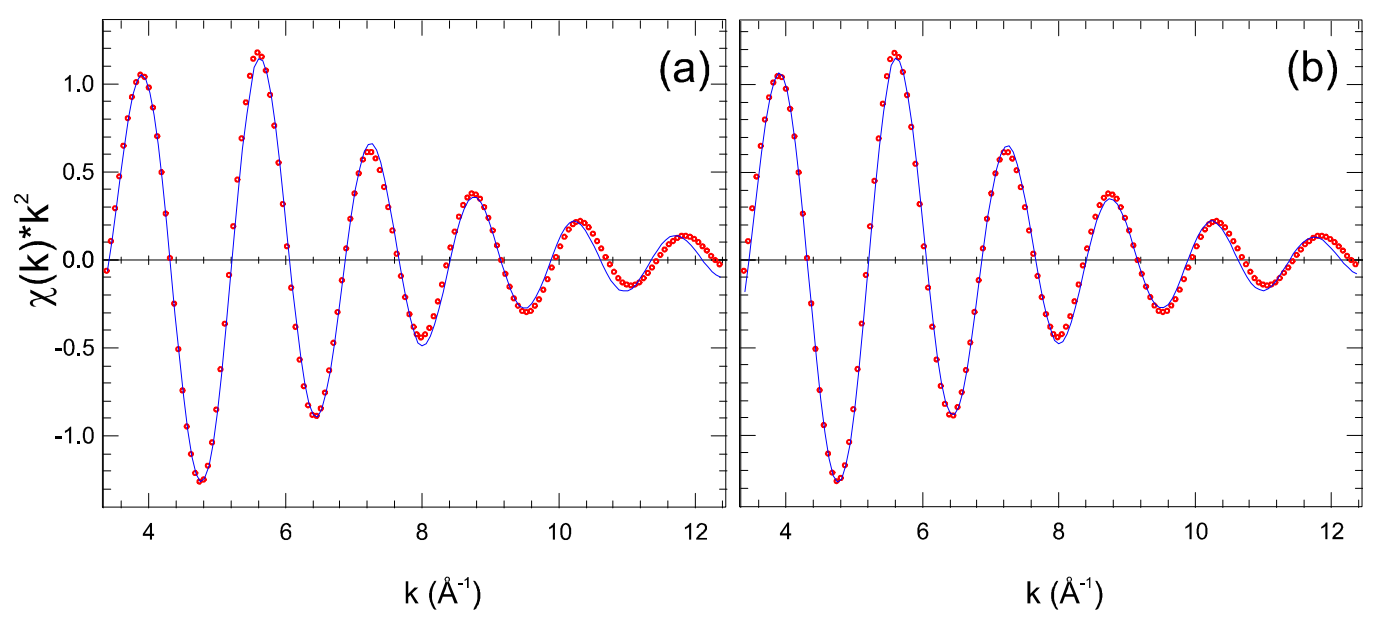

\begin{tabular}{|l|r|r|r|r|r|r|r|r|r|r|r|r|}
\hline EC & \multicolumn{1}{|c|}{$\mathbf{N}$} & \multicolumn{1}{c}{$\mathbf{R}$} & $\sigma^{2}$ & $\mathbf{E}_{0}$ shift & $\chi^{2}$ & \multicolumn{1}{c|}{ Res } & N & \multicolumn{1}{c|}{$\mathbf{R}$} & $\sigma^{2}$ & $\mathbf{E}_{0}$ shift & $\chi^{2}$ & \multicolumn{1}{c|}{ Res } \\
\hline $\mathrm{Ni}-\mathrm{O}$ & 2 & 2.054 & 0.01010 & -11.26 & 0.053 & 8.57 & 1.30 & 2.008 & 0.00849 & -16.96 & 0.043 & 7.75 \\
\hline $\mathrm{Ni}-\mathrm{Cl}$ & 4 & 2.410 & 0.00676 & 1.94 & & & 4.45 & 2.402 & 0.00760 & 0.97 & & \\
\hline
\end{tabular}

$\mathrm{E}_{0}=8342.44 \mathrm{eV}$

$\mathrm{E}_{\mathrm{s}}=1.35$

$\Delta \mathrm{E}=8342.23 \rightarrow 9001.91 \mathrm{eV}$

$\Delta \mathrm{k}=0.00 \rightarrow 13.15 \AA^{-1}$

Figura 58.Amostra tratada á $300^{\circ} \mathrm{C}$. Ajuste teórico por $F E F F$ (linha azul) aos dados experimentais correspondentes ao xerogel com $\left[\mathrm{H}_{2} \mathrm{O}\right]=1 \mathrm{~mol}$ para as contribuições $\mathrm{Ni}-\mathrm{O}$ e $\mathrm{Ni}-\mathrm{Cl}$. (a) Parâmetros fixos: números de coordenação e $R_{N i-C l}(b)$ todos os parâmetros foram ajustados por mínimos quadrados.

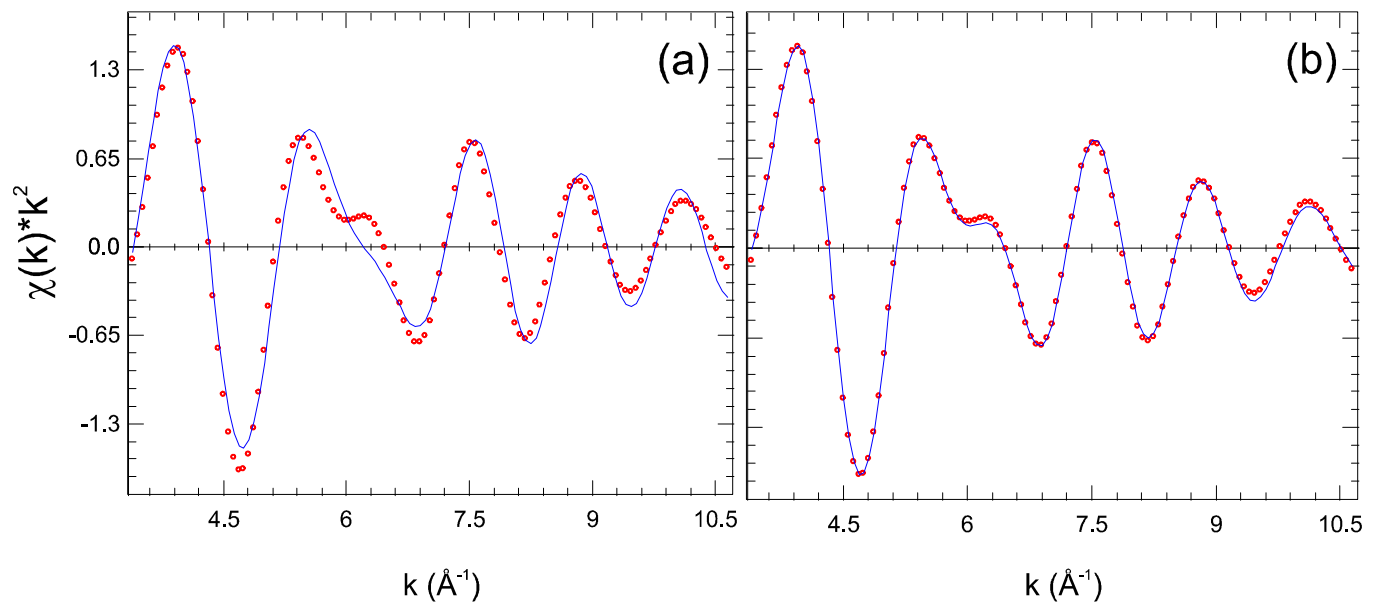

\begin{tabular}{|l|r|r|r|r|r|r|r|r|r|r|r|r|}
\hline EC & $\mathbf{N}$ & \multicolumn{1}{c|}{$\mathbf{R}$} & $\sigma^{2}$ & $\mathbf{E}_{0}$ shift & $\chi^{2}$ & \multicolumn{1}{c|}{ Res } & \multicolumn{1}{c|}{$\mathbf{N}$} & \multicolumn{1}{c|}{$\mathbf{R}$} & $\sigma^{2}$ & $\mathbf{E}_{0}$ shift & $\chi^{2}$ & Res \\
\hline $\mathrm{Ni}-\mathrm{O}$ & 3 & 2.070 & 0.00494 & -3.58 & 0.842 & 22.47 & 4.07 & 2.052 & 0.00968 & -6.06 & 0.017 & 3.71 \\
\hline $\mathrm{Ni}-\mathrm{Cl}$ & 3 & 2.410 & 0.00717 & 2.73 & & & 2.58 & 2.425 & 0.00436 & 6.75 & & \\
\hline $\mathrm{Ni}-\mathrm{Ni}$ & 3 & 2.930 & 0.00524 & -0.37 & & & 11.71 & 2.944 & 0.01768 & 1.27 & & \\
\hline
\end{tabular}

\begin{tabular}{c|c|c|c}
$\mathrm{E}_{0}=8341.84 \mathrm{eV}$ & $\mathrm{E}_{\mathrm{s}}=0.72$ & $\Delta \mathrm{E}=8339.84 \rightarrow 8831.93 \mathrm{eV}$ & $\Delta \mathrm{k}=0.00 \rightarrow 11.30 \AA^{-1}$
\end{tabular}

Figura 59. Amostra tratada á $410^{\circ} \mathrm{C}$. Ajuste teórico por $F E F F$ (linha azul) aos dados experimentais correspondentes ao xerogel com $\left[\mathrm{H}_{2} \mathrm{O}\right]=1 \mathrm{~mol}$ para as contribuições $\mathrm{Ni}-\mathrm{O}, \mathrm{Ni}-\mathrm{Cl}$ e $\mathrm{Ni}-\mathrm{Ni}$. (a) Parâmetros fixos: números de coordenação $R_{N i-C l} \mathrm{e}$ $R_{N i-N i}(b)$ todos os parâmetros foram ajustados por mínimos quadrados. 


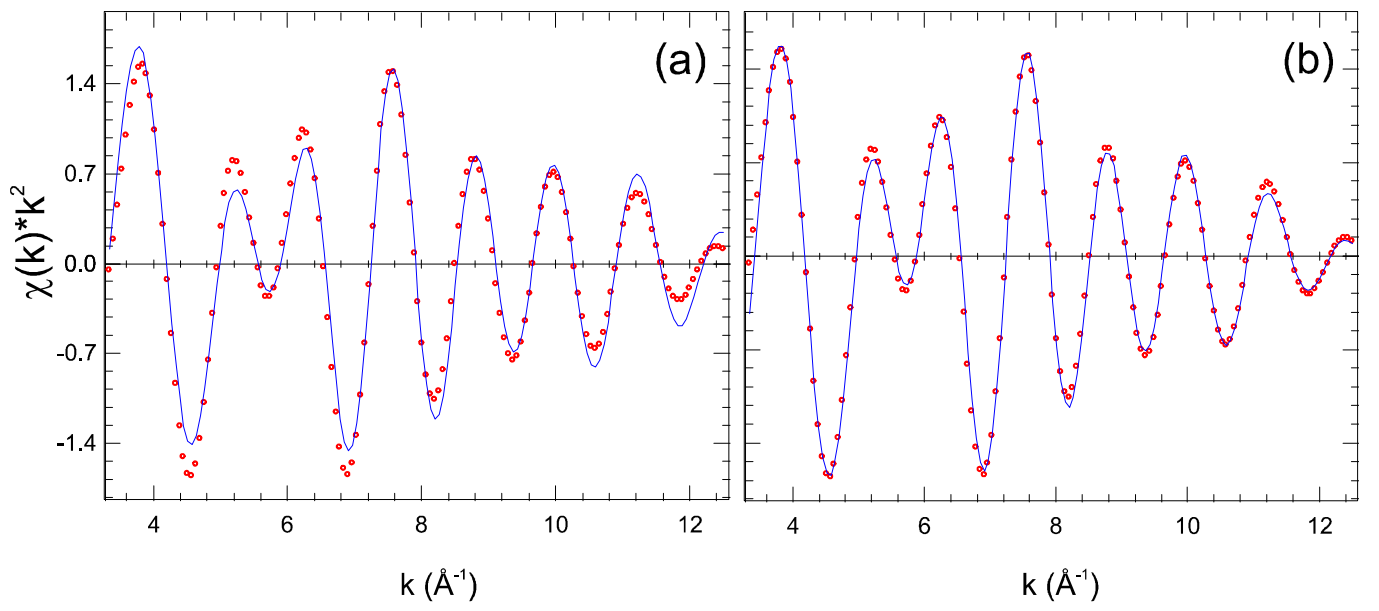

\begin{tabular}{|l|r|r|r|r|r|r|r|r|r|r|r|r|}
\hline EC & \multicolumn{1}{|c|}{$\mathbf{N}$} & \multicolumn{1}{|c|}{$\mathbf{R}$} & $\sigma^{2}$ & $\mathbf{E}_{0}$ shift & $\chi^{2}$ & \multicolumn{1}{c|}{ Res } & \multicolumn{1}{c|}{$\mathbf{N}$} & \multicolumn{1}{c|}{$\mathbf{R}$} & $\sigma^{2}$ & $\mathbf{E}_{0}$ shift & $\chi^{2}$ & \multicolumn{1}{c|}{ Res } \\
\hline$N i-O$ & 4.4 & 2.104 & 0.00310 & -5.00 & 2.083 & 17.66 & 13.58 & 2.094 & 0.00794 & 5.02 & 0.216 & 7.00 \\
\hline$N i-C l$ & 1.6 & 2.410 & 0.00606 & -5.78 & & & 7.86 & 2.341 & 0.01104 & -18.90 & & \\
\hline$N i-N i$ & 7.2 & 2.930 & 0.00310 & 1.87 & & & 9.94 & 2.933 & 0.00799 & -5.04 & & \\
\hline
\end{tabular}

\begin{tabular}{|l|c|c|c|}
$\mathrm{E}_{0}=8344.84 \mathrm{eV}$ & $\mathrm{E}_{\mathrm{s}}=0.51$ & $\Delta \mathrm{E}=8345.99 \rightarrow 9001.91 \mathrm{eV}$ & $\Delta \mathrm{k}=0.50 \rightarrow 13.10 \AA^{-1}$
\end{tabular}

Figura 60.Amostra tratada á $500^{\circ} \mathrm{C}$. Ajuste teórico por $F E F F$ (linha azul) aos dados experimentais correspondentes ao xerogel com $\left[\mathrm{H}_{2} \mathrm{O}\right]=1 \mathrm{~mol}$ para as contribuições $\mathrm{Ni}-\mathrm{O}, \mathrm{Ni}-\mathrm{Cl}$ e $\mathrm{Ni}-\mathrm{Ni}$. (a) Parâmetros fixos: números de coordenação $R_{N i-C l} \mathrm{e}$ $R_{N i-N i}(b)$ todos os parâmetros foram ajustados por mínimos quadrados.

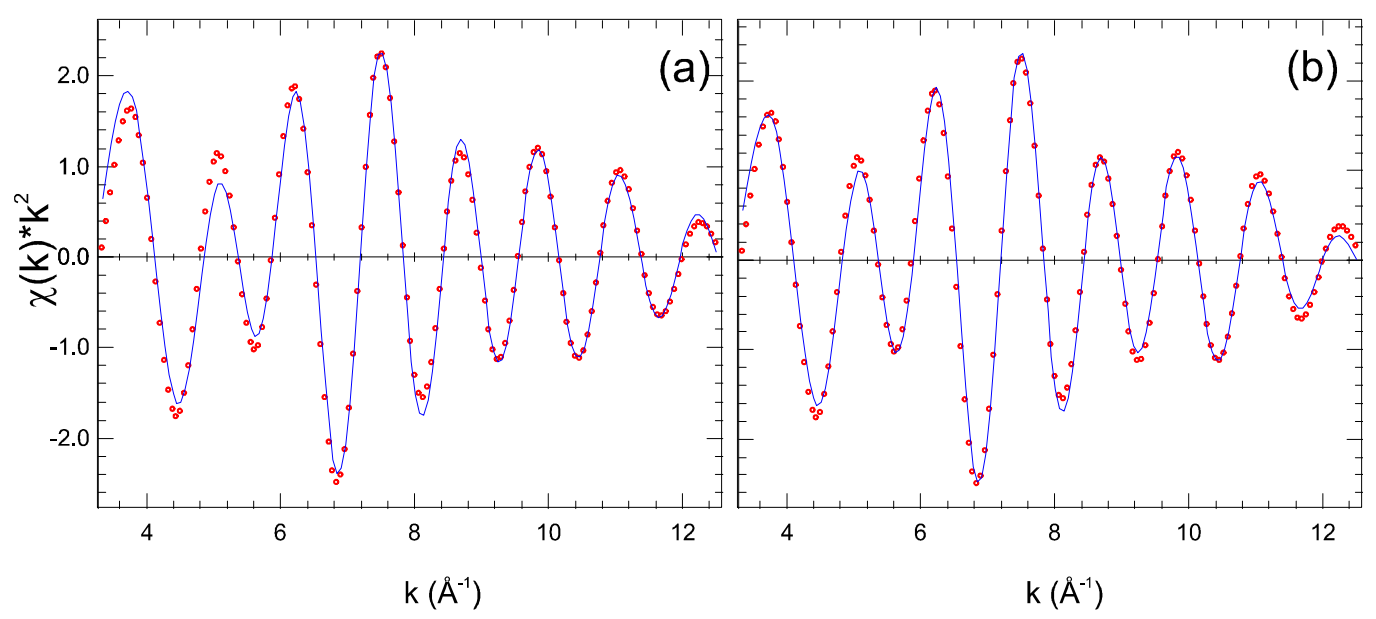

\begin{tabular}{|l|r|r|r|r|r|r|r|r|r|r|r|r|}
\hline \multicolumn{1}{|c|}{ EC } & \multicolumn{1}{|c|}{$\mathbf{N}$} & \multicolumn{1}{c|}{$\mathbf{R}$} & $\sigma^{2}$ & $\mathbf{E}_{0}$ shift & $\chi^{2}$ & \multicolumn{1}{c|}{ Res } & N & \multicolumn{1}{c|}{$\mathbf{R}$} & $\sigma^{2}$ & $\mathbf{E}_{0}$ shift & $\chi^{2}$ & Res \\
\hline $\mathrm{Ni}-\mathrm{O}$ & 6.0 & 2.101 & 0.00698 & -1.88 & 2.817 & 12.02 & 4.23 & 2.091 & 0.00289 & -2.83 & 1.384 & 9.78 \\
\hline $\mathrm{Ni}-\mathrm{Ni}$ & 12.0 & 2.970 & 0.00594 & -3.63 & & & 13.81 & 2.973 & 0.00710 & -3.11 & & \\
\hline
\end{tabular}

\begin{tabular}{|c|c|c|c|}
$\mathrm{E}_{0}=8346.14 \mathrm{eV}$ & $\mathrm{E}_{\mathrm{s}}=1.30$ & $\Delta \mathrm{E}=8345.99 \rightarrow 9001.91 \mathrm{eV}$ & $\Delta \mathrm{k}=0.00 \rightarrow 13.10 \AA^{-1}$ \\
\hline
\end{tabular}

Figura 61.Amostra tratada á $900^{\circ} \mathrm{C}$. Ajuste teórico por $F E F F$ (linha azul) aos dados experimentais correspondentes ao xerogel com $\left[\mathrm{H}_{2} \mathrm{O}\right]=1 \mathrm{~mol}$ para as contribuições $N i-O$ e $N i-N i$. (a) Parâmetros fixos: números de coordenação e $R_{N i-N i}(b)$ todos os parâmetros foram ajustados por mínimos quadrados. 

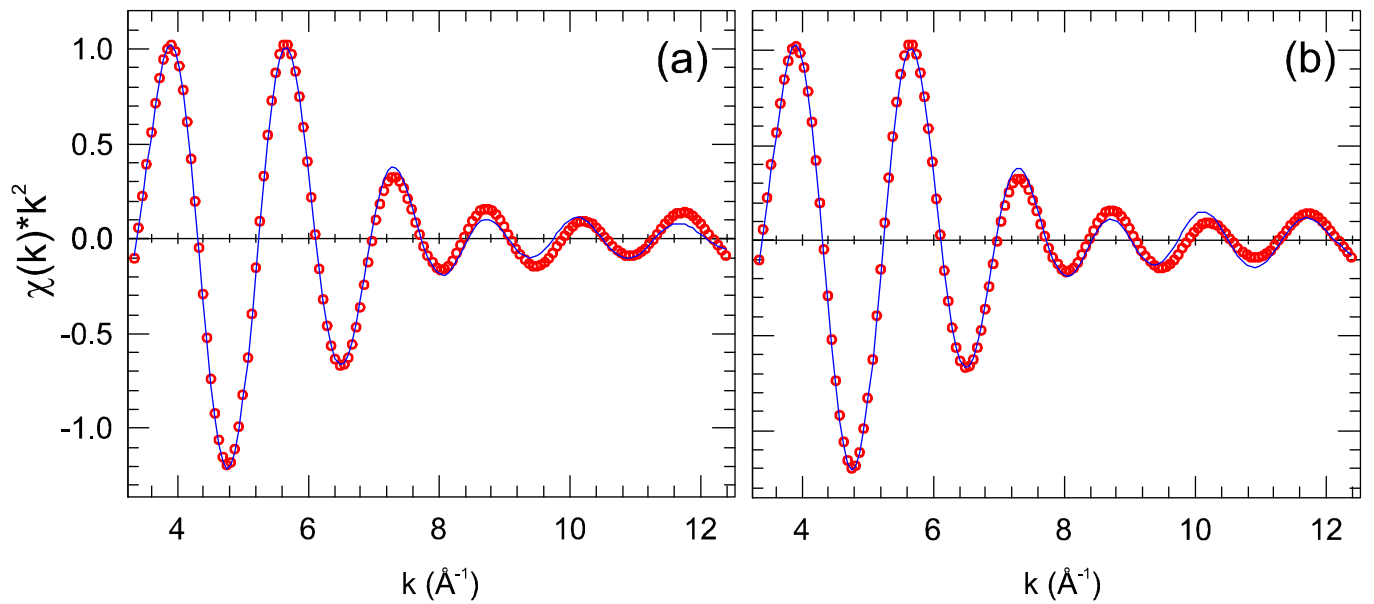

\begin{tabular}{|c|c|c|c|c|c|c|c|c|c|c|c|c|}
\hline EC & $\mathbf{N}$ & $\mathbf{R}$ & $\sigma^{2}$ & $E_{0}$ shift & $\chi^{2}$ & Res & $\mathbf{N}$ & $\mathbf{R}$ & $\sigma^{2}$ & $\mathbf{E}_{0}$ shift & $\chi^{2}$ & Res \\
\hline $\mathrm{Ni}-\mathrm{O}$ & 2 & 2.016 & 0.00623 & -12.34 & 0.033 & 9.44 & 1.57 & 2.003 & 0.00367 & -13.23 & 0.029 & 9.48 \\
\hline $\mathrm{Ni}-\mathrm{Cl}$ & 4 & 2.410 & 0.01085 & 2.42 & & & 3.89 & 2.406 & 0.01002 & 1.83 & & \\
\hline
\end{tabular}

\begin{tabular}{c|c|c}
$\mathrm{E}_{0}=8344.36 \mathrm{eV}$ & $\mathrm{E}_{\mathrm{s}}=1.29$ & $\Delta \mathrm{E}=8355.93 \rightarrow 9001.91 \mathrm{eV}$
\end{tabular}

$\Delta \mathrm{k}=1.70 \rightarrow 13.10 \AA^{-1}$

Figura 62.Amostra tratada á $150^{\circ} \mathrm{C}$. Ajuste teórico por $F E F F$ (linha azul) aos dados experimentais correspondentes ao xerogel com $\left[\mathrm{H}_{2} \mathrm{O}\right]=9$ moles para as contribuições $\mathrm{Ni}-\mathrm{O}$ e $\mathrm{Ni}-\mathrm{Cl}$. (a) Parâmetros fixos: números de coordenação e $R_{N i-C l}(b)$ todos os parâmetros foram ajustados por mínimos quadrados.
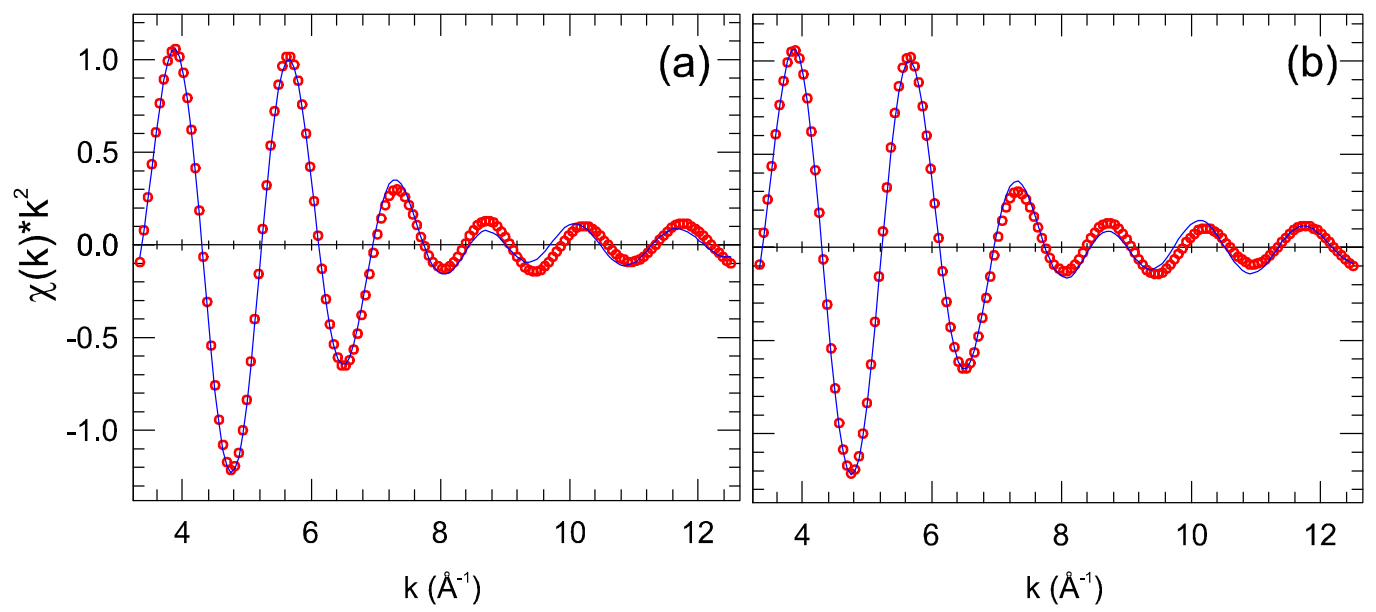

\begin{tabular}{|c|c|c|c|c|c|c|c|c|c|c|c|c|}
\hline EC & $\mathbf{N}$ & $\mathbf{R}$ & $\sigma^{2}$ & $E_{0}$ shift & $\chi^{2}$ & Res & $\mathbf{N}$ & $\mathbf{R}$ & $\sigma^{2}$ & $\mathrm{E}_{0}$ shift & $\chi^{2}$ & Res \\
\hline $\mathrm{Ni}-\mathrm{O}$ & 2 & 2.015 & 0.00540 & -11.86 & 0.033 & 10.07 & 1.47 & 1.996 & 0.00304 & -13.87 & 0.028 & 8.97 \\
\hline $\mathrm{Ni}-\mathrm{Cl}$ & 4 & 2.410 & 0.01123 & 2.29 & & & 4.11 & 2.398 & 0.01094 & 1.16 & & \\
\hline
\end{tabular}

\begin{tabular}{c|c|c}
$\mathrm{E}_{0}=8344.37 \mathrm{eV}$ & $\mathrm{E}_{\mathrm{s}}=1.35$ & $\Delta \mathrm{E}=8343.94 \rightarrow 9001.91 \mathrm{eV}$
\end{tabular}

$\Delta \mathrm{k}=0.00 \rightarrow 13.10 \AA^{-1}$

Figura 63.Amostra tratada á $300^{\circ} \mathrm{C}$. Ajuste teórico por $F E F F$ (linha azul) aos dados experimentais correspondentes ao xerogel com $\left[\mathrm{H}_{2} \mathrm{O}\right]=9$ moles para as contribuições $\mathrm{Ni}-\mathrm{O}$ e $\mathrm{Ni}-\mathrm{Cl}$. (a) Parâmetros fixos: números de coordenação e $R_{N i-C l}(b)$ todos os parâmetros foram ajustados por mínimos quadrados. 

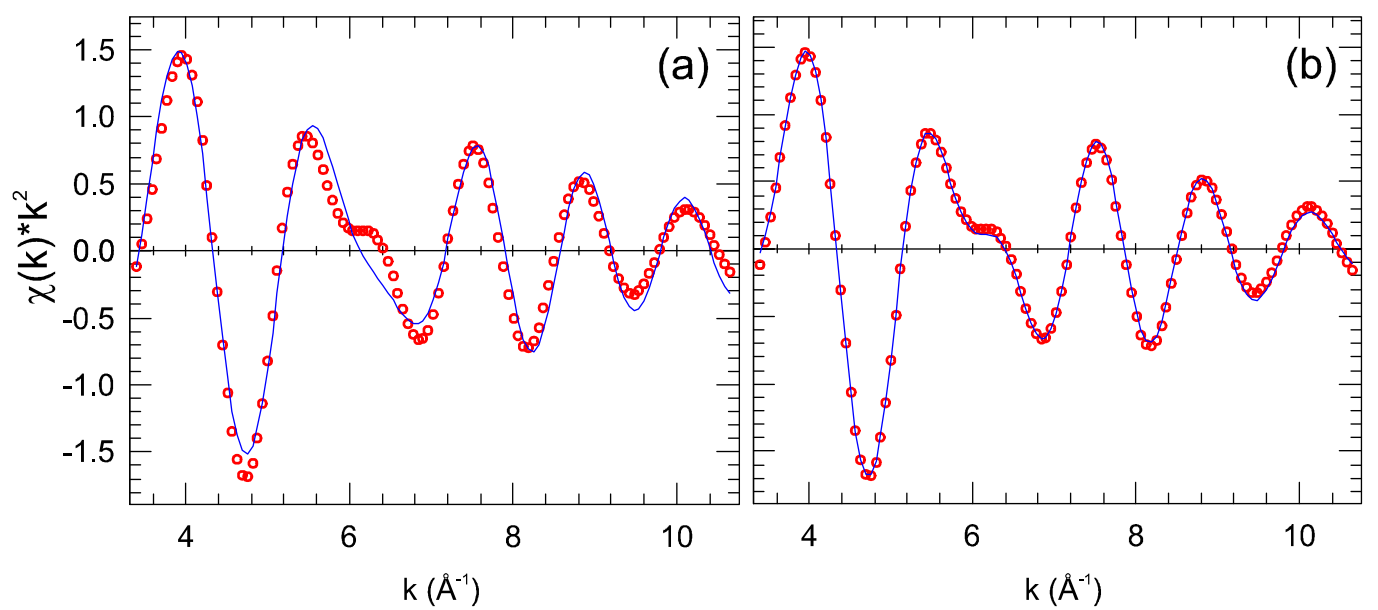

\begin{tabular}{|l|r|r|r|r|r|r|r|r|r|r|r|r|}
\hline $\mathbf{E C}$ & $\mathbf{N}$ & $\mathbf{R}$ & $\sigma^{2}$ & $\mathbf{E}_{\mathbf{0}}$ shift & $\chi^{2}$ & Res & N & R & $\sigma^{2}$ & $\mathbf{E}_{\mathbf{0}}$ shift & $\chi^{2}$ & Res \\
\hline $\mathrm{Ni}-\mathrm{O}$ & 3 & 2.085 & 0.00498 & -2.40 & 0.908 & 22.56 & 4.64 & 2.067 & 0.01217 & -5.51 & 0.023 & 4.26 \\
\hline $\mathrm{Ni}-\mathrm{Cl}$ & 3 & 2.410 & 0.00619 & 2.78 & & & 2.95 & 2.426 & 0.00548 & 6.82 & & \\
\hline $\mathrm{Ni}-\mathrm{Ni}$ & 3 & 2.930 & 0.00567 & 0.04 & & & 10.83 & 2.954 & 0.01700 & 2.21 & & \\
\hline
\end{tabular}

\begin{tabular}{|c|c|c|c}
\hline $\mathrm{E}_{0}=8341.84 \mathrm{eV}$ & $\mathrm{E}_{\mathrm{s}}=1.15$ & $\Delta \mathrm{E}=8342.06 \rightarrow 8832.13 \mathrm{eV}$ & $\Delta \mathrm{k}=0.20 \rightarrow 11.30 \AA^{-1}$
\end{tabular}

Figura 64.Amostra tratada á $410^{\circ} \mathrm{C}$. Ajuste teórico por $F E F F$ (linha azul) aos dados experimentais correspondentes ao xerogel com $\left[\mathrm{H}_{2} \mathrm{O}\right]=9$ moles para as contribuições $\mathrm{Ni}-\mathrm{O}, \mathrm{Ni}-\mathrm{Cl}$ e $\mathrm{Ni}-\mathrm{Ni}$. (a) Parâmetros fixos: números de coordenação $R_{N i-C l} \mathrm{e}$ $R_{N i-N i}(b)$ todos os parâmetros foram ajustados por mínimos quadrados.

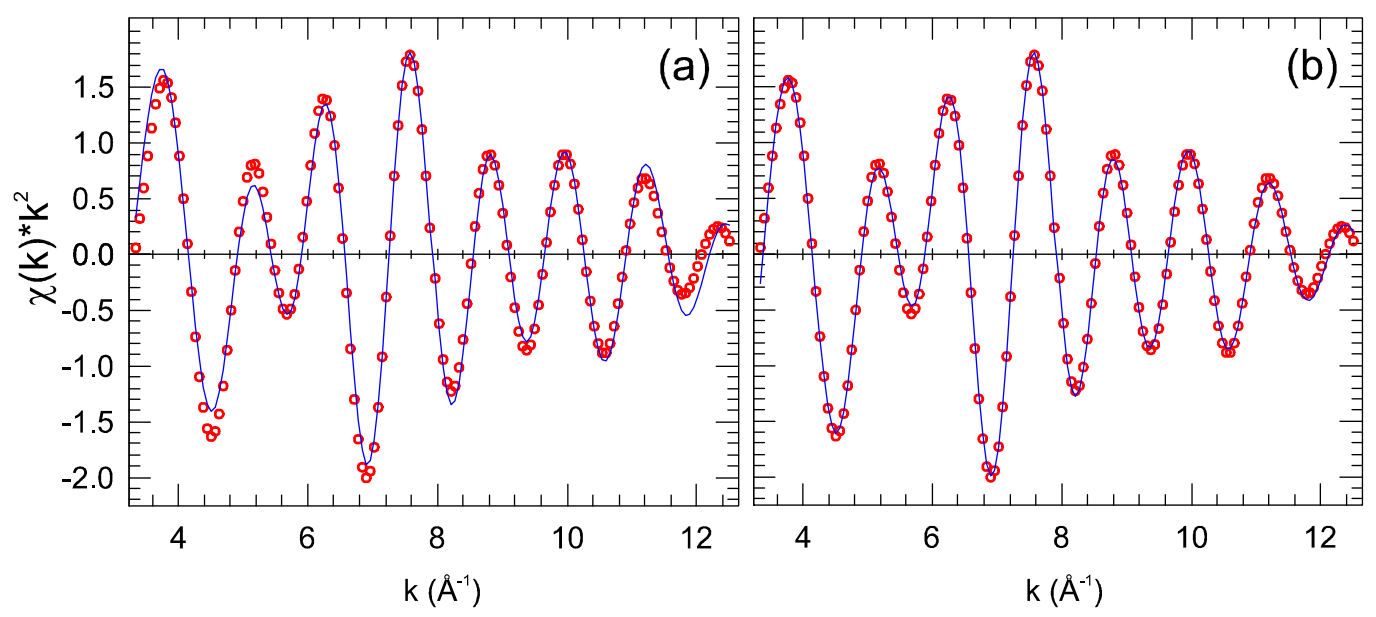

\begin{tabular}{|l|r|r|r|r|r|r|r|r|r|r|r|r|}
\hline $\mathbf{E C}$ & \multicolumn{1}{|c|}{$\mathbf{N}$} & $\mathbf{R}$ & $\sigma^{\mathbf{2}}$ & $\mathbf{E}_{\mathbf{0}}$ shift & $\chi^{\mathbf{2}}$ & \multicolumn{1}{c|}{ Res } & \multicolumn{1}{c|}{$\mathbf{N}$} & $\mathbf{R}$ & $\sigma^{2}$ & $\mathbf{E}_{\mathbf{0}}$ shift & $\chi^{\mathbf{2}}$ & Res \\
\hline $\mathrm{Ni}-\mathrm{O}$ & 5.0 & 2.093 & 0.00344 & 0.44 & 1.58 & 13.10 & 15.25 & 2.083 & 0.00944 & 1.44 & 0.16 & 5.48 \\
\hline $\mathrm{Ni}-\mathrm{Cl}$ & 1.0 & 2.410 & 0.00654 & -10.45 & & & 9.89 & 2.330 & 0.01644 & -24.50 & & \\
\hline $\mathrm{Ni}-\mathrm{Ni}$ & 7.2 & 2.930 & 0.00310 & 1.87 & & & 9.94 & 2.933 & 0.00799 & -5.04 & & \\
\hline
\end{tabular}

\begin{tabular}{|l|l|l|l}
$\mathrm{E}_{0}=8346.03 \mathrm{eV}$ & $\mathrm{E}_{\mathrm{s}}=1.38$ & $\Delta \mathrm{E}=8348.05 \rightarrow 9001.91 \mathrm{eV}$ & $\Delta \mathrm{k}=0.70 \rightarrow 13.10 \AA^{-1}$
\end{tabular}

Figura 65.Amostra tratada á $500^{\circ} \mathrm{C}$. Ajuste teórico por $F E F F$ (linha azul) aos dados experimentais correspondentes ao xerogel com $\left[\mathrm{H}_{2} \mathrm{O}\right]=9$ moles para as contribuições $\mathrm{Ni}-\mathrm{O}, \mathrm{Ni}-\mathrm{Cl}$ e $\mathrm{Ni}-\mathrm{Ni}$. (a) Parâmetros fixos: números de coordenação $R_{N i-C l} \mathrm{e}$ $R_{N i-N i}(b)$ todos os parâmetros foram ajustados por mínimos quadrados. 


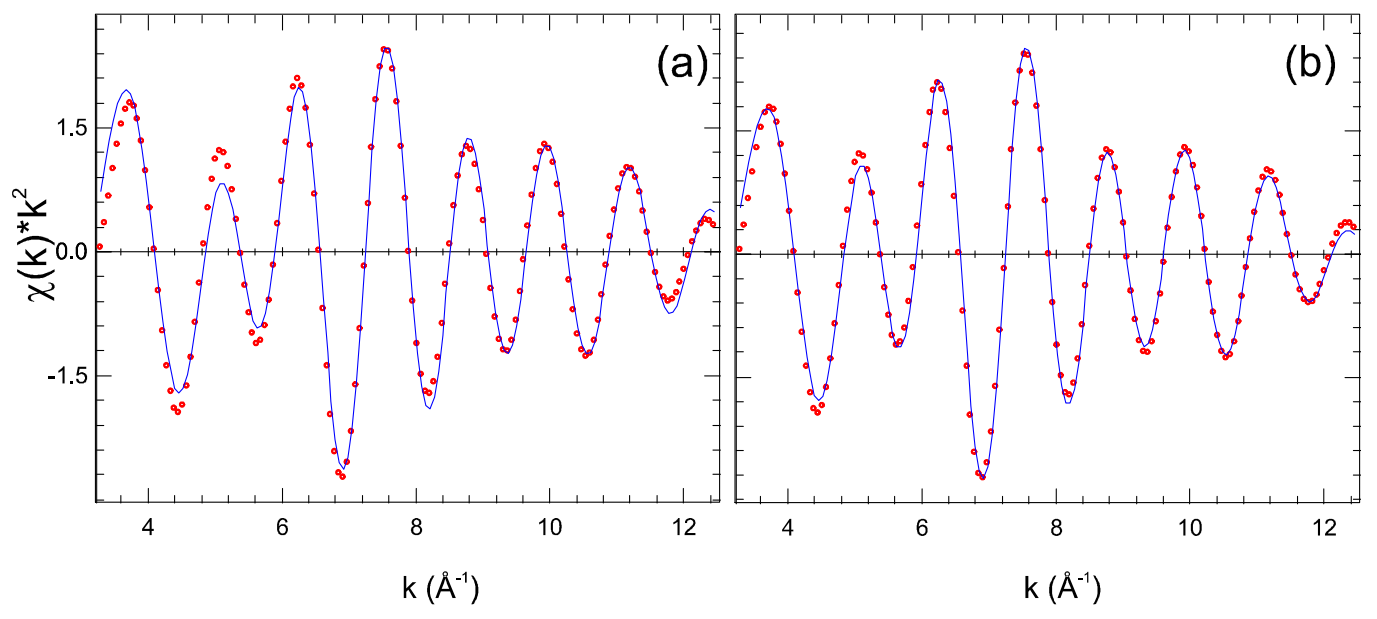

\begin{tabular}{|l|r|r|r|r|r|r|r|r|r|r|r|r|}
\hline \multicolumn{1}{|c|}{ EC } & \multicolumn{1}{|c|}{$\mathbf{N}$} & \multicolumn{1}{c}{$\mathbf{R}$} & $\sigma^{2}$ & $\mathbf{E}_{0}$ shift & $\chi^{2}$ & \multicolumn{1}{c|}{ Res } & N & R & $\sigma^{2}$ & $\mathbf{E}_{0}$ shift & $\chi^{2}$ & Res \\
\hline $\mathrm{Ni}-\mathrm{O}$ & 6.0 & 2.077 & 0.00566 & -3.85 & 3.87 & 11.82 & 4.50 & 2.070 & 0.00270 & -4.51 & 1.71 & 9.18 \\
\hline $\mathrm{Ni}-\mathrm{Ni}$ & 12.0 & 2.930 & 0.00547 & -6.39 & & & 14.44 & 2.943 & 0.00683 & -4.79 & & \\
\hline
\end{tabular}

\begin{tabular}{c|c|c|c}
$\mathrm{E}_{0}=8346.03 \mathrm{eV}$ & $\mathrm{E}_{\mathrm{s}}=1.30$ & $\Delta \mathrm{E}=8345.99 \rightarrow 9001.91 \mathrm{eV}$ & $\Delta \mathrm{k}=0.00 \rightarrow 13.10 \AA^{-1}$
\end{tabular}

Figura 66.Amostra tratada á $900^{\circ} \mathrm{C}$. Ajuste teórico por $F E F F$ (linha azul) aos dados experimentais correspondentes ao xerogel com $\left[\mathrm{H}_{2} \mathrm{O}\right]=9$ moles para as contribuições $N i-O$ e $N i-N i$. (a) Parâmetros fixos: números de coordenação e $R_{N i-N i}(b)$ todos os parâmetros foram ajustados por mínimos quadrados.

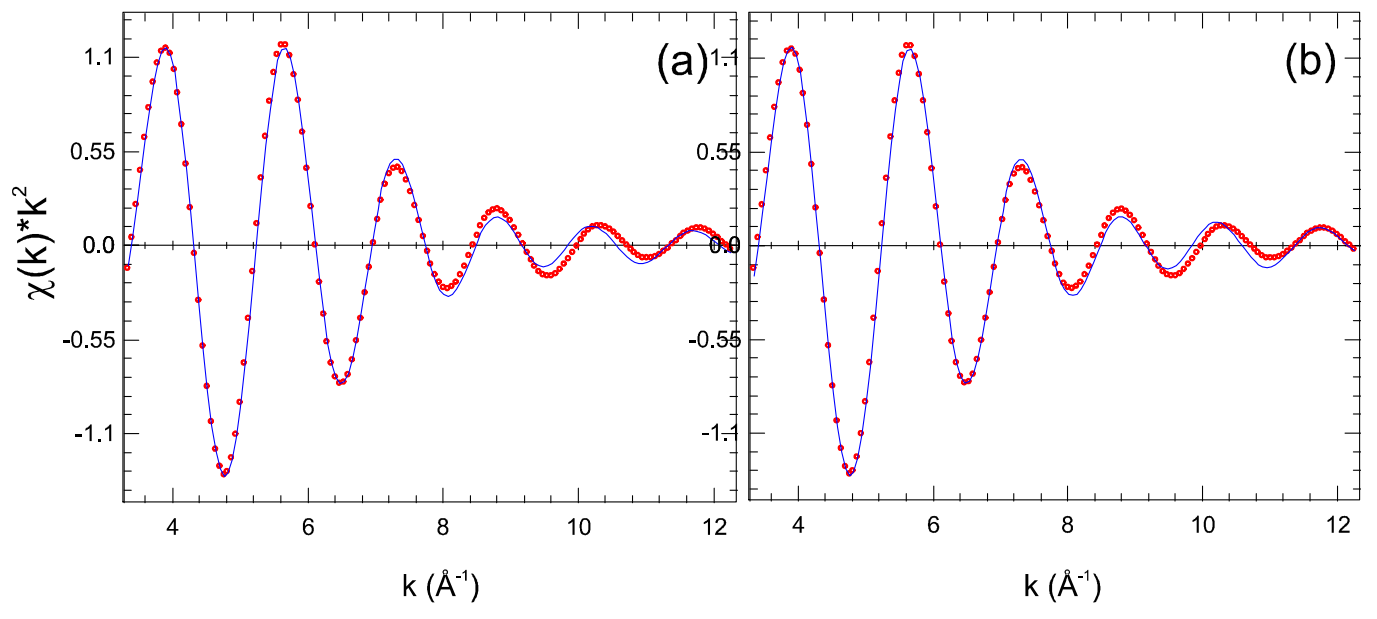

\begin{tabular}{|l|r|r|r|r|r|r|r|r|r|r|r|r|}
\hline EC & \multicolumn{1}{|c|}{$\mathbf{N}$} & \multicolumn{1}{c|}{$\mathbf{R}$} & $\sigma^{2}$ & $\mathbf{E}_{0}$ shift & $\chi^{2}$ & \multicolumn{1}{c|}{ Res } & N & \multicolumn{1}{c|}{$\mathbf{R}$} & $\sigma^{2}$ & $\mathbf{E}_{0}$ shift & $\chi^{2}$ & Res \\
\hline $\mathrm{Ni}-\mathrm{O}$ & 2 & 2.020 & 0.00524 & -12.69 & 0.061 & 10.69 & 1.55 & 1.990 & 0.00537 & -16.44 & 0.035 & 7.30 \\
\hline $\mathrm{Ni}-\mathrm{Cl}$ & 4 & 2.410 & 0.00856 & 2.16 & & & 4.43 & 2.387 & 0.00937 & 0.29 & & \\
\hline
\end{tabular}

\begin{tabular}{c|c|c|c}
$\mathrm{E}_{0}=8345.05 \mathrm{eV}$ & $\mathrm{E}_{\mathrm{s}}=0.90$ & $\Delta \mathrm{E}=8345.82 \rightarrow 9236.10 \mathrm{eV}$ & $\Delta \mathrm{k}=0.40 \rightarrow 15.25 \AA^{-1}$
\end{tabular}

Figura 67.Amostra padrão de $\mathrm{NiCl}_{2}$. Ajuste teórico por $\mathrm{FEFF}$ (linha azul) aos dados experimentais para as contribuições $\mathrm{Ni}-\mathrm{O}$ e $\mathrm{Ni}-\mathrm{Cl}$. (a) Parâmetros fixos: números de coordenação e $R_{N i-C l}(b)$ todos os parâmetros foram ajustados por mínimos quadrados. 


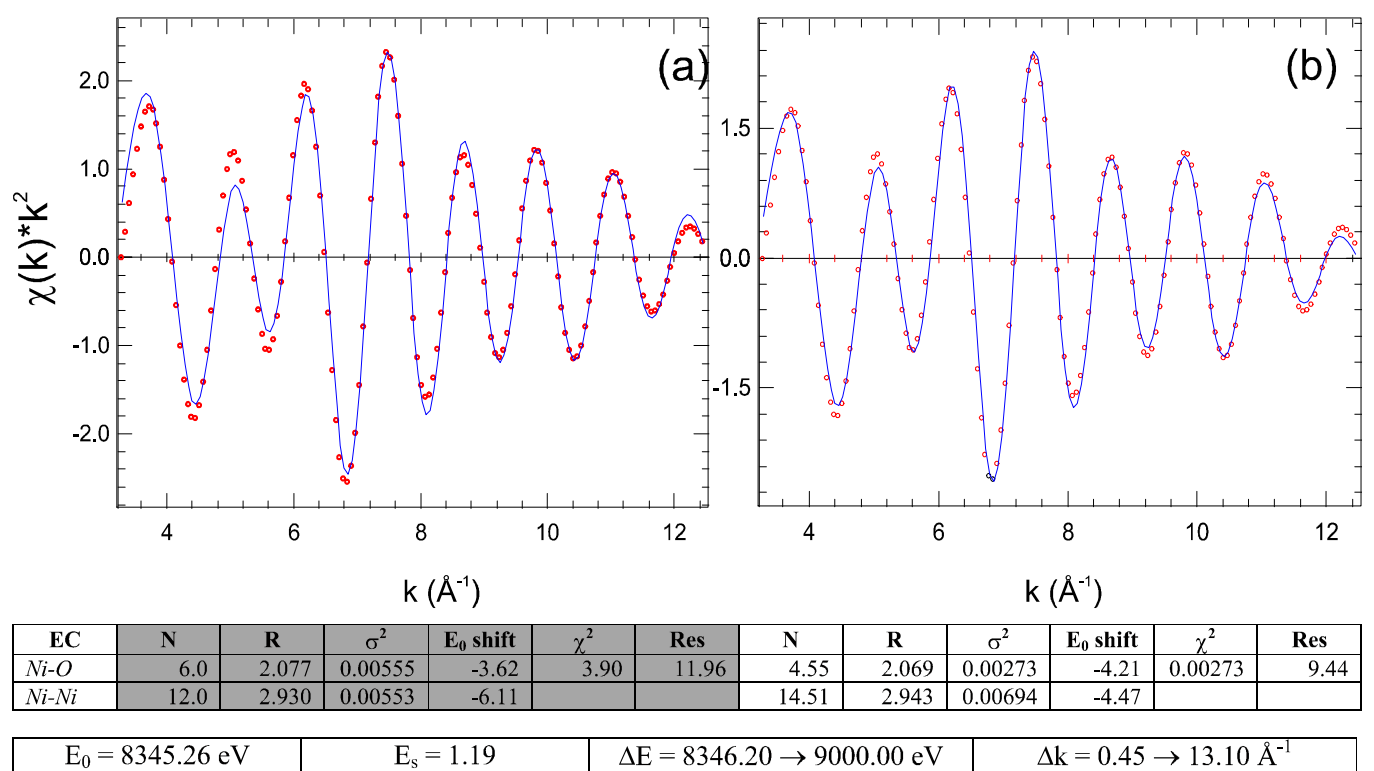

Figura 68.Amostra padrão de $N i O$. Ajuste teórico por $F E F F$ (linha azul) aos dados experimentais correspondentes para as contribuições $N i-O$ e $N i-N i$. (a) Parâmetros fixos: números de coordenação e $R_{N i-N i}(b)$ todos os parâmetros foram ajustados por mínimos quadrados. 

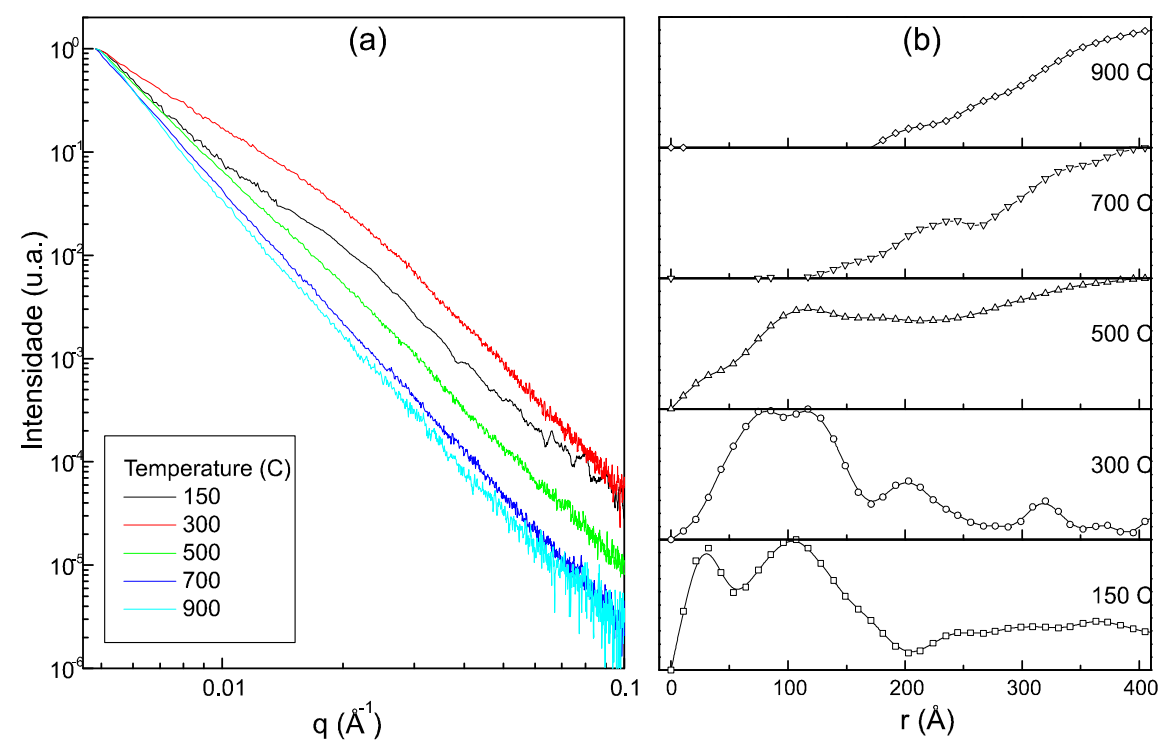

Figura 69.(a) Curvas de $S A X S$ correspondentes a xerogéis de $N i$ com $20 \%$ substituição de $\mathrm{Ti}$ com $\left[\mathrm{H}_{2} \mathrm{O}\right]=1 \mathrm{~mol}$ tratados as temperaturas indicadas. As curvas estão deslocadas verticalmente por motivos de clareza. (b) Função de distribuição de volume de poros $V(R)$ associadas as diferentes curvas de espalhamento.

\section{Appendix B \\ Apêndice B: Resultados das experiências de $S A X S$ em amostras com substituição parcial do $N i$ por $T i$}



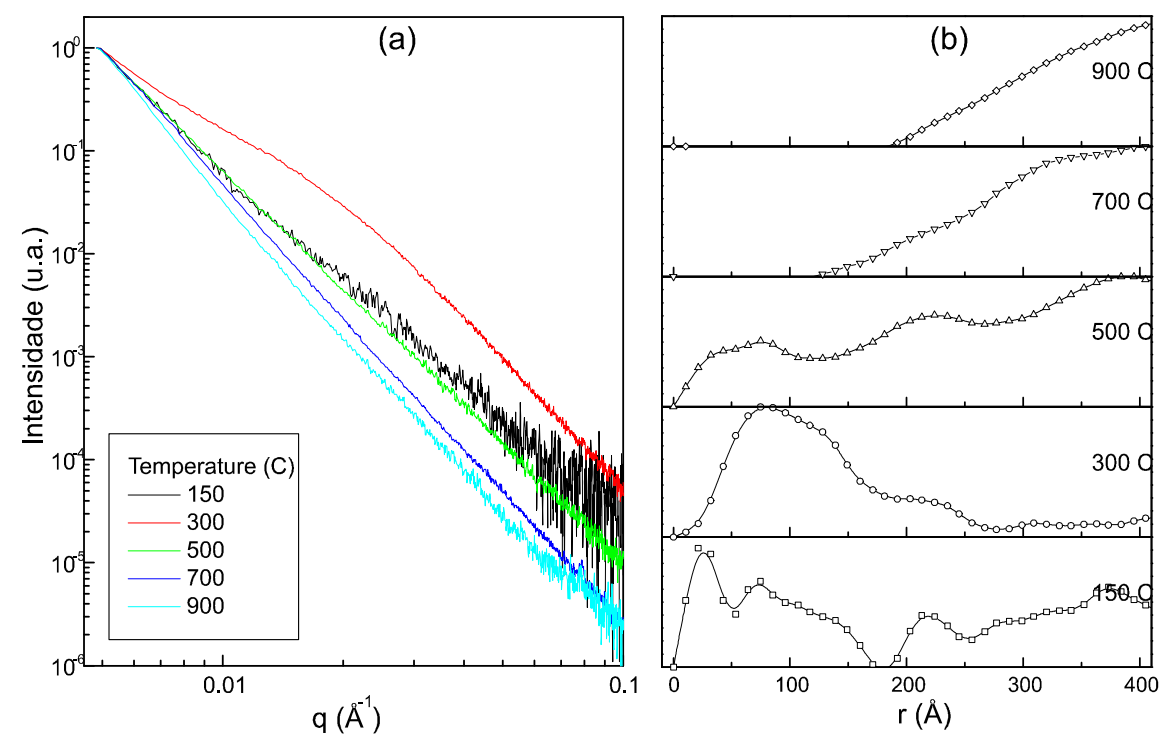

Figura 70.(a) Curvas de $S A X S$ correspondentes a xerogéis de $N i$ com $20 \%$ substituição de $\mathrm{Ti}$ com $\left[\mathrm{H}_{2} \mathrm{O}\right]=2$ moles tratados as temperaturas indicadas. As curvas estão deslocadas verticalmente por motivos de clareza. (b) Função de distribuição de volume de poros $V(R)$ associadas as diferentes curvas de espalhamento.
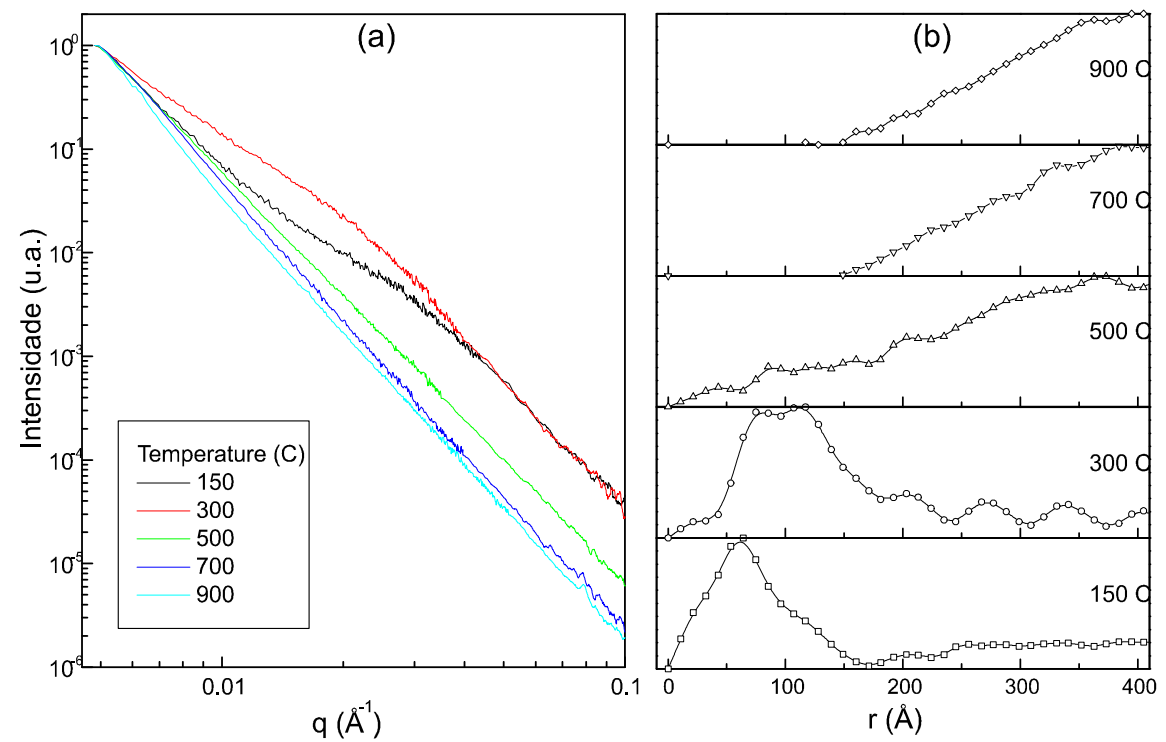

Figura 71.(a) Curvas de $S A X S$ correspondentes a xerogéis de $N i$ com $20 \%$ substituição de $\mathrm{T} i$ com $\left[\mathrm{H}_{2} \mathrm{O}\right]=3$ moles tratados as temperaturas indicadas. As curvas estão deslocadas verticalmente por motivos de clareza. (b) Função de distribuição de volume de poros $V(R)$ associadas as diferentes curvas de espalhamento. 

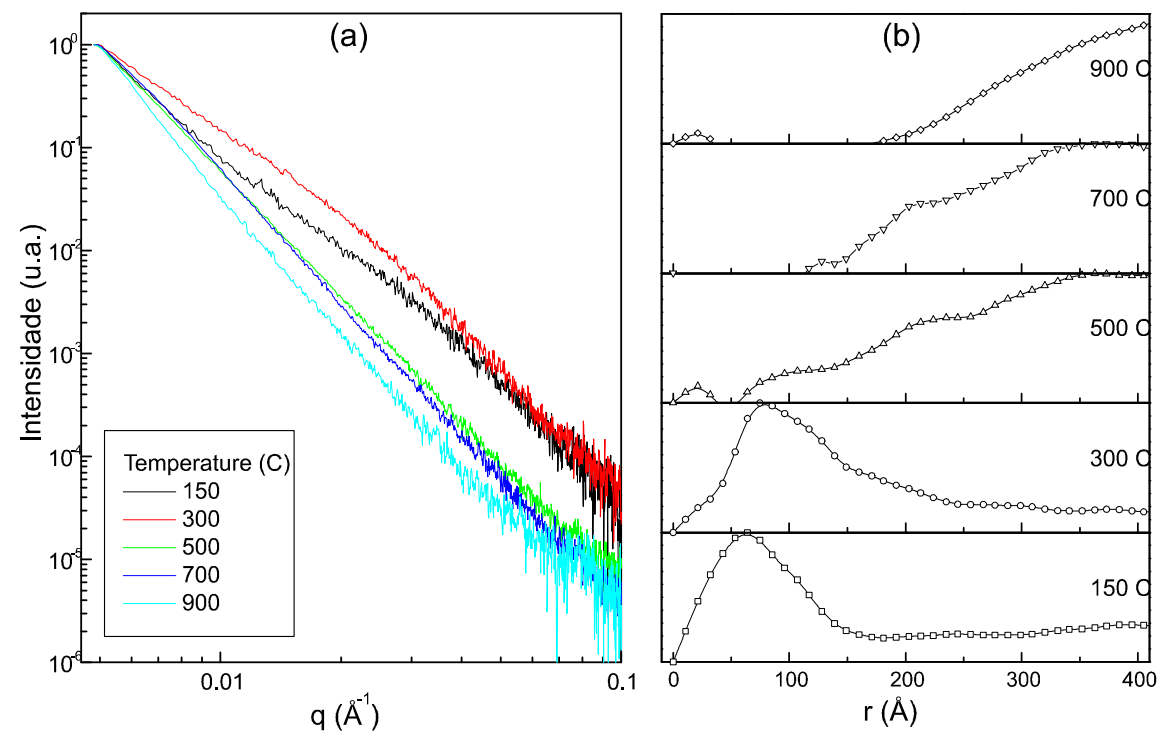

Figura 72.(a) Curvas de $S A X S$ correspondentes a xerogéis de $N i$ com $20 \%$ substituição de $\mathrm{Ti}$ com $\left[\mathrm{H}_{2} \mathrm{O}\right]=6$ moles tratados as temperaturas indicadas. As curvas estão deslocadas verticalmente por motivos de clareza. (b) Função de distribuição de volume de poros $V(R)$ associadas as diferentes curvas de espalhamento.
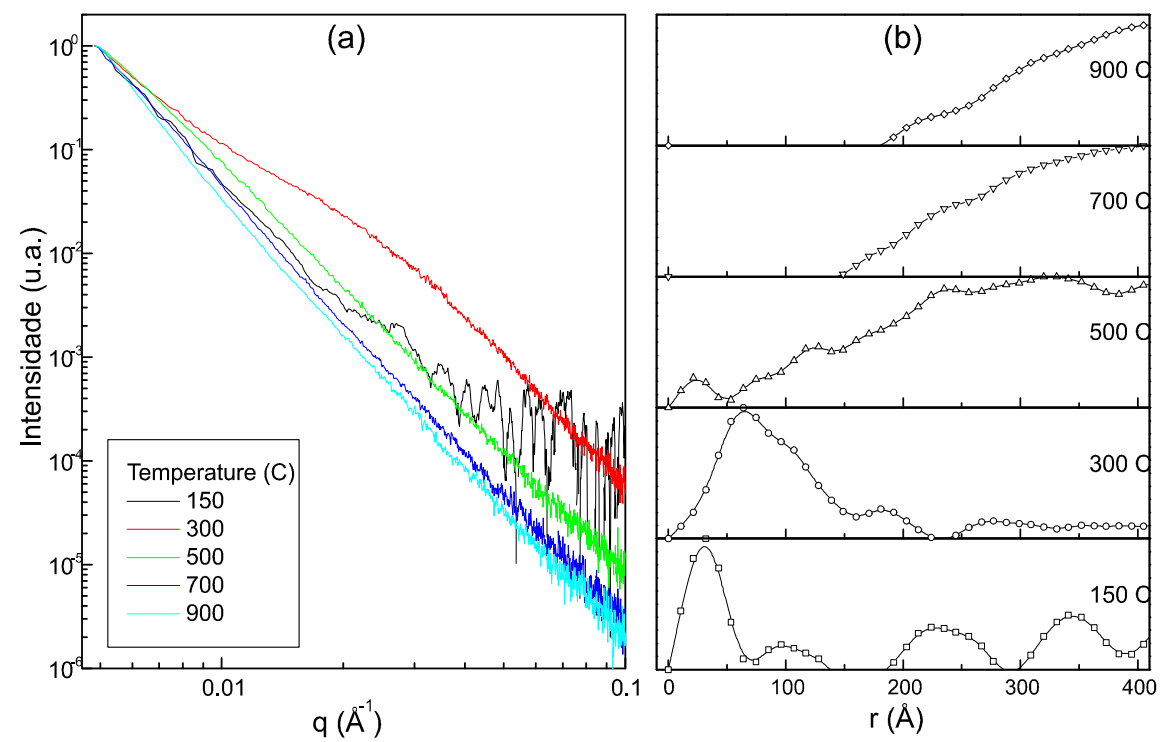

Figura 73. (a) Curvas de $S A X S$ correspondentes a xerogéis de $N i$ com $20 \%$ substituição de $\mathrm{T} i$ com $\left[\mathrm{H}_{2} \mathrm{O}\right]=9$ moles tratados as temperaturas indicadas. As curvas estão deslocadas verticalmente por motivos de clareza. (b) Função de distribuição de volume de poros $V(R)$ associadas as diferentes curvas de espalhamento. 

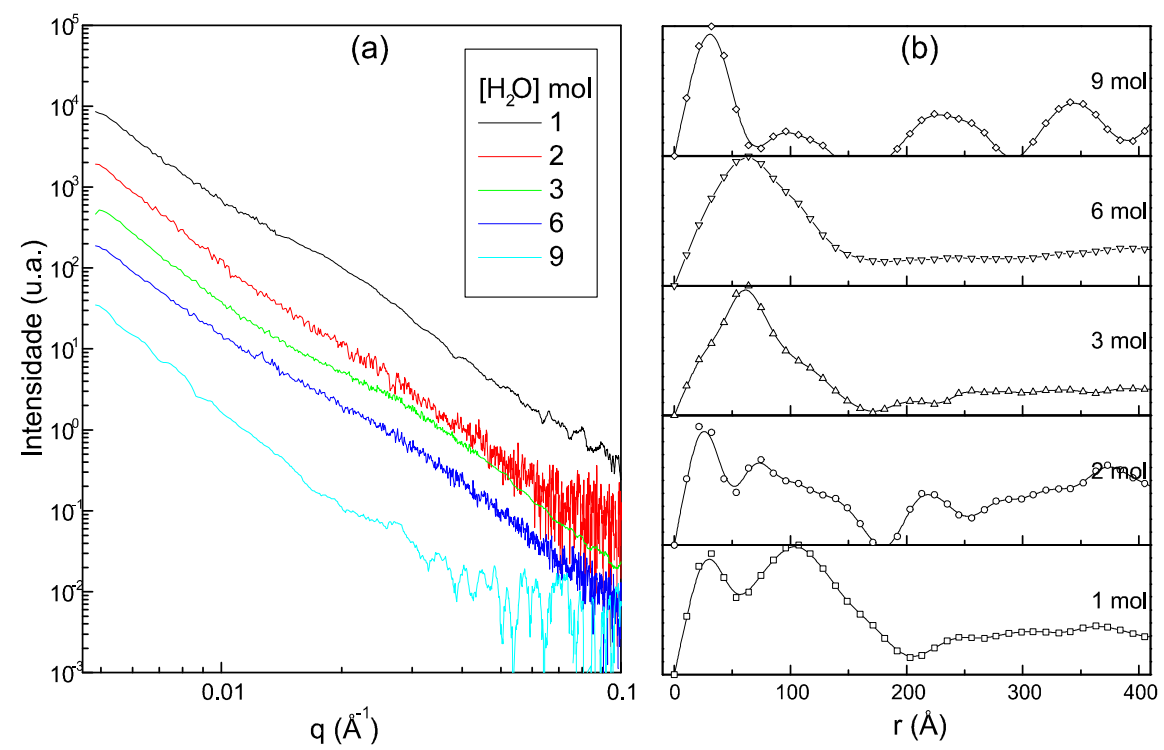

Figura 74.(a) Curvas de $S A X S$ correspondentes a xerogéis de $N i$ com $20 \%$ substituição de $T i$ tratados à $150^{\circ} \mathrm{C}$ com concentração de água indicados. As curvas estão deslocadas verticalmente por motivos de clareza. (b) Função de distribuição de volume de poros $V(R)$ associadas as diferentes curvas de espalhamento.
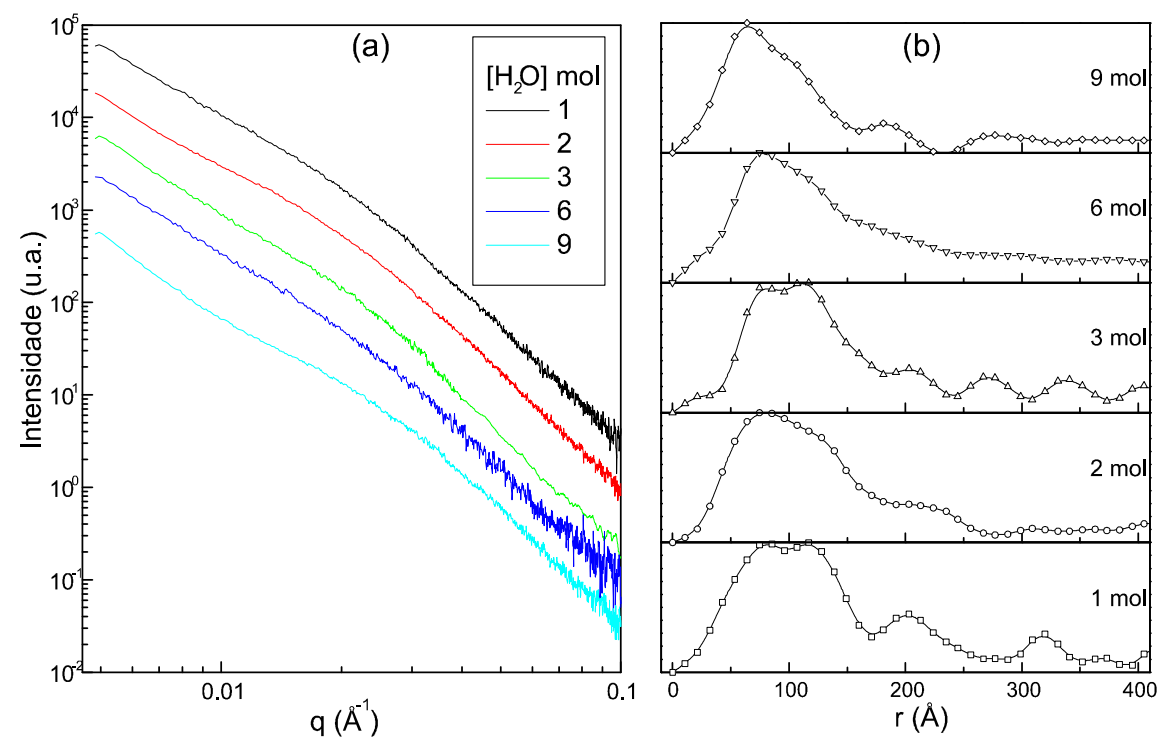

Figura 75.(a) Curvas de $S A X S$ correspondentes a xerogéis de $N i$ com $20 \%$ substituição de $T i$ tratados à $300^{\circ} \mathrm{C}$ com concentração de água indicados. As curvas estão deslocadas verticalmente por motivos de clareza. (b) Função de distribuição de volume de poros $V(R)$ associadas as diferentes curvas de espalhamento. 

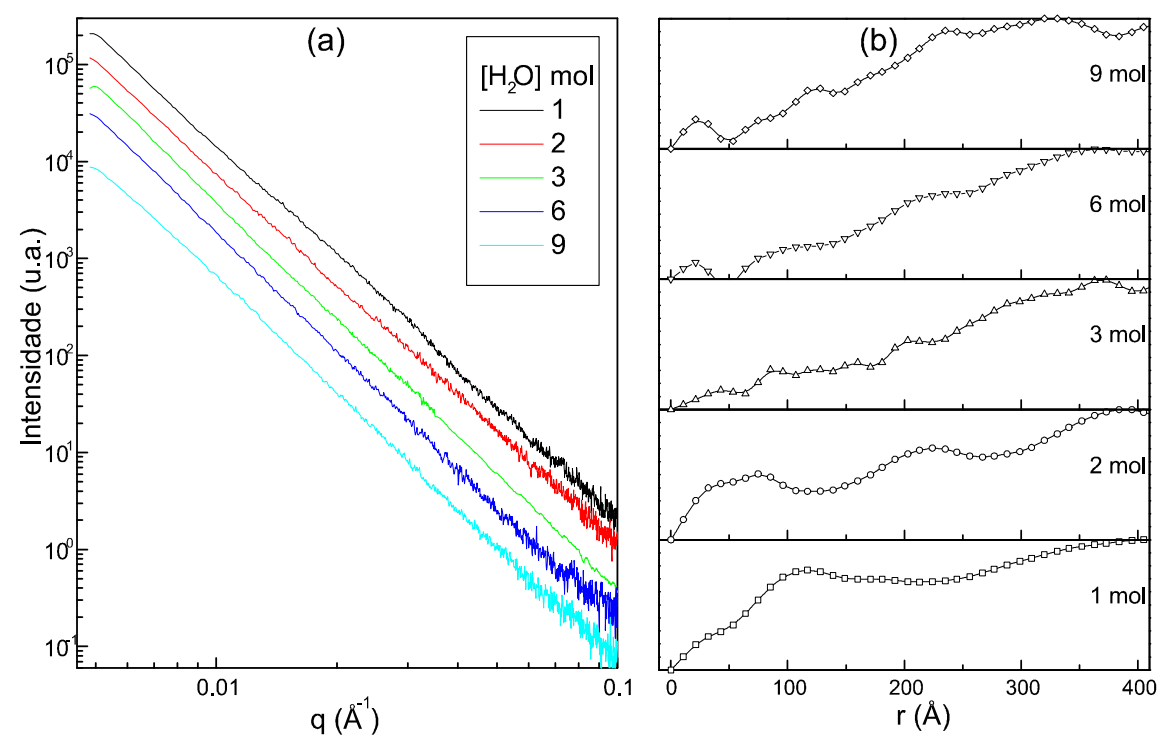

Figura 76. (a) Curvas de $S A X S$ correspondentes a xerogéis de $N i$ com $20 \%$ substituição de $T i$ tratados à $500^{\circ} C$ com concentração de água indicados. As curvas estão deslocadas verticalmente por motivos de clareza. (b) Função de distribuição de volume de poros $V(R)$ associadas as diferentes curvas de espalhamento.
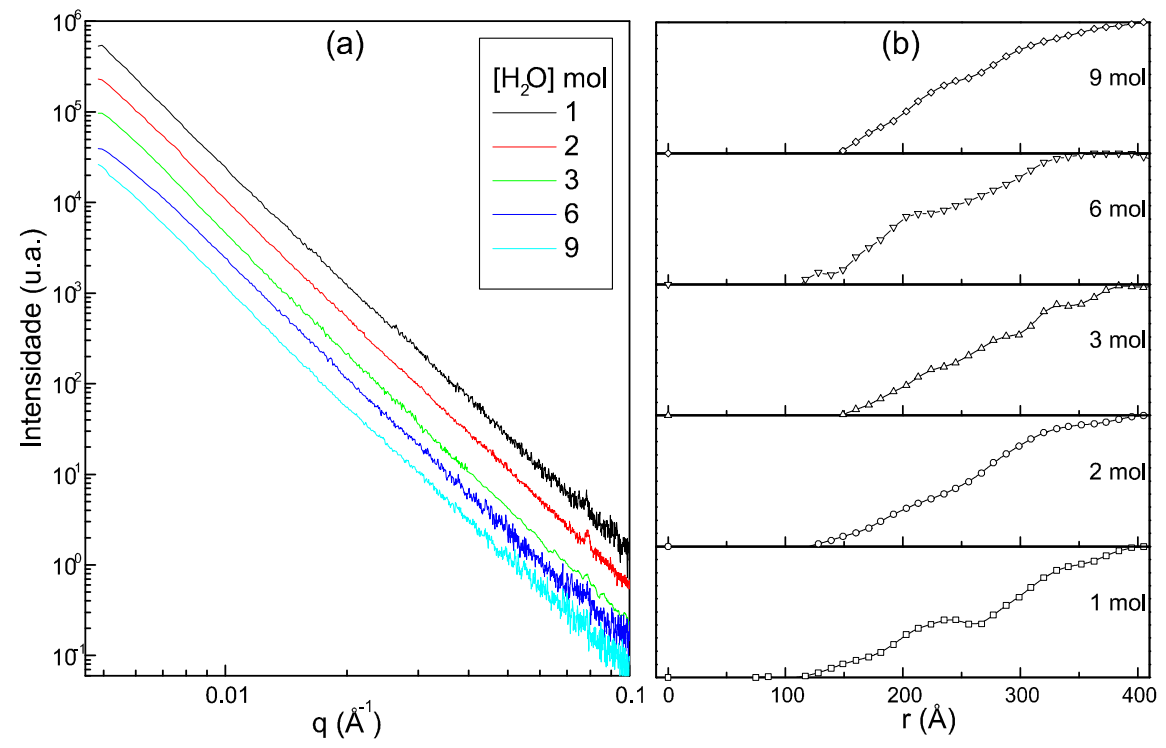

Figura 77.(a) Curvas de $S A X S$ correspondentes a xerogéis de $N i$ com $20 \%$ substituição de $T i$ tratados à $700^{\circ} \mathrm{C}$ com concentração de água indicados. As curvas estão deslocadas verticalmente por motivos de clareza. (b) Função de distribuição de volume de poros $V(R)$ associadas as diferentes curvas de espalhamento. 


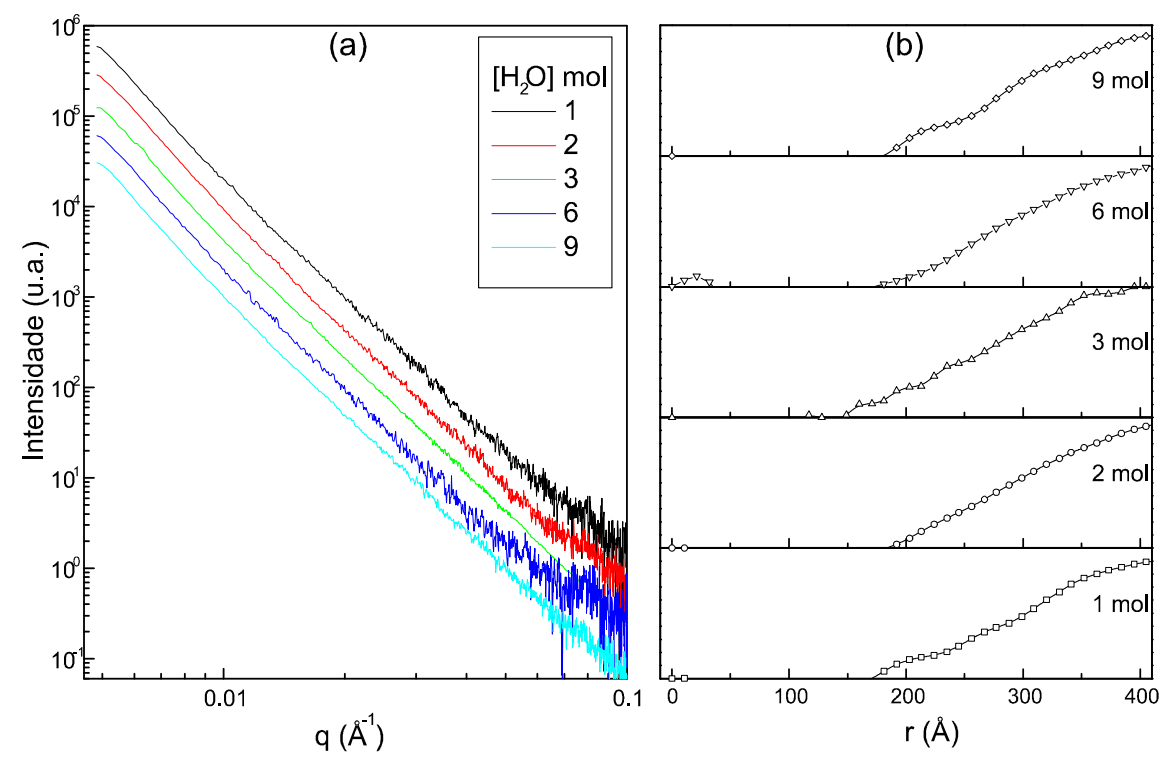

Figura 78.(a) Curvas de $S A X S$ correspondentes a xerogéis de $N i$ com $20 \%$ substituição de $T i$ tratados à $900^{\circ} C$ com concentração de água indicados. As curvas estão deslocadas verticalmente por motivos de clareza. (b) Função de distribuição de volume de poros $V(R)$ associadas as diferentes curvas de espalhamento. 


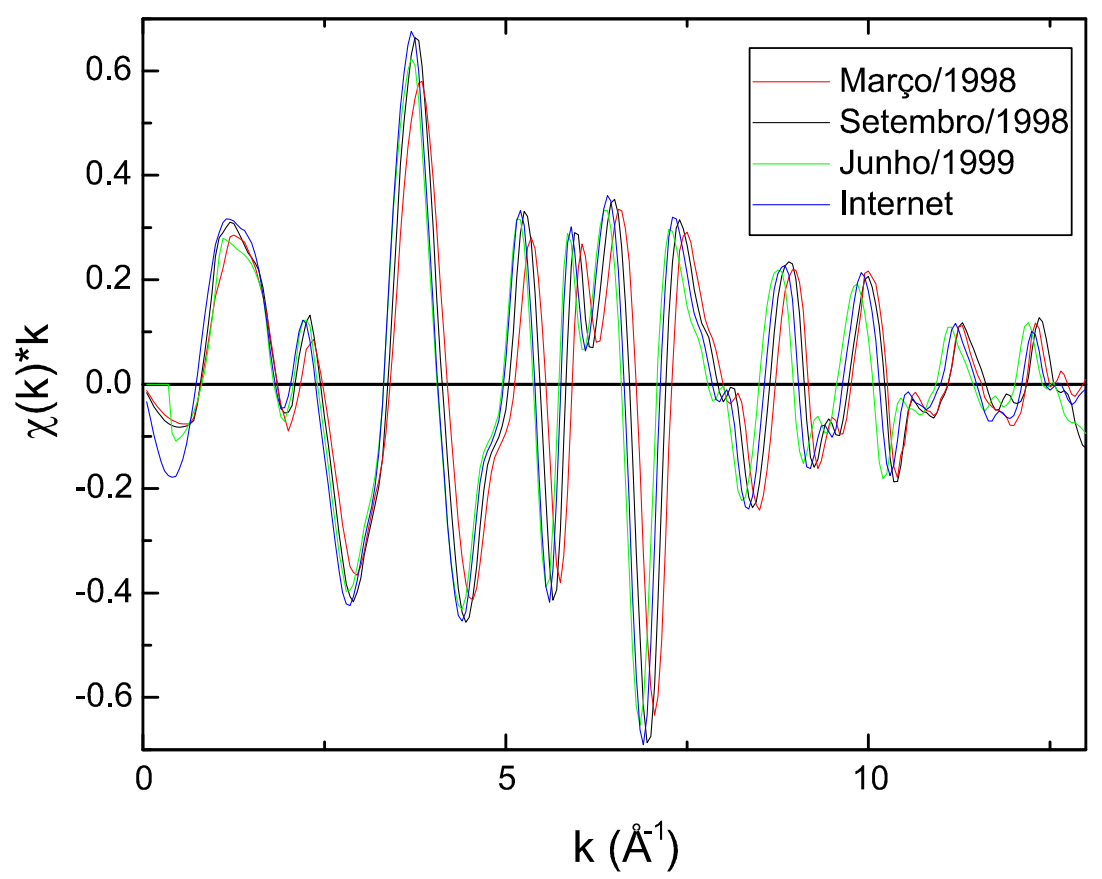

Figura 79.Efeito do deslocamento dos espectros de EXAFS causado por um acoplamento impreciso entre a eletrônica de detecção e o monocromador, resultando em desvios sistemáticos. A amostra utilizada foi sempre a mesma, $\mathrm{NiO}$ padrão.

\section{Appendix C Apêndice C: Observações}

A figura 79 ilustra o efeito do descolamento (ou comprensão) em energia causado por um acoplamento impreciso entre a eletrônica de detecção e o monocromador. Nos espectros percebe-se uma diferença em $k$ da ordem de $\Delta k=0,087$ entre março e setembro de 1998. Já entre setembro de 1998 e junho de 1999 a diferença cai para $\Delta k=0,071$ e em junho de 1999 ela é de $\Delta k=0,030$. A diferença foi calculada em relação a um padrão obtido na internet.

O motivo de se introduzir esta figura é apenas para ilustrar a importância quando se deseja utilizar padrões experimentais como referência. Medidas dos mesmos devem ser realizadas no mesmo dia em que as amostras forem medidas, caso contrário, erros na determinação dos parâmetros estruturais serão inevitáveis. 